UNIVERSIDADE DE SÃO PAULO

ESCOLA DE ENFERMAGEM

Jaqueline de Oliveira Santos

ENSAIO CLÍNICO RANDOMIZADO SOBRE A EFETIVIDADE DO LASER EM BAIXA INTENSIDADE NO ALÍVIO DA DOR PERINEAL NO PARTO NORMAL COM EPISIOTOMIA

SÃO PAULO

2010 
JAQUELINE DE OLIVEIRA SANTOS

\section{ENSAIO CLÍNICO RANDOMIZADO SOBRE A EFETIVIDADE DO LASER EM BAIXA INTENSIDADE NO ALÍVIO DA DOR PERINEAL NO PARTO NORMAL COM EPISIOTOMIA}

Tese apresentada ao Programa de Pós-Graduação em Enfermagem da Escola de Enfermagem da Universidade de São Paulo para obtenção do título de Doutor em Ciências.

Área de concentração: Cuidado em Saúde

Orientadora: Prof $\mathrm{f}^{\mathrm{a}}$. $\mathrm{r}^{\mathrm{a}}$. Sonia Maria Junqueira Vasconcellos de Oliveira

\section{SÃO PAULO}




\section{Catalogação na Publicação (CIP)}

\section{Biblioteca "Wanda de Aguiar Horta"}

\section{Escola de Enfermagem da Universidade de São Paulo}

Santos, Jaqueline de Oliveira

Ensaio clínico randomizado sobre a efetividade do laser em baixa intensidade no alívio da dor perineal no parto normal com episiotomia / Jaqueline de Oliveira Santos. - São Paulo, 2010.

$164 \mathrm{p}$.

Tese (Doutorado) - Escola de Enfermagem da Universidade de São Paulo.

Orientadora: Prof $f^{\mathrm{a}}$. Dra . Sonia Maria Junqueira Vasconcellos de Oliveira

1. Laser - Terapia 2. Períneo 3. Enfermagem obstétrica

4. Ensaios clínicos 5. Dor I. Título. 


\section{FOLHA DE APROVAÇÃO}

Jaqueline de Oliveira Santos

Ensaio clínico randomizado sobre a efetividade do laser em baixa intensidade no alívio da dor perineal no parto normal com episiotomia.

Tese apresentada ao Programa de PósGraduação em Enfermagem da Escola de Enfermagem da Universidade de São Paulo para obtenção do título de Doutor em Ciências.

Aprovado em: ___ de dezembro de 2010.

\section{Banca Examinadora}

$\operatorname{Prof}^{\mathrm{a}}$. Dr ${ }^{\mathrm{a}}$.

Instituição:

Assinatura:

Prof ${ }^{\mathrm{a}}$. Dr ${ }^{\mathrm{a}}$.

Instituição:

Assinatura:

Prof $^{\mathrm{a}}$. Dr ${ }^{\mathrm{a}}$.

Instituição:

Assinatura:

Prof. Dr.

Instituição:

Assinatura:

Prof ${ }^{\mathrm{a}}$. Dr ${ }^{\mathrm{a}}$.

Instituição:

Assinatura: 
DEDICATÓRIA 
Ao meu companheiro, Cristiano, meu amor e gratidão por dividir comigo, durante toda essa jornada, momentos difíceis, estando sempre ao meu lado, me incentivando, acolhendo e apoiando incondicionalmente.

À minha mãe, Abigail, pelo apoio cúmplice e incondicional nesse e em todos os momentos da minha vida. Pela amizade e pelo amor que sempre me foi dedicado.

À minha irmã, Rosiany, e ao meu sobrinho, Rafael, que mesmo longe estão sempre ao meu lado, compartilhando momentos difíceis e felizes.

À Profa . Doutora Sueli Riul da Silva que muito contribuiu para a minha formação profissional e acadêmica, pela sabedoria e pela dedicação dispensadas ao longo da minha vida acadêmica. 
AGRADECIMENTOS 
À Prof ${ }^{a}$. Doutora Sonia Maria Junqueira Vasconcellos de Oliveira pela competência e dedicação na orientação e confecção deste trabalho, especialmente pelos ensinamentos transmitidos no transcorrer desse período.

À Profa . Doutora Ruth Hitomi Osava, pelo incentivo e pelo auxílio na viabilidade da coleta de dados.

À Prof ${ }^{a}$. Doutora Ana Cecília Correa Aranha, pela orientação sobre o laser em baixa intensidade e o desenho de pesquisa, sobretudo pelo carinho e atenção dedicados para a confecção deste estudo.

À equipe do Laboratório Especial de Laser em Odontologia (LELO) da Universidade de São Paulo pela introdução do conhecimento relacionado ao laser em baixa intensidade, pelo direcionamento desta pesquisa e pela viabilização da conferência da emissão da irradiação.

À Enfermeira Camila Arruda Tambellini pelo auxílio e comprometimento na coleta de dados, pela amizade e pela compreensão.

Às obstetrizes Marina Barreto Alvarenga e Nathalie Leister pelo auxílio na coleta de dados, pelo carinho e pela dedicação.

Às amigas e colegas de trabalho Eliana Maria Scarelli Amaral e Raquel Machado Cavalca Coutinho que sempre acreditaram e confiaram no meu trabalho.

Ao Prof. Doutor Moacyr Nobre, pela valiosa orientação na condução desta pesquisa.

À Profa . Doutora Maria do Rosário Dias de Oliveira pela assessoria estatística.

À Prof ${ }^{a}$. Doutora Maria Luiza Riesco, pela colaboração e sugestões de pesquisa.

À Prof ${ }^{a}$. Doutora Maria Alice Tsunechiro pelas importantes contribuições na coleta de dados.

Aos funcionários do Amparo Maternal que contribuíram direta ou indiretamente na condução deste estudo.

Aos funcionários da Secretaria do Departamento de Enfermagem Materno-Infantil e Psiquiátrica, em especial, ao Marcelo Batista Pimentel, pelo apoio à pesquisa.

À Prof ${ }^{\mathrm{a}}$. Ivone Borelli pela revisão da língua portuguesa.

À Fundação de Amparo à Pesquisa do Estado de São Paulo pelo auxílio financeiro.

Em especial, meu carinho e gratidão a todas as mulheres/mães/puérperas que se dispuseram a participar deste estudo, e sem as quais não seria possível a concretização desta pesquisa. 
RESUMO 
Santos JO. Ensaio clínico randomizado sobre a efetividade do laser em baixa intensidade no alívio da dor perineal no parto normal com episiotomia [tese]. São Paulo: Escola de Enfermagem, Universidade de São Paulo; 2010.

Introdução: A dor perineal é um dos efeitos adversos mais comuns da episiotomia, constituindo uma das morbidades maternas mais frequentes. Considerada como um dos maiores avanços na área da saúde, a irradiação com laser em baixa intensidade vêm se mostrando bastante promissora no tratamento de doenças musculoesqueléticas, por sua ação analgésica, anti-inflamatória e pela aceleração do processo cicatricial. Objetivo: Avaliar a efetividade da aplicação do laser em baixa intensidade para alívio da dor na região perineal após a episiotomia. Método: Tratase de um ensaio clínico controlado, randomizado, paralelo e com mascaramento da participante e da pesquisadora. A amostra constitui-se de 114 puérperas com parto normal com episiotomia médio-lateral direita internadas no Alojamento Conjunto do Amparo Maternal, que referiram dor perineal $\geq 3$, pela escala numérica de 0 a 10 . Foram divididas em três grupos de 38 mulheres: grupo experimental infravermelho tratadas com laser $780 \mathrm{~nm}$; grupo experimental vermelho - irradiadas com laser 660 $\mathrm{nm}$ e grupo controle - submetidas à simulação do tratamento, mas sem irradiação do feixe de luz. Foi utilizado um laser de diodo, tamanho do spot de $0,04 \mathrm{~cm}^{2}$, dose de $8,8 \mathrm{~J} / \mathrm{cm}^{2}$, potência de $35 \mathrm{~mW}$, duração da irradiação de 10 segundos por ponto, energia de $0,35 \mathrm{~J}$ por ponto e energia total de 1,05 J. O mesmo protocolo de irradiação foi aplicado nos grupos experimentais, infravermelho e vermelho. A aplicação foi realizada de modo pontual, diretamente sobre a episiotomia, irradiandose a porção central e as extremidades, superior e inferior da lesão, perfazendo três pontos de irradiação. A intensidade da dor perineal foi avaliada antes, imediatamente e 30 minutos após a irradiação, pela escala numérica de 0 a 10 . A coleta de dados foi realizada entre novembro de 2009 e março de 2010, após a aprovação do Comitê de Ética em Pesquisa com Seres Humanos. Resultados: A idade média das puérperas foi de $22,8 \pm 4,4$ anos, a maioria era primigesta $(80,7 \%)$ e nulípara $(88,6 \%)$. As médias da dor perineal intra-grupo antes e imediatamente após a irradiação apresentaram diferença estatisticamente significativa nos três grupos ( $\mathrm{p} \square 0,001)$. Também houve diferença significativa na comparação intra-grupo das médias da dor perineal imediatamente e 30 minutos após a intervenção $(\mathrm{p} \square 0,05)$, e antes e 30 minutos depois da irradiação ( $\square \square 0,001)$ nos três grupos analisados. A comparação das médias da dor perineal entre os grupos controle, infravermelho e vermelho não demonstrou diferença significativa nos três momentos de avaliação, indicando que os resultados analgésicos obtidos nos grupos tratados com laser em baixa intensidade foram equivalentes aos do grupo controle. Não foi constatada diferença significativa na proporção de redução da dor perineal entre os três grupos de comparação, imediatamente e 30 minutos depois da intervenção $(\mathrm{p}=0,234)$, indicando que o alívio da dor foi similar entre os grupos. A maioria das púerperas submetidas à laserterapia $(96,0 \%)$ teve opinião favorável à utilização do laser na prática clínica, considerou o procedimento confortável $(93,4 \%)$ e mencionou que repetiria o tratamento em outro período pós-parto $(96,5 \%)$. Conclusão: O protocolo de tratamento com laser em baixa intensidade utilizado não demonstrou benefícios no alívio da dor perineal comparando-se os grupos experimentais com o controle. É necessário que novas propostas de pesquisa, analisando diferentes protocolos terapêuticos com o laser em baixa intensidade, sejam desenvolvidas para determinar um protocolo ideal efetivo no alívio da dor e do desconforto perineal entre as puérperas. 
Palavras-chave: Lasers. Terapia a Laser de Baixa Intensidade. Períneo. Dor. Período pós-parto. Enfermagem Obstétrica. Ensaio Clínico. 
ABSTRACT 
Santos JO. Randomized clinical trial on the effectiveness of low-level laser therapy in the relief of perineal pain after normal childbirth with episiotomy [thesis]. São Paulo: School of Nursing, University of São Paulo; 2010.

Introduction: Perineal pain is one of the most common adverse effects of episiotomy, constituting one of the most common maternal morbidity. Regarded as one of the biggest advances in health care, the low-level laser therapy have been shown very promising for the treatment of musculoskeletal diseases, for its analgesic and anti-inflammatory effects and for accelerating the healing process. Objective: To evaluate the effectiveness of the application of low intensity laser for pain relief in the perineal region after normal childbirth with episiotomy. Method: This is a controlled clinical trial, randomized, parallel, with blinding of participant and researcher. The sample consisted of 114 women during puerperium after a normal birth with right mediolateral episiotomy staying in the Communal Recovery Area of the Amparo Maternal, who reported perineal pain $\geq 3$ on a scale of 0 to 10 . The women were divided into three groups of 38 women: infrared experimental group treated with laser with $780 \mathrm{~nm}$; red experimental group - irradiated with $660 \mathrm{~nm}$ laser and a control group - underwent treatment simulation, but without irradiation of light beam. It was used a diode laser, with spot size of $0.04 \mathrm{~cm} 2$, the dose of $8.8 \mathrm{~J} / \mathrm{cm} 2,35$ $\mathrm{mW}$ power, irradiation duration of 10 seconds per point, $0.35 \mathrm{~J}$ of energy per point and total energy of $1.05 \mathrm{~J}$. The same irradiation protocol was applied in the experimental groups, infrared and red. The application was done in punctual mode, directly over the episiotomy, radiating from the central portion and edges, top and bottom of the trauma, making up three points of irradiation. The perineal pain intensity was evaluated before, immediately and 30 minutes after irradiation, on a numeric scale from 0 to 10 . The data were collected between November 2009 and March 2010, after the approval by the Research Ethics Committee. Results: The average age of the mothers was $22.8 \pm 4.4$ years, the majority were primiparous $(80.7 \%)$ and nulliparous $(88.6 \%)$. The average intra-group perineal pain before and immediately after irradiation showed a statistically significant difference in the three groups ( $\mathrm{p} \square 0.001$ ). There was also a significant difference intra-group averages of perineal pain immediately and 30 minutes after the intervention ( $\mathrm{p} \square 0.05)$, and 30 minutes before and after irradiation $(\mathrm{p} \square 0.001)$ in the three groups analysed. The comparison of the average of the perineal pain between the control, infrared and red groups showed no significant difference in the three evaluation moments, indicating that the analgesic results obtained in groups treated with low-level laser therapy were equivalent to the control group. There was no significant difference in the proportion of relief of perineal pain among the three comparison groups, immediately and 30 minutes after intervention $(p=0.234)$, indicating that relief pain was similar between groups. The majority of the women underwent low-level laser therapy $(96.0 \%)$ had a favorable opinion on the use of lasers in clinical practice, found the procedure comfortable (93.4\%) and reported that would repeat the treatment in another postpartum period (96.5\%). Conclusion: The treatment protocol with low-level laser therapy used in this study showed no benefit in the relief of perineal pain in the comparison between experimental groups with control. It is necessary that new research proposals, analyzing different treatment protocols with the laser at low-level laser therapy, should be developed to determine an ideal protocol in relief of perineal pain among the mothers. 
Keywords: Lasers. Low-level Laser Therapy. Perineum. Pain. Postpartum period. Obstetric Nursing. Clinical Trial. 
RESUMEN 
Santos JO. Ensayo clínico aleatorizado sobre la eficacia del láser de baja intensidad en el alivio del dolor perineal después del parto normal con episiotomía [tesis]. São Paulo: Escuela de Enfermería, Universidade de São Paulo; 2010.

Introducción: El dolor perineal es uno de los efectos adversos más comunes de la episiotomía, que constituye uno de los más comunes de morbilidad materna. Considerado como uno de los mayores avances en el cuidado de la salud, la irradiación láser de baja intensidad han demostrado ser muy prometedor para el tratamiento de las enfermedades musculoesqueléticas, por su analgésico, antiinflamatorio y acelerar el proceso de curación. Objetivo: Evaluar la eficacia de la aplicación del láser de baja intensidad para el alivio del dolor en la región perineal después de la episiotomía. Método: Se trata de un ensayo clínico controlado, aleatorizado, paralelo, con el cegamiento de los participantes y el investigador. La muestra consistió de 114 madres con parto normal vaginal con episiotomía mediolateral derecha permanecer en el Amparo Maternal mixto, que informaron dolor perineal $\geq 3$ en una escala de 0 a 10 . Se dividieron en tres grupos de 38 mujeres: grupo experimental - láser infrarrojo tratados con $780 \mathrm{~nm}$ rojo grupo experimental - la irradiación con $660 \mathrm{~nm}$ y un grupo de control - se sometieron a la simulación del tratamiento, pero sin irradiación de haz de luz. Se utilizó un láser de diodo, el tamaño de punto de $0,04 \mathrm{~cm} 2$, la dosis de $8,8 \mathrm{~J} / \mathrm{cm} 2,35 \mathrm{~mW}$ de potencia, duración de la irradiación de 10 segundos por punto, la energía $0,35 \mathrm{~J}$ por la energía de punto y total de 1,05 J. El protocolo de irradiación se aplicó el mismo en los grupos experimentales, infrarrojo y rojo. La solicitud se hizo por partes, directamente sobre la episiotomía, que irradia de la parte central y los bordes, superior e inferior de la lesión, lo que representa tres puntos de la irradiación. La intensidad del dolor perineal fue evaluada antes, inmediatamente y 30 minutos después de la irradiación, la escala numérica de 0 a 10 . La recolección de datos se realizó entre noviembre de 2009 y marzo de 2010, tras la aprobación de la Ética en la Investigación en Seres Humanos. Resultados: La edad media de las madres fue de 22,8 $\pm 4,4$ años, la mayoría eran primíparas $(80,7 \%)$ y nulíparas $(88,6 \%)$. Significa el dolor perineal dentro del grupo antes e inmediatamente después de la irradiación mostró una diferencia estadísticamente significativa entre los tres grupos ( $\mathrm{p} \square 0,001)$. También hubo una diferencia significativa promedios dentro de un grupo de dolor perineal inmediatamente y 30 minutos después de la intervención ( $\mathrm{p} \square 0,05)$, y 30 minutos antes y después de la irradiación ( $\mathrm{p} \square 0,001)$ en los tres grupos. La comparación del dolor perineal entre el control, infrarrojo y rojo no mostró diferencias significativas en los tres puntos de tiempo, lo que indica que los resultados analgésicos obtenidos en los grupos tratados con láser de baja intensidad fueron equivalentes al grupo de control. No hubo diferencias significativas en la proporción de la reducción del dolor perineal entre los tres grupos de comparación, y 30 minutos inmediatamente después de la intervención $(\mathrm{p}=0,234)$, lo que indica que el alivio del dolor fue similar entre los grupos. La mayoría de las mujeres se sometieron a la terapia con láser $(96,0 \%)$ tenían una opinión favorable sobre el uso del láser en la práctica clínica, que se encuentra el procedimiento cómodo $(93,4 \%)$ y mencionó que sería repetir el tratamiento en otro período de posparto $(96,5 \%)$. Conclusión: El protocolo de tratamiento con láser de baja intensidad utilizada no mostró ningún beneficio en el alivio del dolor perineal se compararon los grupos experimentales con el control. Es necesario que las nuevas propuestas de investigación, el análisis de diferentes 
protocolos de tratamiento con el láser de baja intensidad, se han desarrollado para determinar un protocolo ideal de efectivos para aliviar el dolor y el malestar perineal entre las madres.

Palabras-clave: Rayos Láser. Terapia por Láser de Baja Intensidad. Perineo. Dolor. Período post-parto. Enfermería Obstétrica. Ensayo Clínico. 


\section{LISTA DE ILUSTRAÇÕES}

Figura 1 - Escala numérica........................................................ 39

Figura 2 - Escala de categoria verbal.......................................... 40

Figura 3 - $\quad$ Escala visual analógica................................................ 40

Figura 4 - $\quad$ Ondas eletromagnéticas................................................ 48

Figura 5 - Espectro eletromagnético............................................. 49

Figura 6 - Interação do laser com tecido-alvo................................... 50

Figura 7 - Etiqueta de aviso do uso do laser..................................... 64

Figura 8 - $\quad$ Aparelho laser em baixa intensidade - Twin Laser ${ }^{\circledR} \ldots \ldots . .78$

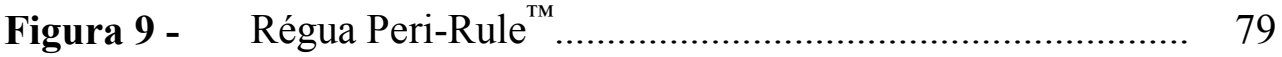

Figura 10 - Diagrama de recrutamento e seguimento das puérperas do estudo. Amparo Maternal, São Paulo, 2010............... 98 


\section{LISTA DE TABELAS}

Tabela 1 - Comparação das médias e desvios-padrão (dp) de dor perineal entre os grupos controle e experimental, antes e imediatamente depois de cada sessão de irradiação de LBI. Amparo Maternal, São Paulo, 2009.

Tabela 2 - Comparação das médias e desvios-padrão (dp) dos escores de cicatrização entre os grupos controle e experimental, segundo o período de avaliação. Amparo Maternal, São Paulo, 2009.

Tabela 3 - Distribuição das puérperas, segundo a idade, cor da pele, escolaridade, estado marital, trabalho remunerado, tabagismo e histórico de alergia medicamentosa. Amparo Maternal, São Paulo, 2010.

Tabela 4 - Distribuição das puérperas, segundo a história obstétrica e presença de acompanhante no parto. Amparo Maternal, São Paulo, 2010

Tabela 5 - Comparação das médias e desvios-padrão (dp) das variáveis quantitativas entre os grupos controle, experimental infravermelho e vermelho. Amparo Maternal, São Paulo, 2010

Tabela 6 - Comparação das médias e desvios-padrão (dp) da dor perineal nos grupos controle e experimental, vermelho e infravermelho, antes e imediatamente após a laserterapia. Amparo Maternal, São Paulo, 2010..............

Tabela 7 - Comparação das médias e desvios-padrão (dp) da dor perineal nos grupos controle e experimental, vermelho e infravermelho, imediatamente e com 30 minutos depois. Amparo Maternal, São Paulo, 2010.

Tabela 8 - Comparação das médias e desvios-padrão (dp) da dor perineal nos grupos controle e experimental, vermelho e infravermelho, antes e 30 minutos após a laserterapia. Amparo Maternal, São Paulo, 2010.

Tabela 9 - Porcentual de redução da dor perineal imediatamente após a intervenção com LBI nos grupos controle, experimental vermelho e infravermelho. Amparo Maternal, São Paulo, 2010. 
Tabela 10 - Porcentual de redução da dor perineal 30 minutos após a intervenção com LBI nos grupos controle, experimental vermelho e infravermelho. Amparo Maternal, São Paulo, 2010.

Tabela 11 - $\quad$ Frequência da interferência da dor perineal nas atividades cotidianas realizadas pelas puérperas antes da intervenção nos grupos controle, experimental vermelho e infravermelho. Amparo Maternal, São Paulo, 2010......

Tabela 12 - $\quad$ Frequência da interferência da dor perineal nas atividades cotidianas realizadas pelas puérperas 30 minutos após a intervenção nos grupos controle, experimental vermelho e infravermelho. Amparo Maternal, São Paulo, 2010.

Tabela 13 - Comparação das atividades diárias que sofrem interferência da dor perineal referidas pelas puérperas, antes e 30 minutos após a intervenção nos grupos controle, experimental vermelho e infravermelho. Amparo Maternal, São Paulo, 2010.

Tabela 14 - Opinião das puérperas dos grupos controle, experimental vermelho e infravermelho sobre a laserterapia. Amparo Maternal, São Paulo, 2010

Tabela 15 - Conforto referido pelas puérperas dos grupos controle e experimental, vermelho e infravermelho, durante a laserterapia. Amparo Maternal, São Paulo, 2010.....

Tabela 16 - Distribuição das puérperas nos grupos controle, experimental vermelho e infravermelho, de acordo com a possibilidade de repetição do tratamento. Amparo Maternal, São Paulo, 2010. 


\section{LISTA DE QUADROS}

Quadro 1 - Escala de avaliação de hiperemia, edema, secreção e coaptação das bordas da lesão (REEDA) 


\section{LISTA DE GRÁFICOS}

Gráfico 1 - Comparação da dor em três momentos (antes da irradiação, imediatamente após e 30 minutos depois) nos grupos controle e experimental vermelho e infravermelho. Amparo Maternal, São Paulo, 2010.......... 


\section{SUMÁRIO}

Resumo

Abstract

Resumen

Lista de Ilustrações

Lista de Tabelas

Lista de Quadros

Lista de Gráficos

1 INTRODUÇÃO.................................................................................. 27

1.1 Aspectos anatomofuncionais do períneo e da episiotomia...................... 32

1.2 Dor: conceito, neurofisiologia e fisiopatologia....................................... 33

1.3 Dor perineal............................................................................ 35

1.4 Avaliação da experiência dolorosa...................................................... 38

1.5 Tratamentos medicamentosos e não medicamentosos para alívio da dor 41 perineal......

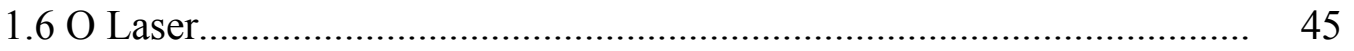

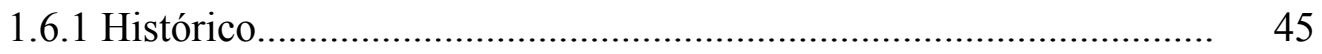

1.6.2 Princípios fundamentais da física do laser........................................ 47

1.6.3 Interação do feixe laser com os tecidos biológicos......................... 50

1.6.4 Laser em baixa intensidade............................................................. 52

1.6.5 Efeitos terapêuticos do laser em baixa intensidade........................ 53

1.6.6 Efeitos primários e secundários do laser em baixa intensidade ........ 54

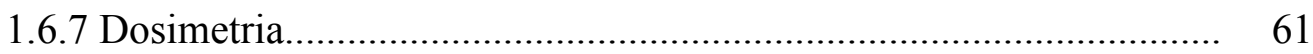

1.6.8 Normas de segurança e contraindicações do LBI........................... 62

1.7 Justificativa do estudo....................................................................... 65

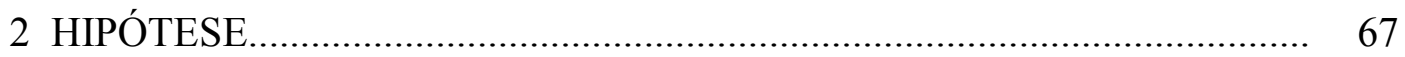

\section{OBJETIVOS}

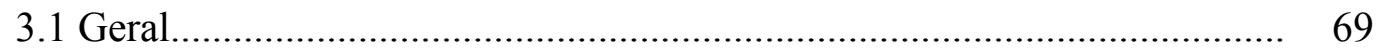

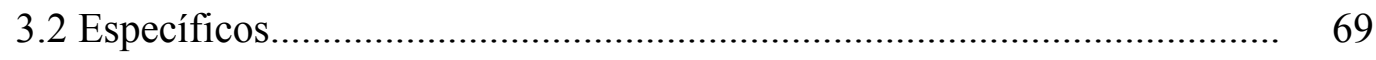

\section{MÉTODO}


4.1Primeira Etapa

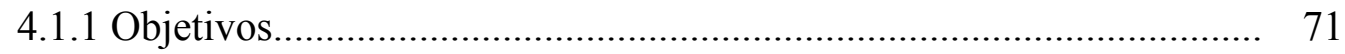

4.1.2 Hipóteses.............................................................................. 71

4.1.3 Tipo de Estudo............................................................................ 71

4.1.4 Local do Estudo......................................................................... 72

4.1.5 População e Amostra........................................................................ 73

4.1.5.1 Critérios de Inclusão................................................................... 74

4.1.5.2 Critérios de exclusão.................................................................... 74

4.1.5.3 Randomização........................................................................... 75

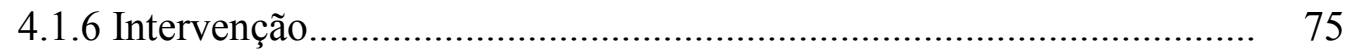

4.1.7 Variáveis e Desfechos....................................................................... 76

4.1.8 Coleta de Dados................................................................................. 77

4.1.8.1 Equipamentos e instrumentos...................................................... 77

4.1.8.2 Procedimentos.......................................................................... 79

4.1.9 Tratamento e Análise dos Dados........................................................ 81

4.1.10 Aspectos Éticos............................................................................. 81

4.1.11 Resultados e Discussão..................................................................... 82

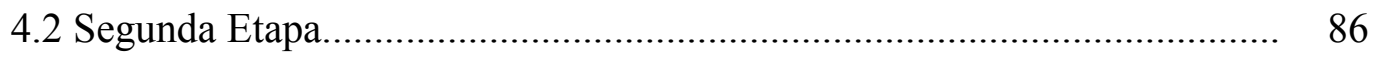

4.2.1 Tipo de Estudo.............................................................................. 86

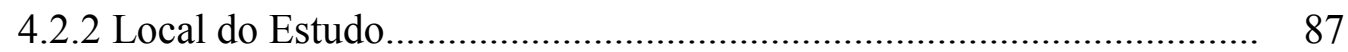

4.2.3 População....................................................................................... 87

4.2.4 Critérios de inclusão e exclusão........................................................ 87

4.2.5 Amostra e randomização.................................................................. 88

4.2.6 Intervenção e desfechos ................................................................... 89

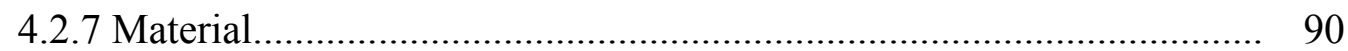

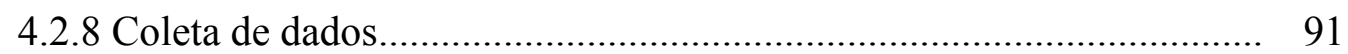

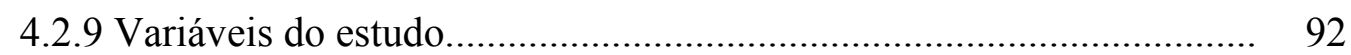

4.2.9.1 Variável independente................................................................. 92

4.2.9.2 Variável dependente................................................................... 92

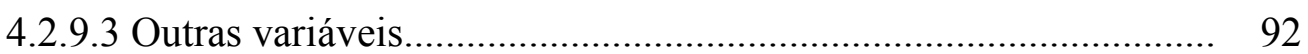

4.2.10 Tratamento e análise dos dados......................................................... 94

4.2.11 Aspectos éticos...................................................................... 95

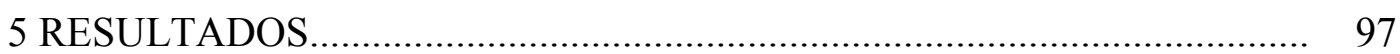


6 DISCUSSÃO.

7 CONCLUSÃO.

8 CONSIDERAÇÕES FINAIS

9 REFERÊNCIAS

APÊNDICES

Primeira Etapa

1 Tabela de Randomização.

148

2 Termo de Consentimento Livre e Esclarecido. 149

3 Formulário de Coleta de Dados. 151

4 Termo de Autorização da Pesquisa... 154

Segunda Etapa

5 Tabela de Randomização. 155

6 Termo de Consentimento Livre e Esclarecido. 157

7 Formulário de Coleta de Dados. 159

\section{ANEXOS}

1 Escala Numérica. 163

2 Carta de Aprovação do Comitê de Ética em Pesquisa 164 
1 INTRODUÇÃO 
O puerpério ou período pós-parto é a fase do ciclo gravídico-puerperal em que as modificações locais e sistêmicas provocadas pela gravidez e pelo parto no organismo da mulher regridem e o corpo feminino retorna ao estado pré-gravídico (Neme, 2005; Ricci, 2008; Rezende, 2008).

Trata-se de um período com duração variável, que tem início após a saída da placenta e com término imprevisto (Brasil, 2001; Rezende, 2008), podendo ser dividido em pós-parto imediato (do $1^{\circ}$ ao $10^{\circ}$ dia), puerpério tardio (do $10^{\circ}$ ao $45^{\circ}$ dia) e pós-parto remoto (além de 45 dias após o parto) (Rezende, 2008).

Neste período, todas as atenções da equipe de saúde e dos familiares estão focadas na chegada do recém-nascido. A assistência à mulher está centrada nas atividades relacionadas ao exercício da maternidade, como o cuidado com o bebê a amamentação. Para exercer essas atividades a puérpera deve estar restabelecida física e emocionalmente. No entanto, esta é uma fase cheia de desafios para a mãe, que necessita enfrentar rápidos ajustes físiológicos e psicológicos, podendo apresentar intensa vulnerabilidade e intercorrências (Burroughs, 1995).

Embora o puerpério seja considerado um período feliz e divertido, é acompanhado pela perda de sono, frustração, irritabilidade, cansaço, desconfortos físicos e dor, em especial, a dor na região perineal decorrente do traumatismo sofrido durante o parto normal (Burroughs, 1995; Enkin et al., 2005).

Estudo realizado em um hospital público de São Paulo, com 100 puérperas que tiveram parto normal, constatou que $96 \%$ delas apresentaram dor entre 20 e 24 horas após o parto, $98 \%$ entre 56 e 60 horas e $93 \%$ no $10^{\circ}$ dia de pós-parto. A localização mais frequente da dor referenciada nas primeiras 24 horas foi na região perineal $(32,9 \%)$, seguida pela dor abdominal do tipo cólica $(31,7 \%)$ e dor nas mamas $(25,3 \%)$. A principal queixa entre 56 e 60 horas foi dor mamária $(39,6 \%)$, seguida pelas dores perineal $(26,3 \%)$ e abdominal $(22,6 \%)$. No $10^{\circ}$ dia após o parto ainda sobressaiu a dor nas mamas $(40,2 \%)$, no períneo $(28,1 \%)$ e lombalgia $(12,1 \%)$ (Alexandre, 2002).

No parto normal, a maioria das mulheres sofre algum tipo de trauma no períneo em função das lacerações perineais espontâneas ou episiotomia (OMS, 1996; Brasil, 2001). As lacerações perineais espontâneas são classificadas (Kettle, 2005) de 
acordo com o grau e a extensão da ruptura dos tecidos envolvidos, como se observa a seguir:

Primeiro grau, quando a lesão é mais superficial e envolve a pele, tecido subcutâneo do períneo e epitélio vaginal.

Segundo grau, quando se estende até os músculos perineais e afeta os músculos bulbocavernoso e transverso perineal, sem lesionar o esfíncter anal.

Terceiro grau, quando a lesão atinge a musculatura do períneo e o esfíncter do ânus, podendo ser subclassificada em:

- 3A, quando afeta menos que 50\% do esfíncter anal externo;

- 3B, ao comprometer mais que 50\% desse músculo,

- 3C, ao incluir lesão do esfíncter anal interno.

Quarto grau, quando envolve a ruptura no conjunto do esfincter anal e a exposição do epitélio anal.

A episiotomia, incisão cirúrgica de ampliação do introito vaginal no parto, foi introduzida empiricamente na obstetrícia, tornando-se um procedimento comum durante o parto vaginal sem que houvesse comprovação científica de sua eficácia. Acreditava-se que a episiotomia evitava ou reduzia as morbidades e a mortalidade materno-infantil. Dentre os efeitos benéficos da intervenção sugeridos pela literatura, citam-se a prevenção de lacerações perineais graves; a preservação do assoalho pélvico e do músculo perineal, levando a melhora da função sexual; a prevenção de futuros problemas ginecológicos, como cistocele, retocele e relaxamento do assoalho pélvico e, por fim, a substituição de uma laceração irregular e de difícil cicatrização, por uma incisão limpa, precisa, de fácil reparo e melhor cicatrização (OMS, 1996; Myers-Helfgott, Helfgott, 1999; Labrecque et al., 2000; Enkin et al., 2005).

Embora tenha se tornado um dos procedimentos cirúrgicos mais frequentes no mundo, pesquisas científicas recentes sugerem vários efeitos adversos da episiotomia, que incluem: a secção ou extensão da secção para o músculo esfíncter anal ou ao reto; resultados anatômicos insatisfatórios, como fibromas moles, assimetria ou estreitamento excessivo do introito vaginal; prolapso vaginal, fístulas retovaginais ou anais; aumento da perda de sangue e hematoma; infecção e 
deiscência de sutura; edema, dor e disfunção sexual (Enkin et al., 2005; Carroli, Mignini, 2009).

Myers-Helfgott e Helfgott (1999) acrescentam que a episiotomia também prolonga o tempo do profissional na sala operatória e aumenta os gastos com material de sutura.

Martins-Costa et al. (2001) e Goldberg et al. (2002) apontam que o uso rotineiro da episiotomia está relacionado ao aumento do risco de incontinência fecal, de elevação no índice de laceração de terceiro e quarto graus, e de dispareunia, além de afetar negativamente a imagem corporal da mulher e sua função sexual, prejudicando sua autoestima.

Estudo realizado com 1.573 puérperas, 2 meses após o parto, associou a episiotomia à problemas intestinais $(\mathrm{p}=0,001)$, à dor perineal $(\mathrm{p}<0,001)$, à infecção perineal $(\mathrm{p}<0,001)$, e à dor interferindo nas atividades de rotina $(\mathrm{p}<0,001)$ em multíparas (Declerq et al., 2008).

A revisão sistemática da Biblioteca Cochrane comparando o uso rotineiro versus o restrito da episiotomia demonstrou mais benefícios relacionados ao uso seletivo da intervenção, como menor risco de trauma perineal posterior, menor necessidade de sutura, redução das complicações associadas ao processo de cicatrização, menor referência para dor e redução dos traumas vaginais graves. A única desvantagem do uso restrito da episiotomia constatada pelo estudo foi o aumento no risco de lesões perineais anteriores, geralmente, lacerações de primeiro e segundo graus (Carroli, Mignini, 2009).

Fundamentado nas melhores evidências científicas publicadas em todo o mundo sobre a assistência à mulher durante o trabalho de parto e parto, um trabalho de metanálise desenvolvido por especialistas de diferentes países culminou na publicação do Guia Prático para a Assistência ao Parto Normal pela Organização Mundial da Saúde (OMS), em 1996, tornando-se referência para a promoção do parto natural e da maternidade segura.

Neste guia, as práticas na assistência ao parto normal foram classificadas em quatro categorias (OMS, 1996):

Categoria A - Práticas demonstradamente úteis e que devem ser estimuladas. 
Categoria $B$ - Práticas claramente prejudiciais ou ineficazes que devem ser eliminadas.

Categoria $C$ - Práticas em relação às quais não existem evidências científicas suficientes para apoiar uma recomendação clara e que devem ser utilizadas com cautela, até que mais pesquisas esclareçam a questão.

Categoria D - Práticas frequentemente utilizadas de modo inadequado.

Seguindo a mesma linha, o Ministério da Saúde do Brasil publicou, em 2001, o Guia Parto, Aborto e Puerpério: Assistência Humanizada à Mulher, no qual incorporou e categorizou as práticas na assistência à saúde da mulher conforme as recomendações da OMS, atualizando-as com base nas novas evidências científicas (Brasil, 2001).

Em ambos os guias, o uso liberal e rotineiro da episiotomia foi classificado como uma prática no parto normal claramente prejudicial ou ineficaz que deve ser eliminada (OMS, 1996; Brasil, 2001).

Apesar da política de uso restrito da episiotomia, recomendada somente em cerca de 10\% dos partos normais pela OMS (1996), a taxa dessa intervenção varia consideravelmente no mundo. No Brasil, segundo a Pesquisa Nacional de Demografia e Saúde da Mulher e da Criança (PNDS), nos últimos 4 anos a episiotomia foi realizada em 70\% dos partos normais (Berquó et al., 2009), chegando a ser efetuada em $94,2 \%$ das primíparas que tiveram parto vaginal (Althabe et al., 2002).

Na América Latina, a episiotomia é realizada em mais de $90 \%$ dos partos hospitalares (Tomasso, 2002), na Holanda a taxa total da intervenção é 8\%, na Inglaterra 14\%, nos Estados Unidos da América é de 50\% e, nos países do Leste Europeu é 99\% (Royal College of Obstetricians and Gynaecologists, 2004). Em países como Taiwan e Guatemala, estima-se uma taxa de 100\% de intervenção em partos normais (Graham et al., 2005).

A prevenção das lacerações perineais graves é uma das principais justificativas para a prática da episiotomia. Determinadas condições são referidas na literatura como fatores de risco para laceração espontânea grave do períneo, como: o parto instrumental (aplicação do fórcipe ou extração a vácuo), a primiparidade, a 
posição litotômica, a rigidez dos tecidos perineais, a má adaptação da apresentação fetal com a sínfise púbica, a posição anômala do feto, a macrossomia fetal e o desprendimento fetal rápido no período expulsivo (Aytan et al., 2005; Scarabotto, Riesco, 2006; Dahlen et al., 2007).

Estudo desenvolvido pela Universidade do Novo México demonstrou que o tipo de puxo Valsalva, o peso elevado do bebê e o ensino médio ou superior são fatores de risco para o trauma perineal em primíparas; para as multíparas, o histórico de trauma perineal suturado e o peso do $\mathrm{RN}$ foram considerados os principais fatores de risco para lesão no períneo (Albers et al., 2006). Além disso, Dahlen et al. (2007) apontaram que a etnia asiática também está associada ao aumento das taxas de laceração perineal grave.

Outros motivos apontados na literatura para a prática da episiotomia são o sofrimento fetal, a macrossomia fetal, a prematuridade, a distensibilidade restrita do assoalho pélvico, a distância entre a fúrcula vaginal e o ânus menor que 3 centímetros, o edema vulvar, a progressão insuficiente do parto, a apresentação pélvica e a distócia de ombro (OMS, 1996; Labrecque et al., 2000; Silva, 2002; Oliveira, Miquilini, 2005).

A dor perineal é um dos efeitos adversos mais comuns da episiotomia, constituindo uma das morbidades maternas frequentes. A presença de algia no período puerperal gera dificuldades para o exercício da maternidade e para o desenvolvimento das atividades cotidianas, como o autocuidado, a amamentação e o cuidado ao recém-nascido, além de interferir no sono, no repouso, na movimentação, na micção, na evacuação e no apetite da puérpera (Alexandre, 2002; Riesco, Oliveira, 2007). Essas dificuldades podem causar importantes problemas físicos, psicológicos e emocionais que colaboram para experiências negativas da maternidade (Burroughs, 1995; Alexandre, 2002).

Apesar de ser uma das principais queixas das mulheres no período pós-parto, a dor perineal, geralmente, é desvalorizada pela própria puérpera, por sua família e pelos profissionais de saúde, pois, nesse período, a atenção ao recém-nascido ganha prioridade e as necessidades da mulher ficam em segundo plano (Alexandre et al., 2006; Pitangui, 2009). 
A identificação da ocorrência da dor perineal espontânea e dos métodos empregados para seu alívio são importantes para seu controle, oferecendo à mulher a possibilidade de vivenciar a maternidade de forma mais positiva e prazerosa.

\subsection{Aspectos anatomofuncionais do períneo e da episiotomia}

O trauma perineal está associado à passagem do feto pelo canal de parto e às intervenções realizadas no períneo da mulher durante o processo de parturição que, por sua vez, estão relacionadas à ocorrência de morbidades maternas no período puerperal. Portanto, torna-se oportuna uma revisão anatomofuncional das estruturas que compõem essa região.

De acordo com Rezende (2008), o períneo é a estrutura responsável pela sustentação dos órgãos pélvicos, e é definido como um conjunto de partes moles (músculos e aponeuroses) que fecha inferiormente a cavidade pélvica, sendo atravessado posteriormente pelo reto e anteriormente pela vagina e uretra.

Anatomicamente, o períneo é subdividido pelo traçado da linha bi-isquiática em região anterior e posterior. A região anterior é constituída pelos músculos isquicarvernoso, bulbocavernoso, transverso superficial e o esfíncter externo da uretra, enquanto os músculos esfíncter do ânus, levantador do ânus e isquiococcígeo compõem a região posterior perineal (Rezende, 2008).

O corpo perineal é uma massa de tecido fibromuscular que ocupa a área entre a vagina e o reto, medindo aproximadamente 4 centímetros em extensão e em profundidade, e se continua no fundo da pelve, com o septo vaginal. Durante o período expulsivo do parto, o corpo perineal é distendido pela passagem do feto através do canal de parto (Kettle; 2005; Rezende, 2008).

A vascularização do períneo é assegurada pela artéria pudenda interna, ramo da hipogástrica. O retorno venoso acompanha a artéria. O nervo pudendo é responsável pela inervação da região perineal, podendo ser bloqueado com anestésicos locais para a realização da episiotomia (Rezende, 2008).

A incisão da episiotomia começa na margem posterior da abertura vaginal, podendo ser feita na linha média em direção ao orifício anal, denominada mediana ou perineotomia, ou pode ser realizada em um ângulo de 45 graus em qualquer um 
dos lados, denominando-se médio-lateral. A intervenção deve ser realizada quando a cabeça do feto está suficientemente baixa a ponto de distender o períneo e exercer uma pressão no local. Sua realização deve preceder uma distensão exagerada da região perineal, não antecedendo demasiadamente o desprendimento cefálico fetal, o que ocasionaria sangramento excessivo (Ziegel, Cranley, 1985; Neme, 2005).

$\mathrm{Na}$ episiotomia, são seccionadas as seguintes estruturas: pele, tecido subcutâneo, mucosa vaginal, músculo bulbocavernoso ou bulboesponjoso e o músculo transverso superficial do períneo. Quando o procedimento é mais profundo, também são seccionados o transverso profundo e ramos do músculo elevador do ânus (Neme, 2005).

Segundo Albers et al. (2007), existe uma relação direta entre a extensão e a complexidade do trauma perineal sofrido no parto normal e as morbidades que afetam as mulheres no período pós-parto. Shorten et al. (2002) as relacionam sobretudo à episiotomia. A intervenção pode provocar morbidades maternas a curto prazo como dor, sangramento vaginal, infecção, deiscência de sutura, hematoma e dificuldades no processo de amamentação. A longo prazo, podem ocorrer dispareunia, incontinência urinária e fecal e problemas no assoalho pélvico (Declerq et al., 2008; Carroli, Mignini, 2009).

\subsection{Dor: conceito, neurofisiologia e fisiopatologia}

A literatura científica analisada retrata que a dor perineal está relacionada à ocorrência de trauma perineal, tornando-se oportuno um aprofundamento da neurofisiologia e da fisiopatologia da sensação dolorosa, favorecendo o suporte analgésico adequado para cada indivíduo.

A dor é uma experiência individual que tem acompanhado os seres humanos através dos tempos. O Comitê de Taxonomia da Associação Internacional para o Estudo da Dor (Internacional Association for the Study of Pain - IASP) conceitua a dor como uma experiência sensorial e emocional desagradável, associada ou relacionada a um dano real ou potencial dos tecidos. Cada indivíduo aprende a utilizar este termo por meio de experiências anteriores (IASP, 1986). 
A definição exprime o conceito de que a dor é uma experiência pessoal e subjetiva, que envolve aspectos sensitivos, emocionais e culturais de cada indivíduo (Pimenta, 2000), podendo ser apreendida de diferentes maneiras. Dor é fundamental para a sobrevivência do ser humano, sendo o primeiro indicador de qualquer lesão tecidual no organismo humano, exercendo assim, uma função protetora (Teixeira, 2006).

Clinicamente, a dor é classificada em termos temporais como aguda e crônica. Segundo Pimenta (2000), a dor aguda está relacionada a traumatismo, processo infeccioso ou inflamatório, com delimitação temporoespacial precisa, com expectativa de desaparecimento após a cura da lesão. É acompanhada por respostas neurovegetativas, como elevação da pressão arterial, taquicardia, taquipneia, ansiedade e agitação psicomotora.

De acordo com Smeltzer e Bare (2002), a dor aguda tem início súbito, com período de duração variando de apenas alguns segundos até 6 meses, e indica um comprometimento de um tecido ou lesão. A dor é considerada crônica quando constante ou intermitente, persiste por certo período, geralmente, associada a processos patológicos crônicos, que não pode ser atribuída a uma lesão ou causa específica (Pimenta, 2000; Smeltzer, Bare, 2002). Teixeira (2006) afirma que a dor crônica corresponde a mecanismos de adaptação do organismo, especialmente musculoesqueléticos e psicocomportamentais que induzem à incapacidade e a repercussões biopsicossociais desfavoráveis.

A transformação de um estímulo em uma sensação dolorosa envolve estruturas específicas do sistema nervoso. Os nociceptores ou receptores consistem nas terminações nervosas livres do sistema nervoso periférico que respondem a estímulos intensos e com potencial de lesão, que podem ser de natureza mecânica (pressão, corte, traumatismo), térmica (calor, frio) ou química (ácidos) (Pimenta, 2000; Teixeira, 2006; Chaves, 2007).

A lesão tecidual resulta na liberação de substâncias algiogênicas, conhecidas como mediadores químicos, compostos por íons $\mathrm{K}^{+}$e $\mathrm{H}^{+}$, aminas vasoativas (histamina e serotonina), bradicinina, catecolaminas, prostaglandinas, entre outras. Tais mediadores sensibilizam os nociceptores e são responsáveis pela hiperalgesia termomecânica e pela vasodilatação observada em lesões traumáticas, inflamatórias ou isquêmicas (Pimenta, 2000; Teixeira, 2006; Chaves, 2007) 
Para Kumar, Abbas e Fausto (2005) e Genovese e Frigo (2007), a prostaglandina E2 desempenha um importante papel na iniciação da dor e do edema pela sensibilização dos receptores de dor, provocando a hiperalgesia no local da lesão tissular. Esses autores acrescentam que a bradicinina é um potente agente que aumenta a permeabilidade vascular causando dilatação dos vasos sanguíneos no local da lesão e dor.

O impulso elétrico nociceptivo é então transmitido pelos aferentes primários, constituídos por fibras nervosas mielínicas finas (A-delta) e amielínicas (C), localizadas sobretudo na pele, músculo, articulações e vísceras, até o corno posterior da medula espinhal. A informação é conduzida, via tratos espinotalâmicos e espinorreticulares, para o sistema nervoso central (SNC), para a região do tronco cerebral, tálamo e áreas corticais envolvidas no processamento da sensibilidade (Teixeira, Filho, 2006).

No SNC, pode ocorrer a hiperpolarização neuronal, inibindo a transmissão do impulso doloroso modulada pelas encefalinas (morfinas endógenas) e endorfinas ou a despolarização neuronal, facilitando a transmissão do impulso (Chaves, 2007). A dor advém do desequilíbrio entre os sistemas nociceptivos (vias excitatórias) e supressor da dor (Pimenta, 2000), podendo ser produto do excesso de estímulos nociceptivos, como na dor inflamatória e traumática ou da hipoatividade do sistema supressor, como nas neuropatias periféricas ou centrais (Teixeira, Filho, 2006).

\subsection{Dor perineal}

A perda da integridade perineal, espontânea ou cirúrgica, funciona como o estímulo de natureza mecânica que desencadeia um processo inflamatório, que está intrinsecamente relacionado à dor aguda, gerando considerável desconforto à mulher. A dor perineal tem sido reportada como uma morbidade materna frequente, associada ao trauma perineal que, dependendo do grau e da intensidade, pode afetar significativamente sua qualidade de vida.

De acordo com a literatura, existe uma relação direta entre a extensão e a complexidade da lesão perineal sofrida e as morbidades que afetam as mulheres no 
período do pós-parto, sobretudo relacionadas à episiotomia (Albers et al., 2007; Declerq et al., 2008).

Estudo realizado por Klein et al. (1994) constatou presença de dor perineal 3 meses após o parto normal, independente da presença de trauma local. Segundo os autores, a dor foi referida por $42 \%$ das mulheres com períneo íntegro, 53\% das puérperas que apresentaram laceração de primeiro e segundo graus, 54\% das que sofreram episiotomia e por $79 \%$ de mulheres com laceração perineal de terceiro e quarto graus. A dor perineal foi descrita como terrível por 11,3\% das puérperas com laceração de primeiro e segundo graus, $20,2 \%$ das mulheres episiotomizadas e 22,2\% das com laceração de terceiro e quarto graus. Entre as mulheres que tiveram a integridade perineal foi preservada, nenhuma a descreveu como terrível.

Um estudo descritivo analisando os dados de um ensaio clínico randomizado controlado que comparou dois métodos de cuidados perineais no final do período expulsivo do parto para evitar trauma perineal ("hands on" ou "hands poised"), identificou informações relacionadas à dor perineal nos períodos de 2 dias, 10 dias e 3 meses após o parto. Participaram desta pesquisa 5.404 mulheres, sendo constatado que a maioria (85\%) sofreu algum tipo de trauma perineal. A presença de dor foi citada mesmo entre as mulheres cuja integridade perineal foi preservada, declinando sua taxa no respectivo período analisado, passando de $41 \%$ no segundo dia pós-parto para $10 \%$ no décimo dia e para $3 \%$ no terceiro mês após o parto. A prevalência de dor variou de acordo com o local e a complexidade do trauma, sendo mais reportada pelas mulheres com laceração perineal de terceiro e quarto graus (Albers et al., 1999).

Outro estudo realizado em um hospital público de São Paulo (SP), com 100 puérperas que tiveram parto normal, evidenciou que $32,9 \%$ das mulheres referenciaram dor perineal nas primeiras 24 horas pós-parto, 26,3\% entre 56 e 60 horas e $28,1 \%$ a mencionaram no décimo dia de puerpério. Segundo a autora, ao longo dos 10 primeiros dias, a dor persistiu como principal queixa álgica, apresentando maior média de intensidade entre 20 e 24 horas pós-parto, com escore 5,5 , avaliada pela escala numérica de 0 a 10 . Além de interferir nas atividades de rotina, ela também foi citada pelas puérperas como a que mais interferiu na amamentação (Alexandre, 2002). 
Estudo prospectivo para determinar a frequência de dor perineal e o tipo de trauma sofrido nos primeiro e sétimo dias e com 6 semanas após o parto, com amostra de 447 puérperas, identificou elevada prevalência de dor perineal, entre $75 \%$ e $100 \%$, sendo a maior frequência associada ao aumento do trauma perineal. Nos primeiro e sétimo dias de puerpério, a dor perineal foi referida por $75 \%$ e $38 \%$ das mulheres com períneo íntegro; 95\% e 60\% nas lacerações de primeiro e segundo graus, $97 \%$ e $71 \%$ das mulheres que sofreram episiotomia e $100 \%$ e $91 \%$ daquelas com laceração de terceiro e quarto graus, respectivamente. Não houve diferença estatística na frequência da dor perineal entre as mulheres, segundo o tipo de trauma, na sexta semana após o parto (Macarthur, Macarthur, 2004).

O mesmo estudo apontou que o tempo médio para a cessação da dor no períneo foi maior para as puérperas que tiveram maiores lesões, sendo de 1,9 semanas (desvio-padrão de 0,15) para mulheres sem lesão perineal, 2,4 semanas (desvio-padrão de 0,09) para laceração de primeiro e segundo graus, 2,6 semanas (desvio-padrão de 0,14) para mulheres com episiotomia e 3,2 (desvio-padrão de $0,21)$ para as que sofreram laceração de terceiro e quarto graus. O tempo de alívio da dor perineal foi maior entre as mulheres que sofreram lesão perineal comparado às puérperas cuja integridade perineal foi preservada $(\mathrm{p}<0,01)$ (Macarthur, Macarthur, 2004).

Estudo de coorte realizado com 241 mulheres no período pós-parto identificou que $173(92 \%)$ delas reportaram dor perineal no primeiro dia após o parto, independente do trauma perineal sofrido (Andrews et al., 2008).

Pesquisa realizada nos Estados Unidos da América reportando a experiência de 1.573 mulheres com a dor 2 meses pós-parto, observou que a algia perineal foi citada por $48 \%$ das puérperas com parto vaginal. Desse total, $68 \%$ foram submetidas ao parto instrumental (vácuo e fórceps), $63 \%$ à episiotomia e $43 \%$ ao parto vaginal espontâneo sem episiotomia. Como já citado anteriormente, a episiotomia foi associada à ocorrência de infecção puerperal, à problemas intestinais, à dor perineal e à dor interferindo nas atividades de rotina entre as multíparas (Declerq et al., 2008).

Recente estudo transversal realizado no Hospital Universitário da Universidade de São Paulo, com 303 puérperas que tiveram parto vaginal no período de janeiro a março de 2007, apontou prevalência de dor perineal de $18,5 \%$ entre as mulheres durante o período de internação hospitalar e a maioria com intensidade 
moderada (51,8\%). As puérperas com episiotomia referiram dor perineal com maior frequência quando comparadas às que não sofreram a intervenção $(80,4 \%$ versus 19,6\%), com diferença estatisticamente significativa $(\mathrm{p}=0,001)$ (Francisco et al., 2011, no prelo).

\subsection{Avaliação da experiência dolorosa}

Atualmente, a dor é considerada um dos grandes problemas de saúde pública, pois induz a danos biopsicossocioculturais, podendo causar limitações e restrições físicas, alterar a função laborativa e os relacionamentos familiares e sociais, comprometer o psiquismo, as atividades da vida diária e até mesmo a auto-estima (Paula, 2006).

A Agência Americana de Pesquisa e Qualidade em Saúde Pública e a Sociedade Americana de Dor descreveram-na como o quinto sinal vital, demonstrando a importância de se registrar a ocorrência de dor em conjunto com os quatro sinais vitais, quais sejam: temperatura, pulso, respiração e pressão arterial (Mendonça, Leão, 2007).

O enfermeiro é o membro da equipe de saúde que permanece a maior parte do tempo junto ao cliente e exerce um papel fundamental na avaliação e no manejo da dor. A intensidade, a qualidade, a duração e a localização da dor, seus fatores de melhora ou de piora, suas repercussões sociais e nas atividades diárias devem ser sistematicamente avaliadas por este profissional (Teixeira, Yeng, 2006).

Por ser uma experiência de caráter subjetivo e multidimensional, a dor não pode ser objetivamente determinada por instrumentos físicos, como os que mensuram o peso corporal, a altura e a pressão arterial (Pimenta, 2000). Para avaliação da experiência dolorosa, é fundamental compreender a origem e a magnitude da dor para a implementação de medidas analgésicas efetivas, garantindo assim o bem-estar físico e emocional do cliente pelo alívio da dor e do sofrimento. Para tanto, o enfermeiro deve escolher o instrumento mais adequado de mensuração da dor de sua população.

Segundo Teixeira e Yeng (2006), os instrumentos para mensurar a dor devem ser escolhidos com base no objetivo do estudo, considerando-se a facilidade de 
compreensão do cliente e de sua aplicabilidade. Vários métodos têm sido desenvolvidos e utilizados para tal fim, dentre eles destacam-se os de autorrelato, de observação do comportamento e de medidas das respostas biológicas à dor.

Os instrumentos de autorrelato são apropriados para avaliar a dor e seu impacto na vida cotidiana do indivíduo. São de primeira escolha para adultos com capacidade de compreensão e verbalização adequadas, sendo frequentemente utilizados na prática clínica (Pimenta, 2000).

Alguns instrumentos consideram a dor como uma qualidade simples e única, designados para quantificar somente a gravidade ou sua intensidade, denominados unidimensionais. Outros métodos consideram a dor uma experiência multidimensional composta também por fatores afetivo-emocionais, empregados para avaliar e mensurar os diferentes aspectos da dor com base nas dimensões sensorial, afetiva e avaliativa (Souza, Hortense, 2007).

São considerados instrumentos unidimensionais a Escala de Categoria Numérica e Verbal e a Escala Analógica Visual. Essas escalas são aplicadas solicitando-se ao paciente que classifique a gravidade ou a intensidade da sensação dolorosa sentida no momento da avaliação (Souza, Hortense, 2007).

A Escala Numérica (Figura 1) consiste em uma série de números que podem variar de 0 a 10 ou de 0 a 100, com as extremidades representando a experiência de dor, com 0 (zero) indicando "nenhuma dor" e 10 ou 100 indicando a "pior dor possível". O indivíduo escolhe um número que melhor represente a intensidade subjetiva da dor. É um instrumento de fácil entendimento e aplicação, útil em pacientes com baixa escolaridade (Pimenta, 2000; Teixeira, Yeng, 2006; Souza, Hortense, 2007).

\begin{tabular}{lllllllllll}
\hline 0 & 1 & 2 & 3 & 4 & 5 & 6 & 7 & 8 & 9 & 10
\end{tabular}

Figura 1. Escala Numérica.

A Escala de Categoria Verbal utiliza descritores relacionados à intensidade da dor, classificando-a como ausente, fraca, moderada, forte e insuportável (Figura 2). 
Apesar de ser de fácil aplicação e compreensão, segundo Souza e Hortense (2007) esta escala apresenta problemas de precisão e validade.

( ) nenhuma dor ( ) dor fraca ( ) dor moderada ( ) dor forte ( ) dor insuportável

Figura 2. Escala de Categoria Verbal.

A Escala Visual Analógica (EVA) é frequentemente utilizada no ambiente clínico (Figura 3). O examinador utiliza uma linha com 10 centímetros de comprimento como instrumento de mensuração da dor, com as extremidades indicando a ausência de dor e a pior dor imaginável. Solicita-se ao indivíduo marcar na linha uma indicação da gravidade da dor que está sentindo no momento da avaliação, uma régua é utilizada para quantificar a mensuração medida a partir da extremidade inferior (Souza, Hortense, 2007).

\begin{tabular}{|c|c|}
\hline $\begin{array}{l}\text { Nenhuma } \\
\text { dor }\end{array}$ & $\begin{array}{r}\text { Pior dor } \\
\text { imaginável }\end{array}$ \\
\hline
\end{tabular}

Figura 3. Escala Visual Analógica.

De acordo com Souza e Hortense (2007) a EVA tem a vantagem de reduzir a influência das respostas prévias quando repetidas respostas são solicitadas ao mesmo cliente. No entanto, está sujeita a erros de mensuração do pesquisador.

Outras escalas quantitativas não numéricas unidimensionais foram desenvolvidas para avaliação da magnitude da dor de pacientes com dificuldades de entendimento das escalas anteriores, como crianças e idosos. Dentre elas, encaixamse a Escala de Expressão Facial de Dor, a Escala de Sequência de Copos e a Escala de Cores em que o cliente escolhe a figura que melhor represente a intensidade da dor (Pimenta, 2000).

As escalas multidimensionais são responsáveis pela avaliação da dor, incluindo os aspectos sensoriais, afetivos e avaliativos do cliente, e não somente a intensidade da dor. Constitui-se em uma importante ferramenta para a avaliação mais apurada da complexidade da experiência dolorosa. Um exemplo frequentemente 
utilizado em pesquisas científicas é o Questionário de Dor McGill, que avalia as dimensões da experiência dolorosa, segundo 20 subgrupos de descritores organizados em dimensões: sensitivo-discriminativo, que avalia aspectos temporoespaciais, térmicos e vividez da dor; afetivo-emocional, que envolvem tensão, respostas neurovegetativas, medo e punição; e avaliativa que reflete a avaliação global do sujeito, com base na experiência prévia e no significado da situação do indivíduo (Pimenta, 2000; Smeltzer, Bare, 2002; Teixeira, Yeng, 2006; Souza, Hortense, 2007).

A avaliação do impacto da dor nas atividades de vida diária do indivíduo também é importante, pois fornece indícios sobre a magnitude do quadro doloroso. Alterações nas atividades diárias podem ser mensuradas por meio de instrumentos que avaliam a movimentação, a deambulação, o padrão de sono, a atividade sexual, o apetite e a alimentação, o desempenho das atividades domiciliares, o relacionamento interpessoal e o humor (Pimenta, 2000; Teixeira, Yeng, 2006).

Pimenta (2000) indica que as alterações nas atividades cotidianas do cliente em função do processo doloroso podem ser mensuradas por meio de números ou frequência de ocorrência. Como exemplo, pode-se citar o prejuízo do sono em função da dor utilizando-se palavras como nenhum, pouco, muito ou totalmente, ou então, graduando-se numericamente de 0 a 10 , sendo que zero $(0)$ significa não haver interferência e dez (10) indica interferência máxima. Pode-se ainda questionar a ausência ou a presença de dor durante o desenvolvimento de suas atividades.

A dor perineal em função do traumatismo é uma das principais queixas das mulheres no período pós-parto, conforme já mencionado. A identificação da ocorrência de dor perineal espontânea e da magnitude da dor no puerpério é importante para a promoção de medidas analgésicas efetivas para que as mulheres possam exercer a maternidade livre desse desconforto.

\subsection{Tratamentos medicamentosos e não medicamentosos para alívio da dor perineal}

Apesar da alta prevalência de dor perineal no período pós-parto, até o momento não existe evidência científica disponível sobre qual a melhor maneira de 
reduzir sua ocorrência e sua intensidade. Segundo Enkin et al. (2005), evitar a lesão perineal e reparar apropriadamente quando houver traumatismo são as condutas primárias para evitar ou reduzir a dor e o desconforto pós-natal. Medidas terapêuticas medicamentosas e não medicamentosas podem ser empregadas para o alívio desse desconforto.

Convencionalmente, analgésicos sistêmicos e anestésicos tópicos têm sido empregados para o controle da dor perineal no período pós-parto. $\mathrm{O}$ tratamento com analgésicos orais requer cuidados importantes, como a avaliação da intensidade da dor que deve ser tratada, a probabilidade do medicamento causar constipação, a passagem da droga para o leite materno e o possível risco para o bebê, o que deve ser evitado durante esse período (Enkin et al., 2005).

Existe uma vasta opção farmacológica ativa para o tratamento por via oral, porém as evidências científicas não são úteis para indicar um fármaco ideal, apesar do expressivo número de estudos randomizados que avaliaram a eficácia dos analgésicos orais. A justificativa apresentada é que a maioria dos trabalhos demonstrou que as preparações ativas são superiores aos placebos, mas não apontou diferenças clínicas importantes entre as opções de analgésicos (Enkin et al., 2005).

O paracetamol (acetaminofeno) é o analgésico oral de escolha para dor perineal leve, pois possui propriedades analgésicas úteis e praticamente não apresenta efeitos adversos indesejáveis (Enkin et al., 2005). Chou et al. (2010) em revisão sistemática para determinar a eficácia de uma única dose desse medicamento no alívio da dor perineal aguda no período pós-parto concluíram que mais mulheres tiveram redução na algia com a droga em comparação com um placebo, embora não tenha sido realizada a avaliação dos potenciais efeitos adversos.

Quando o paracetamol não é efetivo no alívio da dor perineal, um antiinflamatório não-esteroide, como o ibuprofeno, parece ser o mais apropriado, pois é praticamente isento de efeitos colaterais e a excreção no leite é muito pequena. Os derivados de codeína são menos recomendados porque predispõem à constipação (Enkin et al., 2005).

Revisões sistemáticas da Biblioteca Cochrane indicaram a efetividade analgésica de uma única dose de medicamentos orais, como o acetaminofeno (Toms et al., 2008), a dipirona (Edwards et al., 2010), o ibuprofeno (Derry et al., 2009) e o diclofenaco (Derry et al., 2009), para o alívio da dor pós-operatória. 
Os tratamentos medicamentosos tópicos utilizados costumeiramente na prática clínica são as soluções antissépticas, os anestésicos locais e a associação de anestésicos e esteroides tópicos (Enkin et al., 2005). Uma revisão sistemática avaliando a eficácia da aplicação dos anestésicos tópicos para redução da dor perineal pós-parto revelou que os dados informados nos estudos estão limitados e não evidenciaram claros benefícios da conduta, sugerindo que mais pesquisas sejam desenvolvidas, para que possam ser utilizados na prática clínica (Hedayati et al., 2005).

Os tratamentos não medicamentosos empregados para alívio da dor perineal incluem o resfriamento com gelo ou aerossol, os banhos de assento e a aplicação do calor (Steen et al., 2000; Enkin et al., 2005; Steen, Briggs, King, 2006). A crioterapia consiste na aplicação de gelo tópico para bloquear a condução do estímulo doloroso (Steen, Briggs, King, 2006), entretanto ainda não existe uma resposta definitiva para o real mecanismo de alívio ou redução da dor pelo frio, existindo diversas teorias que explicam tal fato (Knight, 2000).

A revisão da literatura que analisou a eficácia e a aceitabilidade dos métodos de resfriamento localizados para atenuar os efeitos do trauma perineal revelou dificuldades para avaliar os trabalhos, pois houve limitação de dados, análise de diferentes desfechos e em distintos períodos e, ainda, o emprego de diferentes métodos de resfriamento. Os autores sugeriram que o resfriamento pode reduzir a resposta inflamatória e diminuir o nível de dor perineal reportada pelas mulheres, mas é necessário o desenvolvimento de mais pesquisas científicas para comprovar sua eficácia e seu impacto no processo de cicatrização (Steen, Briggs, King, 2006).

Uma revisão sistemática que avaliou a eficácia e os efeitos locais da crioterapia no alívio da dor perineal revelou que as bolsas de gelo aliviam essa dor de 24 a 72 horas após o parto comparado com a ausência de tratamento (RR 0,61; IC 0,41-0,91), mas os autores indicam que mais pesquisas devem ser desenvolvidas para apoiar a eficácia desta terapêutica (East et al., 2007).

A aplicação tópica de compressas aquecidas e o banho aquecido são estratégias não medicamentosas empregadas há séculos para alívio da dor. O calor de um banho de imersão quente pode proporcionar conforto imediato para a mulher no puerpério, promovendo alívio no desconforto perineal. Contudo, tal informação está 
baseada em observações clínicas, ainda sem nenhum respaldo científico que comprove sua eficácia (Enkin et al., 2005).

Fisioterapias locais utilizando a descompressão do períneo e os exercícios para o assoalho pélvico também são medidas utilizadas para aliviar a dor perineal, mas também requerem que pesquisas científicas adicionais analisem sua real eficácia (Enkin et al., 2005).

Com o desenvolvimento tecnológico, surgiram novos recursos para o tratamento da dor proveniente de traumatismos nos tecidos moles, dentre eles, a ultrassonografia e a Estimulação Elétrica Nervosa Transcutânea (TENS) (Pitangui, 2007).

Para Enkin et al. (2005), as evidências científicas sobre a eficácia do tratamento terapêutico com ultrassom não são totalmente uniformes e não se compreende exatamente seu mecanismo de ação. Seus proponentes sugerem que o tratamento reduz a dor pela aceleração do processo inflamatório, minimizando o hematoma e o edema da inflamação.

Em revisão sistemática para avaliação dos efeitos terapêuticos do ultrassom no tratamento de dor perineal após o parto, Hay-Smith (1998) refere que as mulheres que foram tratadas com ultrassom tiveram maior probabilidade de relatar melhora na dor aguda e menor chance de referi-la 10 dias após o parto e 3 meses após este, quando comparadas às puérperas que receberam o tratamento placebo. No entanto, o autor afirma que as evidências científicas ainda são insuficientes para indicação desse tratamento.

Ensaio clínico randomizado e controlado desenvolvido em uma Maternidade filantrópica de Ribeirão Preto (SP) demonstrou que a terapêutica TENS foi eficaz no alívio da dor perineal das primíparas submetidas ao parto normal com episiotomia, ocasionando diminuição dos escores de dor nas atividades diárias de repouso e movimentação (Pitangui, 2007).

Considerada como um dos maiores avanços tecnológicos para a área da saúde, a irradiação com laser em baixa intensidade vem se mostrando bastante promissora no tratamento de diversas doenças musculoesqueléticas, indicada por sua ação analgésica, anti-inflamatória e pela aceleração no processo cicatricial. 


\subsection{O Laser}

\subsubsection{Histórico}

A exposição do corpo ao sol para restabelecimento da saúde, chamada de helioterapia, vem desde os primórdios da civilização. Gregos e romanos sabiam que a luz solar contribuía para a cura, mas não conheciam exatamente por quais mecanismos (Genovese, 2007).

A luz solar é essencial para o equilíbrio biológico humano, convertida em energia eletroquímica ela mantém nosso metabolismo, sistema endócrino e imunológico em perfeito funcionamento por meio da fotobioestimulação. Quando o homem é privado da luz solar graves doenças podem se desenvolver (Brugnera, Ladalardo, Cruz, 2007).

Nesse contexto, destacam-se os estudos sobre um tipo específico e característico de luz - o laser. A palavra laser é um acrônimo de Light Amplification by Stimulated Emission of Radiation, que significa amplificação da luz por emissão estimulada de radiação (Tunér, Hode, 1999; Genovese, 2007). É uma forma de energia que se transforma em energia luminosa, podendo ser visível ou não, dependendo da matéria que produz a radiação.

O laser é uma fonte de radiação eletromagnética com características específicas que o difere de outras fontes luminosas, como a lâmpada incandescente. A radiação é a transmissão de energia de um ponto a outro no espaço, independente do meio em que está propagando (Genovese, 2007).

O laser teve seu real início, em 1917, com a Teoria da Emissão Estimulada de Radiação de Albert Einstein, que forneceu bases teóricas para o desenvolvimento da tecnologia. Ele estudava a interação entre a luz e a matéria quando observou que, em certas condições, a incidência da luz na matéria poderia causar uma emissão adicional de luz, que seria conhecida como emissão estimulada (Cordon, 2000).

Em 1954, Townes e Webler, dos Estados Unidos da América, escreveram sobre a amplificação de micro-ondas, criando o MASER (Microwave Amplification by Stimulation Emission Radiation). Em 1958, Townes e Schawlow propuseram os princípios do MASER para uma região visível do espectro eletromagnético 
impulsionando a construção de diferentes tipos de laser (Goldman, 1990; Genovese, 2007).

Em 1960, Maiman colocou a teoria de Einstein em prática construindo o primeiro emissor de laser utilizando um cristal de rubi visível (Goldman, 1990; Cordon, 2000; Genovese, 2007). Em 1961, foi fundado o primeiro laboratório de laser na Universidade de Cincinnati, onde se iniciaram as primeiras experiências com animais (Goldman, 1990).

O começo da utilização do laser em medicina foi acidental, quando um técnico de laboratório teve sua retina queimada pela convergência do raio. Em virtude da reação frente ao acidente, o primeiro uso do laser foi a soldadura do deslocamento da retina, evitando a cegueira total, surgindo suas primeiras aplicações na área da oftalmologia (Goldman, 1990).

O Hospital Presbiteriano de Nova York, em 1961, praticou com êxito a primeira intervenção cirúrgica com laser, na retirada de um pequeno tumor de retina (Brugnera, Villa, Genovese, 1991; Genovese, 2007). Nos últimos 40 anos, o laser vem sendo amplamente empregado em diversas áreas da medicina, sobretudo o laser de alta potência (LAP), cujo efeito fototérmico promove a precisão do corte cirúrgico e a hemostasia do tecido subjacente, além de reduzir o desconforto e as complicações no pós-operatório (Tunér, Hode, 1999; Genovese, 2007).

Em 1967, o professor Ender Mester, em Budapeste, foi o primeiro a publicar um artigo científico reportando o efeito de bioestimulação do laser na pele de ratos, quando observou o rápido e inesperado crescimento de pelos nos locais em que a luz laser foi irradiada nos animais (Goldman, 1990; Enwemeka, 2001). Esta experiência impulsionou o desenvolvimento de pesquisas sobre os efeitos biológicos do laser em baixa intensidade (LBI) nos tecidos (Enwemeka, 2001).

Conforme relatam Lucas et al. (2002) e Rocha Júnior et al. (2006), os tratamentos experimentais em seres humanos iniciaram-se na década de 1970, após relatos de resultados positivos da irradiação com a terapia a laser de baixa potência em culturas de células e experimentos animais. Por ser amplamente estudado, o método foi aceito pela Food and Drug Administration (FDA) norte Americana como forma de tratamento clínico eficaz para cicatrização de feridas. 
Nos últimos 20 anos, na busca por novas modalidades terapêuticas menos invasivas e mais eficientes, a irradiação com LBI tem sido amplamente utilizada na prática clínica em função de seus efeitos biomodulatórios.

\subsubsection{Princípios fundamentais da física do laser}

A radiação emitida pelo sol, luz de lâmpadas, incêndios, transmissores de rádio, entre outros, é chamada de radiação eletromagnética e consiste em uma forma de energia composta por fótons (pacotes de energia), que viajam na forma de ondas na velocidade da luz, a 300.000 quilômetros por segundo (Tunér, Hode, 1999).

A produção da energia laser acontece pelo bombeamento de grande número de átomos do meio laser (rubi, argônio, dióxido de carbono, entre outros) em estado excitado, utilizando um fornecimento de energia extrínseca. Certos números de átomos caem de nível energético espontaneamente, emitindo fótons gerados por emissão estimulada (Brugnera, Villa, Genovese, 1991).

O laser diferencia-se totalmente da luz natural em função de suas características peculiares como coerência, monocromaticidade e unidirecionalidade (Tunér, Hode, 1999; Brugnera, Ladalardo, Cruz, 2007). Segundo Karu (2003), coerência refere-se à sincronia da radiação emitida pelo laser, ou seja, fótons propagando-se na mesma direção e vibrando na mesma faixa, sendo descrita como temporal e espacial.

A luz laser é composta por fótons de uma única cor e com o mesmo comprimento de onda, definindo a monocromaticidade do laser, uma luz pura. A colimação ou unidirecionalidade são os fótons emitidos pelo laser que se propagam em uma única direção, havendo uma divergência muito pequena (Tunér, Hode, 1999).

Para maior compreensão dos fundamentos físicos do laser há necessidade de destacar alguns aspectos teóricos importantes. Onda eletromagnética é um distúrbio transmitido através do vácuo ou de meio gasoso, líquido ou sólido, que pode transmitir energia de um ponto a outro. São exemplos: ondas do mar, ondas numa corda, ondas de rádio, entre outras (Genovese, Prokopowitsch, 2007). 
A frequência, a amplitude e o comprimento da onda são características importantes das ondas eletromagnéticas (Figura 4). Frequência é medida pelo número de cristas que passam por um único ponto em um segundo, é expressa em Hertz (Hz); amplitude é a altura do topo da crista até a concavidade da próxima onda, indicando a força da onda; e comprimento de onda $(\lambda)$ é a distância entre duas sucessivas cristas do espectro eletromagnético, medido em metros (m), milímetros (mm), micrômetros $(\mu \mathrm{m})$, angstrons e nanômetros $(\mathrm{nm})$ (Genovese, Prokopowitsch, 2007).

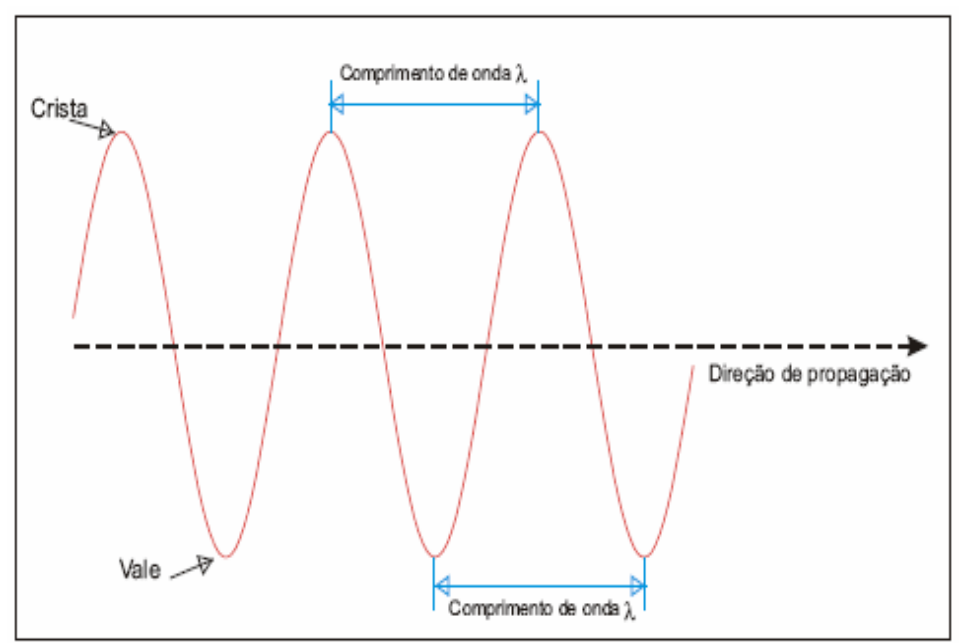

Figura 4: Ondas eletromagnéticas

O espectro eletromagnético é o conjunto de ondas eletromagnéticas, composto de radiações que são familiares, por exemplo, os raios-X, a luz visível, o micro-ondas e a televisão (Figura 5). Essas radiações possuem o mesmo tipo de energia, mas um comprimento de onda diferente, que as diferencia (Mintertag, 1990). 


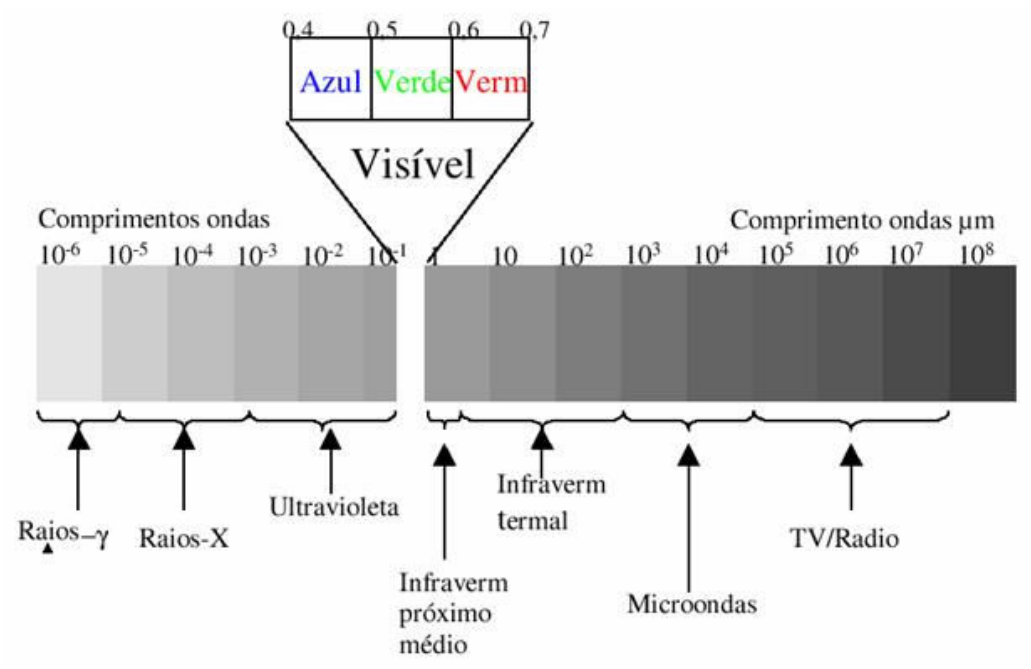

Figura 5: Espectro eletromagnético ${ }^{1}$

O espectro de luz pode se dividir em três partes: radiação infravermelha, invisível, cuja interação com tecidos gera calor; luz visível, que não gera calor ao interagir com tecido e; radiação ultravioleta, invisível, com altíssima energia podendo causar ionização (Mintertarg, 1990).

Uma série de elementos ativos (gases, líquidos, cristais e semicondutores) é utilizada na fabricação das fontes de laser, que fornecem uma variedade de emissões no espectro eletromagnético, cobrindo uma faixa espectral do ultravioleta ao infravermelho (Brugnera, Ladalardo, Cruz, 2007) e potências, variando desde miliwatts até megawatts (Brugnera, Villa, Genovese, 1991).

Na prática clínica, são empregados basicamente dois tipos de laser, os de alta potência, utilizados especialmente, em cirurgias ou remoção de tecidos, e os de baixa potência, cuja irradiação gera um fenômeno fotobiológico na célula-alvo, sem alteração da temperatura, que incorre em importante resposta celular e tecidual (Karu, 1988). Esse fenômeno é responsável pela ação analgésica e anti-inflamatória e pela promoção da reparação tecidual (Karu, 1988; Tunér, Hode, 1999), que serão descritas posteriormente.

\footnotetext{
${ }^{1}$ Disponível em: http://www6.ufrgs.br/engcart/PDASR/imagem2.JPG
} 


\subsubsection{Interação do feixe laser com os tecidos biológicos}

Quando um tecido biológico é atingido pela luz laser podem ocorrer diferentes fenômenos físicos: a reflexão, a difusão, a transmissão e a absorção (Figura 6). Denomina-se reflexão o fenômeno pelo qual a luz é refletida pela superfície do tecido, não provocando efeito sobre ele. Parte da luz pode ser espalhada dentro do tecido por uma vasta área, dependendo das dimensões das partículas que se relacionam com o comprimento de onda, fenômeno chamado de difusão ou espalhamento. Transmissão é o processo no qual a luz é transmitida ao longo de toda a espessura do tecido sem causar nenhum efeito (Tunér, Hode, 1999).

A absorção acontece quando parte da luz é absorvida pelo tecido em ressonância com o cromóforo absorvedor, como água, melanina, hemoglobina, entre outros. Esta se transforma em outras formas de energia (calórica, química) que provocarão um processo bioquímico ou bioelétrico nos tecidos absorvidos (Tunér, Hode, 1999).

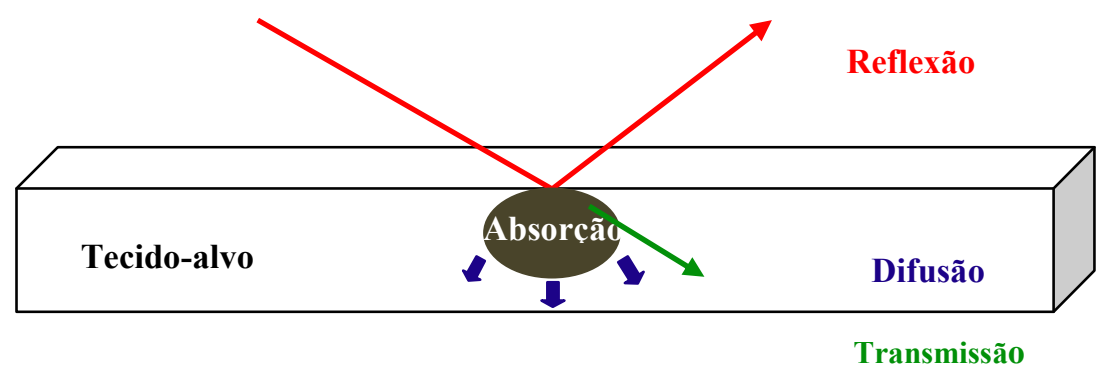

Figura 6: Interação do Laser com o tecido-alvo.

A reação da energia radiante com os tecidos orgânicos depende da natureza da luz ou do comprimento de onda do espectro eletromagnético, da densidade de energia aplicada e do tipo de tecido exposto à radiação. Os principais efeitos biológicos sobre o tecido envolvem efeitos fototérmicos, fotoquímicos e fotofísicos (Tunér, Hode, 1999; Brugnera, Ladalardo, Cruz, 2007).

Os efeitos térmicos são esperados quando a energia laser é absorvida na forma de calor, que são característicos dos lasers cirúrgicos de alta potência, responsáveis pela fotocoagulação, fotovaporização e fotoablação dos tecidos (Brugnera, Ladalardo, Cruz, 2007). 
Segundo Cordon (2000), os lasers de alta potência são usados em cirurgias cardiovasculares (angioplastia, revascularização transmiocardial), dermatologia (remoção de tatuagens, queloides e verrugas), gastroenteorologia (excisão de hemorroidas), ginecologia (excisão e destruição de lesões na vulva, útero e uretra, como miomectomia e ooforectomia), neurocirurgia, pediatria (tratamento de amígdalas e palato), cirurgia torácica, entre outras.

Os efeitos fotoquímicos e fotofísicos ou fotoelétricos acontecem em função da absorção dos fótons por biomoléculas intracelulares que produzem estimulação ou inibição de atividades enzimáticas e de reações químicas, que permitem a instalação de processos fisiológicos de natureza terapêutica, gerando as ações analgésicas, antiinflamatórias e de bioestimulação tecidual. Tais efeitos são denominados de fotoestimulação ou fotomodulação celular, promovidos pelos lasers em baixa intensidade, também chamado de laser de baixa potência (Karu, 1988; Brugnera, Ladalardo, Cruz, 2007).

O efeito térmico não é verificado no laser de baixa potência, mas pode ser observado um pequeno aumento da temperatura local, como consequência do aumento da atividade metabólica celular na área atingida pela irradiação, que não excede a um grau Celsius (Brugnera, Villa, Genovese, 1991; Genovese, Prokopowitsch, 2007).

Tunér e Hode (1999) apresentam diversas indicações médicas e odontológicas para aplicação do laser em baixa intensidade, em função de seus efeitos biomodulatórios, com base nos benefícios já documentados como: condições alérgicas, mucosite, regeneração óssea, síndrome do túnel do carpo, úlceras venosas, epicondilite, fibromialgia, herpes simples, modulação do sistema imunológico, úlceras aftosas, entre outras.

Assim, a resposta celular é o referencial biológico que diferencia a ação dos lasers operando em diferentes densidades de potência, enquanto o laser de alta potência acarreta agressão celular, o de baixa potência provoca uma resposta biomodulatória. 


\subsubsection{Laser em baixa intensidade}

Os lasers em baixa intensidade (LBI) ou low intensity laser também são conhecidos como soft laser, laser de bioestimulação, laser de biomodulação, low power laser (laser de baixa potência) e low level laser therapy. São denominados LBI os aparelhos que emitem radiações sem potencial destrutivo, cuja terapia está baseada nos efeitos fotoquímicos e fotobiológicos nos tecidos.

Os lasers de baixa potência são empregados com frequência na clínica, como de Diodo e de Hélio-Neônio (HeNe). O laser diodo pode ser composto por diferentes tipos de semicondutores, como Arsenieto de Gálio (AsGa), Arsenieto de Gálio e Alumínio (AsGaAl) e Fosfeto de Índio-Gálio-Alumínio (InGaAlP), que geram radiação com diferentes comprimentos de onda: luz invisível infravermelha $(\lambda=720$ $1500 \mathrm{~nm})$ e visível vermelha $(\lambda=620-690 \mathrm{~nm})$. Enquanto o laser HeNe emite radiação visível de coloração vermelha e com comprimento de onda de 632,8 nm (Genovese, Rodrigues, 2007).

Como regra geral, quanto maior o comprimento de onda do dispositivo de laserterapia maior será a penetração do feixe no tecido. Como a luz infravermelha tem comprimento de onda maior que $700 \mathrm{~nm}$ e a luz vermelha é tipicamente menor que $700 \mathrm{~nm}$, a luz infravermelha penetra mais profundamente no tecido-alvo que a vermelha. No entanto, isso não significa que a luz infravermelha não é absorvida superficialmente, mas indica que, apesar de sua absorção no tecido superficial, as ondas atingem níveis mais profundos dos tecidos. Por esta razão, comprimentos de onda mais longos geralmente são recomendados para o tratamento de lesões mais profundas e os comprimentos de onda mais curtos são considerados vantajosos no tratamento de tecidos-alvos superficiais (Enwemeka, 2009).

Para uma radiação ser considerada ionizante, é necessário que a intensidade de energia seja suficiente para causar queimaduras (muitos watts) e/ou conter fótons com alta energia (comprimentos curtos de onda). Todas as radiações eletromagnéticas com $\lambda$ menor que $320 \mathrm{~nm}$, como radiação UVB e UVC, raios-X e radiação gama são ionizantes e, por isso, podem causar câncer (Tunér, Hode, 1999).

Os LBI empregados na prática clínica sempre possuem um comprimento de onda acima de $630 \mathrm{~nm}$ e, por isso, não são considerados cancerígenos ou ionizantes. 


\subsubsection{Efeitos terapêuticos do laser em baixa intensidade}

Os reais mecanismos fotobiológicos para fundamentar os efeitos terapêuticos do LBI ainda são desconhecidos. A teoria mais aceita pelos cientistas foi descrita por Tiina Karu, em 1988, ao explicitar que a irradiação de luz visível vermelha no tecido provoca alteração na mitocôndria celular, que resulta no estímulo à proliferação e diferenciação celular ou no aumento da síntese de proteínas, conforme representado no esquema abaixo (Karu, 1988).

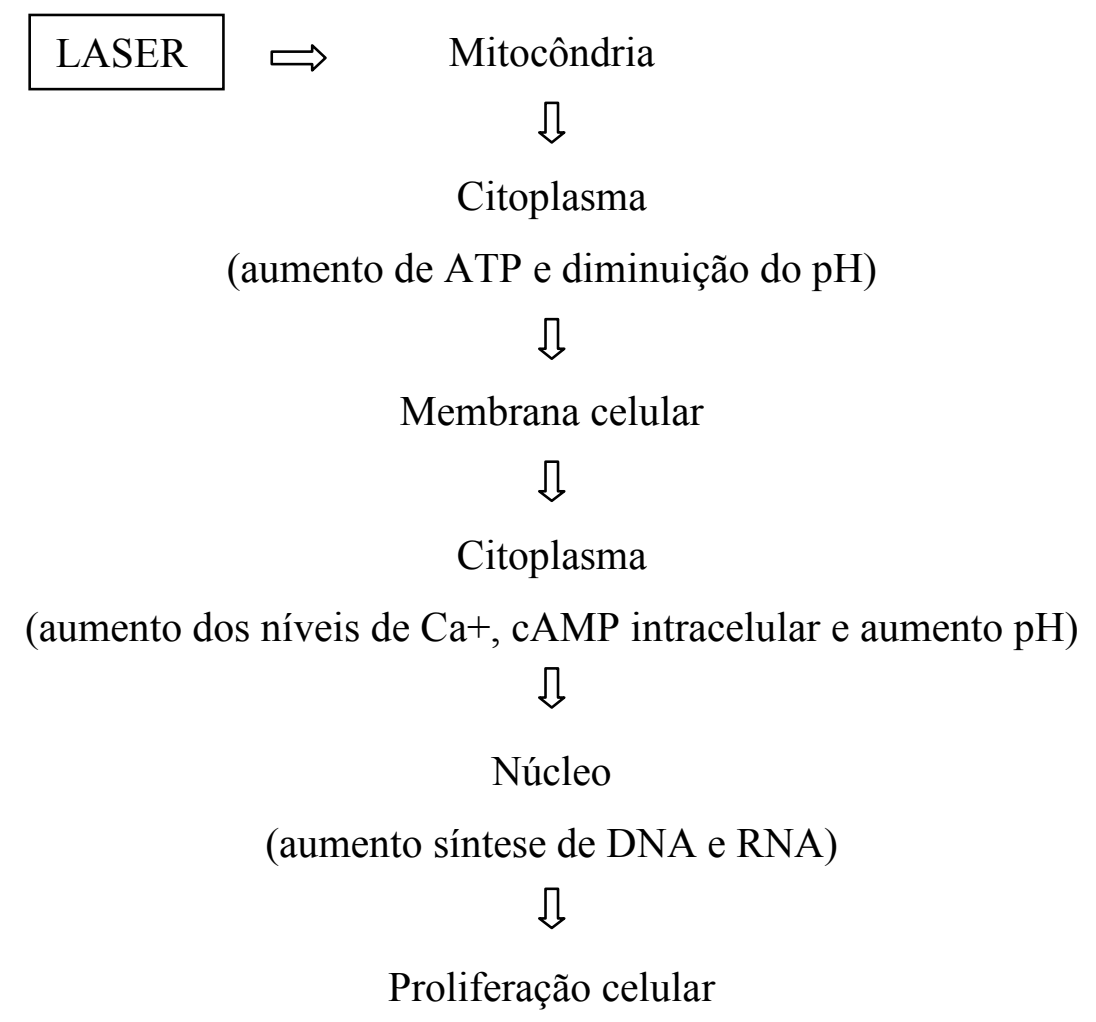

Karu (1989) acrescenta que os efeitos terapêuticos da LBI podem ser explicados pelo aumento da proliferação de células quiescentes (fases $G_{0}$ e $G_{1}$ do ciclo do crescimento celular) ou por modificações na atividade fisiológica das células excitadas.

Resumidamente, tais ações consistem em energia luminosa emitida pelo laser que é absorvida e depositada no tecido, transformando-se em energia vital, produzindo efeitos primários (diretos) e secundários (indiretos), cujo mecanismo de ação continua indefinido. 


\subsubsection{Efeitos primários e secundários do laser em baixa intensidade}

Os efeitos primários ou diretos do LBI são divididos em três categorias: bioquímicos, bioelétricos e bioenergéticos (Brugnera, Villa, Genovese, 1991; Genovese, Barreira Filho, 2007).

Os efeitos bioquímicos são caracterizados pelo controle da produção de substâncias químicas liberadas nos fenômenos da dor e de inflamação, como prostaglandinas, prostaciclinas, histamina, serotonina, entre outros; a modificação das reações enzimáticas normais, no sentido de excitação e de inibição, como a produção de ATP (adenosina tri-fosfato) e a síntese das prostaglandinas (Brugnera, Villa, Genovese, 1991; Genovese, Barreira Filho, 2007).

Os efeitos bioelétricos do LBI incluem a normalização do potencial da membrana, atuando como reequilibrante e normalizador da atividade funcional da célula, por meio da produção de ATP produzida pela célula (modo indireto) e agindo sobre a mobilidade iônica - bomba de sódio e potássio (modo direto) (Brugnera, Villa, Genovese, 1991; Genovese, Barreira Filho, 2007). Em condições patológicas, a célula não consegue manter seu equilíbrio, e com doses ideais de laser pode-se ajudar a normalizar suas funções.

O aporte energético da irradiação com laser tem a capacidade de normalizar o contingente energético que coexiste com o contingente físico de cada indivíduo, constituindo os efeitos bioenergéticos do LBI. Dessa forma, a terapêutica estimula, em todos os níveis, o trofismo celular, normalizando as deficiências e equilibrando as desigualdades (Brugnera, Villa, Genovese, 1991; Genovese, Barreira Filho, 2007).

Os efeitos primários do LBI desencadeiam dois grandes efeitos secundários ou indiretos no tecido-alvo: o estímulo à microcirculação e ao trofismo celular. A irradiação atua indiretamente no esfíncter pré-capilar, por meio de mediadores químicos, paralisando-o e produzindo sua constante abertura, estimulando a microcirculação e normalizando a irrigação vascular da área lesionada (Bjordal et al., 2006; Genovese, Barreira Filho, 2007).

Mohammed (2005) constatou em seu estudo que o laser diodo (GaAlAs), com comprimento de onda de $904 \mathrm{~nm}$, aplicado após o corte cirúrgico, aumentou a oxigenação do tecido lesionado, com expansão substancial da microcirculação, acelerando a restauração das funções normais do tecido. 
Revisão sistemática sobre os efeitos biológicos do LBI aponta uma forte evidência de que a irradiação melhora a angiogênese, por meio do aumento da secreção de fator de crescimento e da formação de circulação colateral na região lesionada no tecido animal, nos primeiros 7 dias após o trauma. O efeito foi evidenciado em lasers com comprimento de onda igual a 632, 820 e $904 \mathrm{~nm}$, sendo dose-dependente e com janelas terapêuticas que vão de 0,5 a $6 \mathrm{~J} / \mathrm{cm}^{2}$ (Bjordal et al., 2006).

O LBI também provoca um aumento na produção de ATP e na velocidade mitótica que proporciona, em escala tissular, um aumento da velocidade de reparação tecidual, decorrente do estímulo na capacidade de cicatrização do tecido conjuntivo; da neoformação de vasos com base nos pré-existentes; do equilíbrio na produção de fibroblastos, com normalização no depósito de fibras colágenas e elásticas no tecido de reparação e também do melhor trofismo dos tecidos (Genovese, Barreira Filho, 2007).

Os efeitos primários e secundários da irradiação com LBI permitem a instalação de processos fisiológicos de natureza terapêutica, responsáveis pelas ações analgésicas, anti-inflamatórias, antiedematosas e de bioestimulação tecidual, denominados de efeitos biomodulatórios (Cools, 1984; Tunér, Hode, 1999; Genovese, Barreira Filho, 2007; Brugnera, Ladalardo, Cruz, 2007).

\subsubsection{Efeitos Biomodulatórios}

Os reais mecanismos fotobiológicos para fundamentar os efeitos biomodulatórios do LBI ainda são desconhecidos, conforme citado anteriormente. Assim, diversas explicações para as ações analgésicas, anti-inflamatórias, antiedematosas e de reparação tecidual são apresentadas pela literatura.

\section{Efeito Analgésico}

Uma variedade de mecanismos biológicos é identificada na literatura como potencial contribuinte para o alívio da dor associada ao tratamento. Estes incluem o 
fator anti-inflamatório, a interferência na mensagem elétrica, evita a redução do limiar de excitabilidade dos receptores dolorosos, a promoção do equilíbrio da energia no local da lesão e a estimulação da liberação de betaendorfinas (Bjordal et al., 2006).

O mecanismo anti-inflamatório do LBI é explicado pelo estímulo à microcirculação, que desencadeia a redução do processo inflamatório local, provocando a absorção de exsudatos e favorecendo a eliminação de substâncias alógenas (Cools, 1984; Tunér, Hode, 1999; Genovese, 2007).

Segundo Mizutani et al. (2004), o LBI inibe a cascata do ácido araquidônico no tecido lesionado, reduzindo a produção de prostaglandina, com consequente interferência na produção de bradicinina e de outros mediadores do processo inflamatório. Também aumenta a circulação sanguínea local, promovendo a redução de substâncias causadoras da dor levando a inibição dos estímulos nociceptivos geradores da sensação dolorosa.

A interferência na mensagem elétrica está embasada na ideia de que o estímulo com LBI provoca a manutenção do potencial de membrana, evitando sua despolarização, prejudicando assim a transmissão do estímulo doloroso local (Cools, 1984; Tunér, Hode, 1999; Genovese, 2007).

De acordo com Bjordal et al. (2006), o LBI evita a redução do limiar de excitabilidade dos receptores dolorosos porque provoca a inibição da ação da enzima ciclo-oxigenase, interrompendo a conversão do ácido araquidônico em prostaglandina, reduzindo a síntese de prostaglandina e diminuindo a potencialização da bradicinina. Consequentemente, a irradiação provoca a manutenção do limiar de excitabilidade dos receptores dolorosos.

Estudo controlado randomizado, duplo-cego, realizado com indivíduos saudáveis para analisar a influência da irradiação com LBI na condução elétrica do nervo periférico observou redução significativa na velocidade de condução do estímulo doloroso e aumento no limiar da dor nas pessoas tratadas com laser GaAlAs, com a dose de um Joule por ponto de estimulação e com comprimento de onda de $830 \mathrm{~nm}$ (Cambier et al., 2000).

De acordo com a literatura, o LBI pode provocar a normalização $e \quad o$ equilíbrio da energia no local da lesão, porque promove a sensibilização dos receptores dolorosos com a liberação de histamina e bradicinina, que é corrigida pelo 
aumento da permeabilidade de vênulas e da dilatação das arteríolas provocadas pelo laser (Cools, 1984; Genovese, 2007).

Pesquisas científicas recentes sugerem que o efeito analgésico do LBI também pode ser explicado, porque a irradiação promove um estímulo à liberação de betaendorfinas, direta ou indiretamente.

Ensaio clínico controlado, realizado no Japão, demonstrou que o nível de betaendorfina eleva-se após a aplicação da irradiação, utilizando o laser diodo com GaAlAs como semicondutor, sem aumentar o acúmulo de células inflamatórias, sugerindo que os opioides periféricos estão envolvidos ativamente no mecanismo de analgesia do LBI (Hagiwara et al., 2007). Mizutani et al. (2004) também observaram redução significativa nos escores da dor $(\mathrm{p}<0,001)$ e no nível sérico de prostaglandina $(\mathrm{p}<0,05)$ em mulheres tratadas com laser de diodo (GaAlAs), com $\lambda$ de $830 \mathrm{~nm}$ e um Watt de potência. Por outro lado, uma revisão sistemática encontrou limitada evidência no mecanismo de analgesia pela liberação de opioides endógenos (Bjordal et al., 2006).

\section{Efeito Anti-inflamatório}

O LBI atua interferindo na síntese de prostaglandina, um dos principais mediadores químicos do processo inflamatório, minimizando as alterações da inflamação, como também estimulando a microcirculação no local da lesão, garantindo o aporte nutricional e defensivo eficiente para a região, favorecendo assim sua resolução (Genovese, Barreira Filho, 2007).

Revisão sistemática aponta que existe uma forte evidência de que os comprimentos de onda, vermelho e infravermelho, do LBI podem agir localmente na área lesionada, modulando o processo inflamatório. Esses efeitos incluem as alterações nos marcadores bioquímicos, redução do edema, da hemorragia e de necrose, minimizando a dor aguda, a curto prazo (Bjordal et al., 2006).

Lim et al. (2007) realizaram um ensaio clínico, comparando os efeitos do laser diodo, emitido no comprimento de onda de $635 \mathrm{~nm}$, com medicamentos antiinflamatórios não esteroides (indometacina e ibuprofeno). Os autores constataram 
que o LBI e os medicamentos inibem a ciclo-oxigenase e a liberação de prostaglandinas, agindo por mecanismos diferentes.

Segundo Bjordal et al. (2006), quatro estudos realizados em animais, comparando os efeitos do LBI com drogas anti-inflamatórias não esteroides (indometacina, meloxicam, celecoxib e diclofenaco), não constataram diferenças estatisticamente significativas entre os efeitos anti-inflamatórios do LBI e das medicações, quando administradas em doses equivalentes às utilizadas na prática clínica.

\section{Efeito Antiedematoso}

Dois fenômenos importantes acontecem após a aplicação do LBI para garantir o efeito antiedematoso: o estímulo à microcirculação - que oferece melhores condições de drenagem do plasma que forma o edema, e a ação fibrinolítica - que proporciona a resolução efetiva do isolamento causado pela coagulação do plasma no local da lesão (Genovese, Barreira Filho, 2007).

Ferreira et al. (2005) utilizando o laser $\mathrm{HeNe}(632,8 \mathrm{~nm})$ em 70 ratos de laboratório demonstraram que o LBI induziu a analgesia quando aplicado 4 horas após o início da inflamação, aumentou em 68\% o limiar da dor dos animais irradiados e também produziu efeito antiedematoso pela redução da liberação de prostaglandina E.

\section{Efeito na Aceleração do Processo Cicatricial}

A irradiação laser provoca diversas reações teciduais, dentre elas, a formação de ATP, proporcionando um aumento na atividade mitótica e na síntese de proteína, que geram uma elevação da regeneração tecidual, conforme referido anteriormente (Karu, 1988).

Estudos experimentais realizados in vitro e in vivo sugerem que os lasers em baixa intensidade aceleram o processo cicatricial por promover a proliferação celular, acelerar a formação de tecidos de granulação, facilitar a síntese de colágeno, 
aumentar a síntese de ATP na mitocôndria e ativar os linfócitos (Enwemeka et al., 2004).

Para Genovese e Barreira Filho (2007), a regeneração dos vasos sanguíneos apoiados nos já existentes, estimulada pelo LBI melhora a microcirculação local, eleva o aporte nutricional e a velocidade mitótica e facilita a multiplicação celular. Brugnera, Villa e Genovese (1991) mencionam ainda que o estímulo na produção de fibroblastos, com fabricação de fibras colágenas e elásticas de modo mais ordenado, são fatores que determinam melhor efeito cicatricial da terapia.

Estudo experimental que empregou o laser AsGa com comprimento de onda de $904 \mathrm{~nm}$ e dose $4 \mathrm{~J} / \mathrm{cm}^{2}$, irradiando a lesão no tendão calcâneo de ratos, constatou diferença estatística significativa $(\mathrm{p}<0,05)$ na deposição de colágeno na área lesionada no grupo laser, quando comparado ao grupo que não recebeu a terapêutica (Tavares, 2002).

Estudo controlado randomizado triplo cego utilizando placebo, desenvolvido em 22 modelos experimentais humanos saudáveis que sofreram queimaduras superficiais na região anterior do antebraço, constatou que o grupo tratado com laser tinha feridas menores que o grupo não tratado $(\mathrm{p}<0,05)$, indicando a efetividade da terapêutica em humanos (Hopkins et al., 2004).

Rocha Júnior et al. (2006) ao irradiarem a área central da ferida cirúrgica de ratos com laser após o ato cirúrgico, sob o método de varredura, 48 horas após a lesão e 7 dias após esta, observaram aceleração do processo cicatricial no grupo irradiado. No décimo dia, o grupo controle, que não foi submetido à terapia, exibia padrão de reparação tecidual em fase inicial, enquanto o grupo submetido à terapia apresentava completa reparação tecidual.

Pela análise histológica, ao final do experimento, esses últimos autores encontraram uma redução significativa dos diâmetros das áreas ulceradas no grupo dos animais tratados $(p<0,05)$, comparando com aqueles sem tratamento. Foi constatado que os animais submetidos à laserterapia apresentaram maior velocidade de reparação tecidual, traduzida pelo aumento da proliferação celular e da vascularização, e uma redução expressiva no número de células inflamatórias na lesão, indicando que o LBI foi eficaz na cicatrização.

Em contraponto, uma revisão sistemática dos ensaios clínicos experimentais in vitro e in vivo empregando o LBI na reparação tecidual demonstrou uma pobre 
qualidade metodológica de muitas publicações científicas. O estudo não apontou vantagem da terapêutica, indicando que esta não deve ser considerada como tratamento adjuvante para aceleração da cicatrização em humanos (Lucas et al., 2002).

Hopkins et al. (2004) consideram que os resultados conflitantes sobre os efeitos do LBI na reparação tecidual provavelmente ocorram em função dos diferentes desenhos de pesquisa realizados, incluindo comparações de lesões clínicas com características heterogêneas, falta de grupo controle e o não cegamento dos investigadores. Acrescentam ainda que diferentes comprimentos de onda e diversos métodos de aplicação do laser têm produzido uma variedade de conclusões relacionadas à eficácia do método, tornando difícil a formulação de uma teoria sobre seu mecanismo de ação.

No entanto, um estudo de metanálise analisando todas as literaturas científicas publicadas em língua inglesa nos últimos 30 anos que envolviam o LBI para a reparação tecidual, incluindo estudos in vivo e in vitro, e aqueles realizados em humanos para controle da dor revelou que a terapia é altamente efetiva na promoção do reparo tecidual e no alívio da dor (Enwemeka et al., 2004).

Para análise estatística dos resultados, foi utilizado o tratamento effect size determinado pelo cálculo Cohens's d, que indica a força da relação entre duas variáveis, para indicar correlação estatisticamente significativa entre o tratamento e os efeitos obtidos no experimento, determinando os valores de 0,$2 ; 0,4$ e 0,8 ou mais, para pequena, média e grande correlação, respectivamente (Enwemeka et al., 2004).

No reparo tecidual, a média do effect size (d) foi $+1,81$ (desvio padrão 2,26 e intervalo de confiança de $95 \%$ de 1,16-2,46), indicando que o laser é altamente benéfico na promoção do reparo tecidual. Em contexto geral, os autores explicam que seria necessário que 370 estudos indicassem os efeitos negativos do laser para neutralizar os efeitos positivos encontrados nos trabalhos analisados. Com relação à redução da dor, o valor effect size também foi positivo, $\mathrm{d}=+1,11$ (desvio-padrão de 1,02 e intervalo de confiança de $95 \%$ de 0,44-1,78), indicando que o laser também é benéfico no controle da dor. Para neutralizar tal afirmativa, seria necessário que 41 estudos com efeitos negativos da terapia fossem desenvolvidos (Enwemeka et al., 2004). 
Tais achados clínicos apontam que a irradiação com laser em baixa intensidade pode ser uma terapêutica simples, não invasiva, indolor e efetiva para o alívio da dor aguda, para a redução de processos inflamatórios e de edema, como também para a aceleração da reparação tecidual em feridas.

\subsubsection{Dosimetria}

O sucesso da terapia com laser em baixa intensidade depende da dosimetria, que implica a determinação do tecido-alvo, da posologia e dos parâmetros do laser (Enwemeka, 2001).

Para o cálculo da dosimetria, é preciso que o profissional conheça os seguintes termos (Tunér, Hode, 1999; Enwemeka, 2001; Genovese, 2007):

- Potência: número de fótons emitido pela fonte, medido em watts (W).

- Irradiancia ou Densidade de Potência: quantidade de potência por unidade de área que a fonte está emitindo $\left(\mathrm{W} / \mathrm{cm}^{2}\right)$.

- Densidade de energia ou dose: energia entregue ao tecido por unidade de área $\left(\mathrm{J} / \mathrm{cm}^{2}\right)$.

- Energia: energia entregue ao tecido em cada ponto irradiado (J).

- Energia total: energia por ponto multiplicado pelo número de pontos irradiados (J).

- Tempo: tempo de exposição do tecido, medido em segundos (s).

- Área: medida em centímetros quadrados $\left(\mathrm{cm}^{2}\right)$.

- Comprimento de onda: distância entre dois picos da onda eletromagnética do fóton (nanômetro ou micrometro).

- Tipos de aplicação: forma como a irradiação é aplicada.

- Pontual (ponto a ponto, com distância de um centímetro entre um ponto e outro).

- Varredura (aplicação em área maior que um ponto). 
Para o cálculo da dosimetria utilizam-se as seguintes fórmulas:

- $\quad$ Potência $(\mathrm{W})=$ Energia $(\mathrm{J}) /$ tempo $(\mathrm{s})$.

- $\quad$ Energia $(J)=$ Potência $(\mathrm{W}) \times$ tempo $(\mathrm{s})$.

- Densidade de energia $\left(\mathrm{J} / \mathrm{cm}^{2}\right)=$ Potência $(W) \times$ tempo $(\mathrm{s}) /$ Área $\left(\mathrm{cm}^{2}\right)$ ou,

- Tempo $(\mathrm{s})=$ Densidade de energia $\left(\mathrm{J} / \mathrm{cm}^{2}\right) \mathrm{x}$ área $\left(\mathrm{cm}^{2}\right) /$ Potência $(\mathrm{W})$.

Cools (1984) descreveu um esquema para orientação dos profissionais de saúde para utilização da dosimetria na clínica, indicando a densidade de energia necessária para o efeito desejado, conforme segue.

- Efeito antiálgico - 2 a $4 \mathrm{~J} / \mathrm{cm}^{2}$.

- Efeito anti-inflamatório - 1 a $3 \mathrm{~J} / \mathrm{cm}^{2}$.

- Efeito regenerativo -3 a $6 \mathrm{~J} / \mathrm{cm}^{2}$.

- Efeito circulatório - 1 a $3 \mathrm{~J} / \mathrm{cm}^{2}$.

O número de sessões da terapia com LBI é variável, podendo ser efetivada diariamente, a cada 48 horas ou semanalmente, dependendo da doença e da disponibilidade do paciente. Como exemplo, Genovese (2007) estabeleceu um protocolo para aplicação do LBI nas úlceras traumáticas dos tecidos moles da cavidade oral, para eliminar a dor e para maior velocidade de reparação, com uma dosimetria energética recomendada de 3 a $4 \mathrm{~J} / \mathrm{cm}^{2}$, aplicada de modo pontual sobre a úlcera de até $5 \mathrm{~mm}$ de diâmetro, e em varredura quando acima desse valor, com duas aplicações em um intervalo de 24 horas.

\subsubsection{Normas de segurança e contraindicações do LBI}

Os lasers são classificados conforme seu grau de periculosidade, sobretudo em relação aos danos que podem causar aos olhos humanos, em cinco classes diferentes (Tunér, Hode, 1999; Genovese, 2007):

Classe 1: menor potência, sem perigo para os olhos humanos, como o tocadiscos laser (CD-ROM player). 
Classe 2: baixa potência, com perigo de lesão se alguém olhar direta e intencionalmente para o feixe, como os leitores de código de barras.

Classe 3A: média potência, que constituem perigo ocular se a luz laser for coletada e focalizada pelo olho, através de lentes ópticas, como os lasers point, usados em conferências.

Classe 3B: média potência, que somente constituem perigo ocular quando o feixe é visto diretamente (potência máxima de $0,5 \mathrm{~mW}$ para $\lambda 315$ $\mathrm{nm})$, como o LBI.

Classe 4: risco potencial de dano à pele e aos olhos, como lasers de alta potência ou lasers cirúrgicos (maior que $0,5 \mathrm{~W}$ de potência), com possibilidades de lesionar a pele e originar fogo.

Para não haver danos oculares, é essencial que o operador, os assistentes e o paciente façam uso dos óculos de proteção individual que devem ter coloração e densidade óptica específicas, determinadas pelo fabricante do laser (Genovese, 2007).

Medidas de proteção geral (não individuais) e relativas à instalação e ao local para aplicação também podem ser utilizadas, sobretudo quando o laser de alta intensidade for empregado. A remoção da chave de contato quando o equipamento não estiver em funcionamento, a utilização do conector de travamento a distância e o isolamento do recinto no momento do procedimento, mantendo o número essencial de pessoas são medidas de segurança que devem ser consideradas (Bologna, Santos, Brugnera, 2007).

Durante a irradiação, o profissional também deve evitar a reflexão especular no local de utilização do laser, provocada pelos objetos metálicos, e verificar se o aparelho está ligado corretamente, respeitando a voltagem específica do equipamento. Deve haver espaço suficiente para o operador posicionar-se confortavelmente e facilidade no acesso ao painel de controle do equipamento. Também é recomendada a instalação de sinais visuais de advertência de emissão de raio na parte externa da porta do ambiente onde a irradiação será realizada (Figura 7) (Bologna, Santos, Brugnera, 2007). 


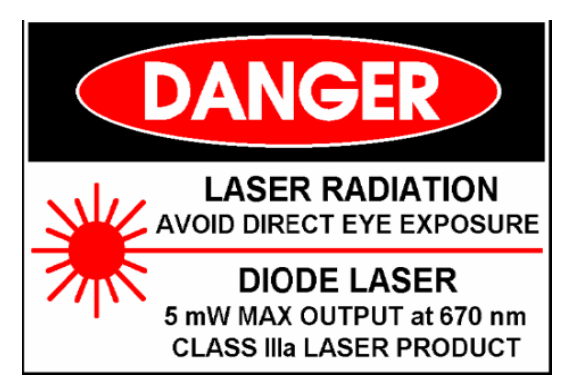

Figura 7: Etiqueta de aviso do uso do laser

Para evitar a contaminação do paciente, deve-se proteger a ponteira do laser em baixa intensidade com uma única camada de filme de policloreto de venila (PVC) como barreira mecânica contra fluidos ou sangue do cliente. De acordo com Cordon (2000), não existe perda de energia da irradiação quando aplicado o PVC. A desinfecção com álcool a 70\% também pode ser realizada na ponteira ativa do laser entre uma aplicação e outra, não havendo necessidade de esterilização do material (Genovese, 2007).

Antes de iniciar a terapia, o profissional deve avaliar minuciosamente o paciente para detectar qualquer tipo de contraindicação. Segundo Tunér e Hode (1999) são consideradas contraindicações absolutas os casos de fotossensibilidade ou uso de medicamentos fotossensíveis (ácido retinoico, tetraciclina, gliseofulvina, sulfamina e furocumarina), aplicações em focos neoplásicos, áreas hemorrágicas e olhos.

$\mathrm{Na}$ literatura pesquisada, não foram descritos efeitos colaterais da irradiação com laser em baixa intensidade no tecido. 


\subsection{Justificativa do estudo}

Ainda não existem evidências científicas suficientes que indiquem a melhor maneira de prevenir os traumas perineais (Albers et al., 2005). As pesquisas sobre a efetividade dos tratamentos empregados na prática clínica para aliviar a dor perineal apontam a necessidade do desenvolvimento de estudos adicionais (Enkin et al., 2005; Pitangui, 2007; East et al., 2007). A busca por métodos, sobretudo não medicamentosos que promovam o alívio da dor perineal e não interfiram na lactação é primordial, e tornou-se um desafio para os profissionais que prestam assistência à mulher durante o parto e o período puerperal.

A irradiação com laser em baixa intensidade, uma terapia indolor e não invasiva, vêm demonstrando resultados positivos no que tange à redução da dor, do edema e da inflamação local e na aceleração da cicatrização tecidual, conforme apresentado anteriormente.

No atual estudo, a proposta de utilizar o LBI para alívio da dor perineal após a episiotomia, surgiu em razão dos efeitos positivos constatados em pesquisas científicas (Bjordal et al., 2006; Hagiwara et al., 2007; Chow et al., 2009), como também pela ação analgésica evidenciada em ensaio clínico desenvolvido na área de odontologia (Zand et al., 2009). Como a mucosa oral é semelhante à vaginal, ambas compostas por epitélio do tipo pavimentoso estratificado (Junqueira, Carneiro, 2008), acredita-se que essa tecnologia poderia ser útil no tratamento da dor perineal após a episiotomia.

Considerando que o enfermeiro é o profissional que permanece grande parte do tempo ao lado da mulher, é imprescindível que ele busque outras possibilidades de tratamento para o alívio da dor perineal, condição frequente no puerpério, que poderia contribuir para a satisfação da mulher com a maternidade e para a melhora da qualidade da assistência de enfermagem. 
2 HIPÓTESE 
A irradiação com laser em baixa intensidade diminui a intensidade da dor perineal referida pelas puérperas com episiotomia no período de internação hospitalar. 
3 OBJETIVOS 


\subsection{Geral}

- Avaliar a efetividade da aplicação do laser em baixa intensidade para alívio da dor na região perineal após a episiotomia.

\subsection{Específicos}

- Mensurar a dor perineal referida pelas puérperas antes, imediatamente após e 30 minutos depois da irradiação com laser em baixa intensidade.

- Verificar a proporção de redução da dor perineal, após a aplicação do laser em baixa intensidade.

- Verificar a interferência da dor perineal nas atividades diárias das puérperas.

- Identificar a opinião das puérperas em relação à laserterapia. 
4 MÉTODO 
O estudo foi desenvolvido em duas etapas. Inicialmente, apresentam-se os dados relacionados à primeira etapa - o estudo piloto. Posteriormente, descrevem-se as informações referentes à segunda etapa desta pesquisa.

\subsection{Primeira Etapa - Estudo Piloto}

\subsubsection{Objetivos}

- Identificar a magnitude da dor perineal referida pelas puérperas submetidas à laserterapia em baixa intensidade.

- Avaliar o processo de cicatrização da episiotomia ocorrida no parto normal com a aplicação do laser em baixa intensidade.

\subsubsection{Hipóteses}

- A irradiação com LBI após a episiotomia diminui a intensidade da dor perineal referida pelas mulheres após o parto normal.

- A irradiação com laser em baixa intensidade acelera o processo de cicatrização da episiotomia.

\subsubsection{Tipo de estudo}

Trata-se de um ensaio clínico controlado, randomizado, paralelo, com mascaramento duplo sobre os efeitos do LBI na cicatrização e na redução da dor perineal em puérperas de pós-parto normal submetidas à episiotomia médio-lateral 
direita. O cegamento ocorreu na avaliação dos desfechos, realizado por uma pesquisadora assistente, e para as participantes do estudo piloto.

\subsubsection{Local do Estudo}

O estudo foi desenvolvido nas Unidades de Centro de Parto Normal (CPN) e Alojamento Conjunto (AC) do Amparo Maternal (AM), instituição localizada na zona sul da cidade de São Paulo - SP. Fundada em 1939, a maternidade é uma entidade filantrópica vinculada ao Sistema Único de Saúde (SUS) que presta assistência obstétrica e neonatal e é referência para gestações de baixo risco. Desde o ano de 2008, a instituição conta com o apoio da Associação Congregação de Santa Catarina, que vem desenvolvendo novos projetos sociais e de formação profissional na maternidade.

A maternidade possui um Centro de Parto Normal (CPN) com 16 leitos de pré-parto, seis salas de parto, seis leitos de pós-parto imediato, 80 leitos de pós-parto e oito de terapia intensiva neonatal. A assistência ao trabalho de parto, ao parto normal e ao puerpério imediato é prestada por enfermeiras obstétricas e obstetrizes, com o mínimo de intervenção. Os médicos obstetras são responsáveis pela admissão da parturiente e pela assistência em caso de intercorrências obstétricas.

Segundo dados estatísticos da instituição, no mês de agosto de 2008, foram realizados 762 partos, dos quais 80,2\% (611) foram espontâneos, 19,4\% (148) cesarianas e, $0,4 \%$ (3) fórcipes. Com relação à condição perineal, 42,9\% das mulheres tiveram períneo íntegro, 13,3\% sofreu a episiotomia, 34,9\% laceração de primeiro grau, $8,6 \%$ de segundo grau e $0,3 \%$ laceração de terceiro grau*

Após a admissão hospitalar, a parturiente é encaminhada ao pré-parto, com o acompanhante de sua escolha, sendo estimulada a deambular e a tomar banho de chuveiro ou de banheira e recebe o apoio emocional do acompanhante ou de uma doula.

Os procedimentos de rotina como tricotomia da região vulvar, lavagem intestinal, jejum durante o trabalho de parto e infusão de ocitocina foram

\footnotetext{
* Dados extraídos do livro de controle de registro de parto normal do Amparo Maternal.
} 
abandonados desde a reestruturação do CPN, ocorrida em maio de 1998. No final do período de dilatação, a parturiente é transferida para uma sala de parto privativa, onde ocorre a expulsão fetal.

A episiotomia é praticada seletivamente nos partos normais, conforme a indicação da enfermeira obstétrica que assiste ao parto. A incisão é precedida pela anestesia local com infiltração de lidocaína na região perineal, sem vasoconstritor, para suprimir a dor do corte e da sutura. O bloqueio do nervo pudendo não é utilizado pelas profissionais da instituição na anestesia local. A episiorrafia é realizada rotineiramente de modo contínuo com o fio categute zero simples atraumático.

Após a dequitação, as puérperas são encaminhadas à sala de pós-parto imediato onde permanecem em observação durante a primeira hora de puerpério. Em seguida, as mulheres são encaminhadas ao AC onde ficam internadas por um período mínimo de 48 horas. Depois de avaliado pelo neonatologista, o recém-nascido também é encaminhado para o AC, permanecendo com mãe, até a alta hospitalar.

Em geral, o estímulo à amamentação inicia-se imediatamente após o parto, sendo mantido durante todo o período de permanência do binômio na maternidade. $\mathrm{O}$ leite artificial é introduzido na presença de doenças maternas que contraindiquem a amamentação, como hepatite $\mathrm{C}$ e síndrome da imunodeficiência adquirida.

Durante o período de internação no $\mathrm{AC}$, as puérperas são medicadas de acordo com prescrição médica de rotina, que consta de um analgésico oral, dipirona sódica 500 miligramas, a cada 6 horas. Um anti-inflamatório não esteroidal (diclofenaco de sódio - 50 miligramas) é administrado a cada 8 horas, quando a queixa dolorosa persiste. Na maternidade, não é habitual a utilização de tratamento não medicamentoso para aliviar a dor na região perineal e não há agendamento de retorno da mãe e do recém-nascido após a alta hospitalar.

\subsubsection{População e amostra}

O cálculo da amostra foi realizado com base nos dados obtidos em um estudo conduzido previamente pela pesquisadora principal, que comparou as diferenças 
entre as médias de dor perineal de um grupo com dez mulheres submetidas ao tratamento com LBI e um grupo controle com 15 mulheres sem o tratamento com LBI. No grupo da intervenção, houve uma redução de 2,0 pontos na média de dor perineal imediatamente após a irradiação com laser (de 3,4 $\pm 2,7$ para 1,4 $\pm 1,6$ ), enquanto no grupo controle a média de dor foi de $2,8 \pm 1,7$.

Estabelecendo um nível de significância de 5\% e um poder de teste de $90 \%$, o tamanho da amostra do estudo piloto foi de 24 mulheres em cada grupo. A amostra final foi composta por 52 puérperas divididas aleatoriamente em dois grupos: experimental $(\mathrm{n}=26)$, submetidas à irradiação com laser em baixa intensidade e controle $(\mathrm{n}=26)$, sem a irradiação com LBI.

\subsubsection{Critérios de inclusão}

Foram incluídas no estudo piloto as puérperas com episiotomia médio-lateral direita; idade igual ou maior que 18 anos; sem parto vaginal anterior; gravidez a termo com feto único, vivo e em apresentação cefálica; sem processo infeccioso, hemorróidas, hematoma ou varizes na região da vulva; sem laceração perineal associada à episiotomia; que não realizaram preparo da região perineal na gravidez; que não utilizaram drogas fotossensibilizantes endógenas (tetraciclina, griseofulvina, sulfamida e furocumarina) ou exógenas (ácido retinoico e glicólico), sem intercorrências clínicas ou obstétricas, não ter dificuldades de comunicação ou compreensão e ter tido recém-nascido em boas condições clínicas.

\subsubsection{Critérios de exclusão}

Foram excluidas as puérperas que utilizaram qualquer produto na região vulvoperineal, diferente de água e sabão durante o período de internação hospitalar. 


\subsubsection{Randomização}

A aleatorização foi feita por meio de uma tabela gerada por um programa de randomização. Foi elaborada uma lista com 52 números, sendo 26 em cada um dos grupos (Apêndice 1). Cada número da listagem com a sequência dos grupos experimental e controle foi colocada individualmente em um envelope opaco, numerado e fechado. Estas etapas foram realizadas por indivíduo alheio ao estudo. $\mathrm{O}$ envelope foi aberto pela pesquisadora principal, para identificar ao qual grupo a mulher pertenceria, no momento que antecedeu a primeira irradiação.

As mulheres excluídas do estudo foram substituídas automaticamente por outras, seguindo a mesma tabela.

\subsubsection{Intervenção}

O grupo experimental foi submetido a três sessões da irradiação com laser em baixa intensidade diretamente sobre a episiotomia. A primeira irradiação ocorreu até duas horas depois do parto, a segunda entre 20 e 24 horas e a terceira com 40 a 48 horas. A irradiação foi realizada de modo pontual, tocando-se a ponta ativa do laser na região da episiotomia. Foram irradiadas a porção central e as extremidades, superior e inferior, da episiotomia perfazendo três pontos de irradiação em cada sessão, independente da sua extensão.

As participantes do grupo controle também foram submetidas a três sessões de tratamento, como no experimental, porém sem a emissão da irradiação. Isto possibilitou a avaliação dos possíveis efeitos placebo da terapia (grupo sham). Para garantir que não houvesse a emissão do feixe de luz, a caneta do infravermelho teve sua ponteira bloqueada, utilizando-se um pedaço de algodão e com a ponta ativa externa do laser recoberta com papel alumínio.

No grupo controle o tempo de duração da simulação da irradiação e o número de pontos irradiados foram os mesmos empregados no grupo experimental. 
Essa terapêutica foi fundamentada no protocolo de aplicação para tratamento de úlceras na mucosa bucal, que tem como objetivos eliminar a dor e acelerar a reparação tecidual (Genovese, 2007).

\subsubsection{Variáveis e desfechos}

A variável independente foi a irradiação com LBI na região perineal, após episiotomia médio-lateral direita.

As variáveis dependentes avaliadas foram a intensidade da dor perineal (analisada como média) e o processo de cicatrização.

Os desfechos primários analisados na primeira etapa foram intensidade da dor perineal e o processo de cicatrização. Os desfechos secundários foram idade materna, paridade, cor da pele, estado marital, tabagismo, comprimento da episiotomia, idade gestacional, peso do RN e o perímetro cefálico.

A intensidade da dor perineal foi avaliada antes e imediatamente após cada sessão de irradiação por meio da aplicação da Escala Numérica (Anexo 1), de 0 a 10, sendo o valor zero equivalente à ausência de dor e dez à dor insuportável. Uma representação desta escala foi mostrada a cada puérpera e solicitou-se que ela apontasse com o dedo o valor que melhor representasse a intensidade da sua dor.

O processo de cicatrização foi avaliado por meio da escala REEDA (Redness, Edema, Echymosis, Discharge Aproximation), antes de cada uma das três sessões de irradiação e também entre 15 e 20 dias após a alta hospitalar, considerando-se as condições perineais e o tipo de cicatrização.

A escala REEDA compreende a avaliação de cinco itens da cicatrização: hiperemia, edema, equimose, secreção e coaptação das bordas da lesão (Quadro 1). 
Quadro 1 - Escala de avaliação de hiperemia, edema, equimose, secreção e coaptação das bordas da lesão (REEDA).

\begin{tabular}{|c|c|c|c|c|c|}
\hline Pontos & Hiperemia & Edema & Equimose & Secreção & Coaptação \\
\hline 0 & Nenhuma & Nenhum & Nenhuma & Nenhuma & Fechada \\
\hline 1 & $\begin{array}{l}\text { Até } 0,25 \mathrm{~cm} \text { da } \\
\text { incisão } \\
\text { bilateralmente }\end{array}$ & $\begin{array}{l}\text { Perineal a } \\
\text { menos de } 1 \mathrm{~cm} \\
\text { a partir da } \\
\text { incisão }\end{array}$ & $\begin{array}{l}\text { Até } 0,25 \mathrm{~cm} \mathrm{da} \\
\text { incisão } \\
\text { bilateralmente } \\
\text { ou a } 0,5 \mathrm{~cm} \\
\text { unilateralmente }\end{array}$ & Serosa & $\begin{array}{l}\text { Pele separada } \\
3 \mathrm{~mm} \text { ou } \\
\text { menos }\end{array}$ \\
\hline 2 & $\begin{array}{l}\text { Até } 0,5 \mathrm{~cm} \mathrm{da} \\
\text { incisão } \\
\text { bilateralmente }\end{array}$ & $\begin{array}{l}\text { Perineal e/ou } \\
\text { vulvar de } 1-2 \\
\mathrm{~cm} \text { da incisão }\end{array}$ & $\begin{array}{l}\text { Entre } 0,25-1 \mathrm{~cm} \\
\text { da incisão } \\
\text { bilateralmente } \\
\text { ou até } 0,5-2 \mathrm{~cm} \\
\text { unilateralmente }\end{array}$ & Serosanguínea & $\begin{array}{l}\text { Pele } \quad \text { e } \\
\text { subcutâneos } \\
\text { separados }\end{array}$ \\
\hline 3 & $\begin{array}{l}\text { Além de } 0,5 \\
\mathrm{~cm} \text { da incisão } \\
\text { bilateralmente }\end{array}$ & $\begin{array}{l}\text { Perineal } \mathrm{e} / \mathrm{ou} \\
\text { vulvar maior } \\
\text { que } 2 \mathrm{~cm}, \mathrm{da} \\
\text { incisão }\end{array}$ & $\begin{array}{l}\text { Maior que } 1 \mathrm{~cm} \\
\text { bilateralmente } \\
\text { ou } 2 \mathrm{~cm} \\
\text { unilateralmente }\end{array}$ & $\begin{array}{l}\text { Sanguinolenta, } \\
\text { purulenta }\end{array}$ & $\begin{array}{l}\text { Pele, } \\
\text { subcutâneo e } \\
\text { músculos } \\
\text { separados }\end{array}$ \\
\hline \multicolumn{6}{|l|}{ Escore } \\
\hline & & & & TOTAL & \\
\hline
\end{tabular}

A cada item avaliado pela escala REEDA pode ser atribuída uma pontuação de zero a três, de acordo com a intensidade de cada intercorrência observada, sendo que o valor máximo de 15 corresponde à pior condição perineal (Hill, 1990).

\subsubsection{Coleta de dados}

A coleta de dados ocorreu de março a junho de 2009, e foi realizada pela pesquisadora principal, e por uma enfermeira (assistente da pesquisa), previamente treinada para avaliação da magnitude da dor e da cicatrização perineal. As pesquisadoras permaneceram diariamente no CPN, por um período de 8 horas, para identificar as mulheres elegíveis ao estudo.

\subsubsection{Equipamentos e instrumentos}

A fonte de irradiação utilizada foi o modelo clínico portátil de LBI denominado Twin Laser ${ }^{\circledR}$ (MMOptics, São Carlos, SP, Brasil) com registro na 
Agência Nacional de Vigilância Sanitária (ANVISA) número 80051420007 e certificado pelo Instituto Nacional de Metrologia, Normalização e Qualidade Industrial (Inmetro) sob o número NCC 2756/05 (Figura 8).

O aparelho é classificado como laser classe 3B, que emite irradiação nas faixas do infravermelho e vermelho.

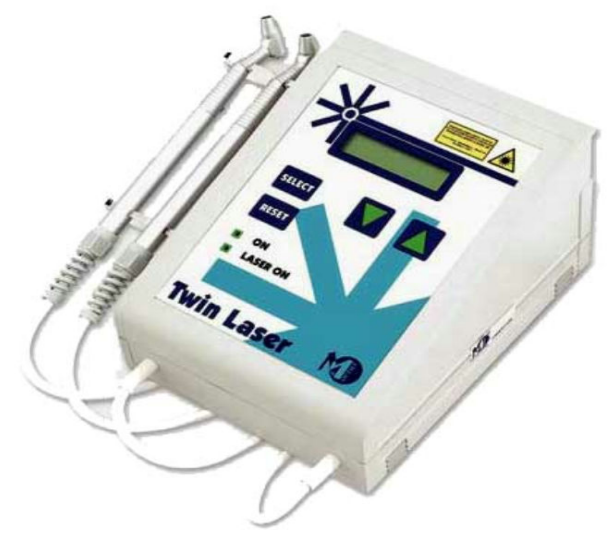

Figura 8: Aparelho Laser em Baixa Intensidade - Twin Laser ${ }^{*}$

No estudo piloto foi utilizado o seguinte protocolo: laser de diodo com semicondutor de AlGaInP, comprimento de onda de $660 \mathrm{~nm}$, feixe de luz vermelho, tamanho do spot de $0,04 \mathrm{~cm}^{2}$, dose de $3,8 \mathrm{~J} / \mathrm{cm}^{2}$, potência de $15 \mathrm{~mW}$, duração da irradiação de 10 segundos por ponto, energia de $0,15 \mathrm{~J}$ por ponto e energia total de $0,45 \mathrm{~J}$ por sessão.

Foram tomadas as precauções individuais para a utilização do LBI, tais como, restrição a entrada de terceiros no ambiente de tratamento e o uso de óculos de proteção individual, específico para o feixe de luz, pela pesquisadora e pela puérpera.

Durante o período de coleta dos dados, o aparelho foi semanalmente submetido à avaliação da potência emitida, utilizando-se um medidor de potência (Coherent Inc., Santa Clara, Ca, EUA), para garantir a emissão da quantidade de energia adequada para o estudo. Também foi avaliada a efetividade do bloqueio da irradiação, sem quaisquer alterações.

\footnotetext{
* Disponível em http://www.mmo.com.br/pt/
} 
A régua Peri-Rule ${ }^{\mathrm{TM}}$ foi empregada como instrumento auxiliar para avaliar a cicatrização e o comprimento da episiotomia (Figura 9).

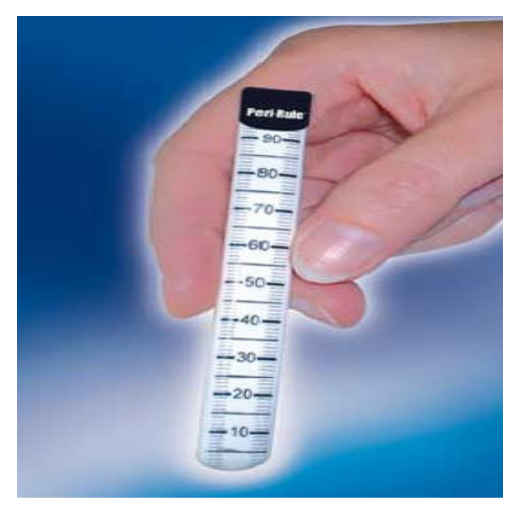

Figura 9: Régua Peri-Rule ${ }^{\mathrm{TM} * *}$

A régua Peri-Rule ${ }^{\mathrm{TM}}$ é uma ferramenta válida e confiável para medição e avaliação das lacerações perineais ocorridas no parto, desenvolvida por um grupo de pesquisadores internacionais. É feita de plástico macio e constituída por um dispositivo de medida e uma avaliação pró-forma para avaliar a extensão e a profundidade da lesão. O instrumento pode ser esterilizado em autoclave e desinfetado com solução alcoólica (Metcalfe, Tohill, 2005).

Em razão do elevado custo de importação e da falta de contato do material com a ferida aberta, para evitar a disseminação de agentes patogênicos, a régua foi submetida, antes de cada utilização, à lavagem com água e sabão, assepsia com álcool a $70 \%$ e foi envolvida em uma camada de filme PVC.

\subsubsection{Procedimentos}

Para a obtenção de informações referentes à mulher, foram consultados o Livro de Registro dos Partos do CPN e os prontuários das puérperas. A abordagem das mulheres elegíveis para o estudo foi feita até duas horas após o parto, na sala de

\footnotetext{
** Disponível em: http://www.peri-rule.bham.ac.uk/index.shtml
} 
observação do CPN. Os objetivos da pesquisa, o procedimento a ser realizado e a possibilidade de pertencer a um dos dois grupos, que seria indicado por sorteio foram explicados as puérperas quando elas foram convidadas a participar da investigação.

A puérpera também recebeu informações sobre o direito de ter esclarecimentos em relação às suas dúvidas quanto ao estudo, assim como a liberdade de desistir de participar da pesquisa a qualquer momento, sem prejuízo da sua assistência na instituição.

Após a anuência da mulher e da assinatura no Termo de Consentimento Livre e Esclarecido (Apêndice 2), o formulário de coleta de dados contendo a identificação da puérpera, seus antecedentes obstétricos e dados do parto e do recém-nascido foi preenchido(Apêndice 3).

Antes da primeira sessão do tratamento, a pesquisadora assistente avaliou a magnitude da dor perineal e a extensão da episiotomia. Em seguida, a pesquisadora principal abriu o envelope com o grupo randomizado para identificar o grupo ao qual a puérpera pertenceria. Uma vez identificado o grupo da puérpera, foi realizada a primeira laserterapia ou a simulação do tratamento, respeitando o tempo de, no máximo, 2 horas após o parto, conforme técnica já descrita. A primeira irradiação do laser ocorreu no CPN, com a mulher na sala de parto, em posição litotômica.

Após a primeira sessão de irradiação, a puérpera foi orientada pela pesquisadora principal a ingerir medicações analgésicas somente na ocorrência de dor, visto que, no serviço é rotina a administração de analgésico no pós-parto normal. Durante o período de permanência da puérpera no CPN, a pesquisadora principal ficou ao lado da mulher esclarecendo suas dúvidas, promovendo atividades educacionais e estimulando o aleitamento materno.

No período de 20 a 24 horas depois do parto, as duas pesquisadoras procuravam as participantes do estudo no $\mathrm{AC}$, onde a assistente as abordava novamente para avaliar a cicatrização e a dor perineal imediatamente antes da irradiação. Sequencialmente, a pesquisadora principal realizava o tratamento com LBI, conforme o grupo específico. Imediatamente após o término desta sessão e da saída da pesquisadora principal do quarto, houve novo questionamento da dor perineal pela assistente de pesquisa. Esse procedimento ocorreu também no período 
de 40 a 48 horas de pós-parto normal, perfazendo o total de três sessões durante a internação hospitalar da puérpera.

Nas três aplicações do LBI, para evitar a contaminação da puérpera, a ponteira do laser foi protegida com uma camada de filme de PVC, colocada de forma bem esticada para evitar a difusão do feixe de luz na saída da caneta. Também foi realizada a desinfecção da ponteira do laser com álcool 70\% entre uma aplicação e outra.

Ao final da terceira irradiação laser, as pesquisadoras solicitaram o retorno da puérpera à maternidade, entre 15 e 20 dias após o parto, para reavaliação da dor e da cicatrização perineal.

\subsubsection{Tratamento e análise dos dados}

Para a análise estatística, utilizou-se o programa Statistical Package for Social Sciences (SPSS) for Windows, versão 13.0. A análise descritiva das variáveis quantitativas compreendeu o cálculo das médias, desvios-padrão, medianas, valores mínimos e máximos, utilizando o teste $t$ de Student.

Para comparação dos grupos em relação às variáveis qualitativas foi empregado o teste Qui-quadrado. A comparação das médias entre os grupos foi utilizada a análise de variância com dois fatores, um fator independente (grupo) e outro fator foi o momento em que a irradiação foi realizada. As comparações múltiplas foram feitas pelo teste de Tukey - HSD (Honestly Significant Difference).

\subsubsection{Aspectos éticos}

Seguindo as diretrizes e normas regulamentadoras de pesquisas que envolvem seres humanos, aprovadas pelo Conselho Nacional de Saúde - Resolução 196/96, previamente a inserção da pesquisadora no local de coleta de dados, o estudo 
foi aprovado pelo Comitê de Ética em Pesquisa da Escola de Enfermagem da Universidade de São Paulo (processo 778/2008 - Anexo 2).

Os dados foram coletados após aprovação do Comitê e do local onde o estudo foi desenvolvido mediante autorização da Presidente Executiva do Amparo Maternal e da coordenadora de enfermagem da instituição (Apêndice 4).

A participação das puérperas foi voluntária, mediante assinatura do Termo de Consentimento Livre e Esclarecido, assegurando-lhe a preservação de sua identidade e o direito de exclusão do estudo em qualquer momento, sem oferecer prejuízo e/ou interferência na assistência prestada.

Como declaração de conflito de interesses, cumpre salientar que as pesquisadoras não têm nenhum tipo de vínculo com o fabricante ou distribuidor do aparelho laser em baixa intensidade utilizado para irradiação da região perineal.

\subsubsection{Resultados e discussão}

Durante o período de coleta de dados ocorreram na maternidade 2.395 partos, dos quais 21,8\% (523) foram cesarianas e 78,2\% (1.872) normais, destes 40,9\% (766) das mulheres tiveram a integridade perineal preservada, 39,4\% (737) com laceração espontânea, 18,8\% (351) com episiotomia e 0,9\% (18) dos casos não foi relatada a condição perineal.

No período de estudo, 351 mulheres foram elegíveis, sendo que 100 não preencheram os critérios de inclusão, 187 foram submetidas à episiotomia no período em que as pesquisadoras não estavam na maternidade, 10 foram excluídas e 2 se recusaram a participar do estudo, restando 52 participantes, com 26 em cada grupo.

Em ambos os grupos, a média da idade das participantes foi de 23,4 $\pm 4,9$ anos, mediana de 22 anos e valores mínimo e máximo de 18 e 39 anos, respectivamente. Oito participantes tinham cesariana prévia, a maioria das mulheres era nulípara $(84,6 \%)$, de cor parda $(51,9 \%)$, não fumante $(86,5 \%)$ e residia com companheiro $(76,9 \%)$.

A extensão da episiotomia variou de 1,7 a $5 \mathrm{~cm}$, com média de 3,2 $\pm 0,8 \mathrm{~cm}$, sendo empregado o fio categute zero simples em todas as episiorrafias e técnica de sutura contínua em 88,5\% (46) dos casos. O peso do recém-nascido oscilou de 2.570 
a 4.160 gramas, com média de 3.257,3 $\pm 394,6$ gramas, enquanto o perímetro cefálico variou de 31 a $37 \mathrm{~cm}$, com média total de 33,6 $\pm 1,3 \mathrm{~cm}$.

Constatou-se semelhança dos grupos quanto à história obstétrica, cor da pele e escolaridade. Houve diferença estatisticamente significativa em relação ao estado marital e o hábito de fumar $(\mathrm{p}<0,05)$.

Não houve diferença estatística entre os grupos quanto à idade materna, a extensão da episiotomia, o peso e o perímetro cefálico do recém-nascido, e a administração de dipirona sódica durante o período de internação hospitalar, demonstrando que os grupos foram equivalentes.

Houve redução estatisticamente significante no nível de dor perineal do grupo controle somente após a primeira irradiação $(p=0,043)$. No grupo experimental houve redução significativa no escore médio de dor após a segunda e a terceira sessões de tratamento $(p=0,003$ e $p<0,001$, respectivamente) (Tabela 1$)$.

Tabela 1. Comparação das médias e desvios-padrão (dp) de dor perineal entre os grupos controle e experimental, antes e imediatamente após cada sessão de irradiação de LBI. Amparo Maternal, São Paulo, 2009.

\begin{tabular}{|c|c|c|c|c|}
\hline \multirow{2}{*}{ Sessão de LBI } & & \multicolumn{2}{|c|}{ Dor perineal } & \multirow[b]{2}{*}{$p$-value } \\
\hline & & $\begin{array}{l}\text { Controle } \\
\text { Média (dp) }\end{array}$ & $\begin{array}{l}\text { Experimental } \\
\text { Média (dp) }\end{array}$ & \\
\hline \multirow[t]{3}{*}{ Até 2 horas } & Antes & $2,4(2,4)$ & $2,2(2,4)$ & 0,999 \\
\hline & Após & $1,6(2,3)$ & $1,7(2,3)$ & 0,999 \\
\hline & $p$-value $e^{\S}$ & 0,043 & 0,161 & \\
\hline \multirow[t]{3}{*}{$20-24$ horas } & Antes & $3,0(2,0)$ & $2,5(2,3)$ & 0,934 \\
\hline & Após & $2,3(1,9)$ & $1,5(2,1)$ & 0,758 \\
\hline & $p$-value $e^{\S}$ & 0,072 & $\mathbf{0 , 0 0 3}$ & \\
\hline \multirow[t]{3}{*}{$40-48$ horas } & Antes & $2,8(2,3)$ & $2,3(2,4)$ & 0,925 \\
\hline & Após & $2,5(2,3)$ & $1,5(1,9)$ & 0,662 \\
\hline & $p$-value $e^{\S}$ & 0,116 & $<0,001$ & \\
\hline
\end{tabular}

No entanto, na comparação dos escores médios de dor entre os grupos controle e experimental não foram observadas diferenças estatisticamente significantes nos três momentos que antecederam a aplicação do LBI e também nos 
três momentos imediatamente após as sessões de irradiação, conforme observado na Tabela 1.

No período de 15 a 20 dias depois do parto, nenhuma das 29 mulheres (16 do grupo controle e 13 do experimental) que retornou à maternidade para avaliação puerperal referiu dor perineal. É importante ressaltar que nenhuma participante da investigação relatou dor durante as irradiações.

Com relação à avaliação do processo cicatricial, constatou-se que não houve diferença significativa na média dos escores de cicatrização entre os dois grupos nos três diferentes momentos de avaliação, durante a internação hospitalar e no período de 15 a 20 dias após o parto (Tabela 2).

Tabela 2. Comparação das médias e desvios-padrão (dp) dos escores de cicatrização entre os grupos controle e experimental, segundo o período de avaliação. Amparo Maternal, São Paulo, 2009.

\begin{tabular}{llll}
\hline \multirow{2}{*}{ Período de avaliação } & \multicolumn{2}{c}{ Escores de cicatrização } & \\
\cline { 2 - 3 } & Controle & Experimental & \multirow{2}{*}{ p-value $^{\S}$} \\
\cline { 2 - 3 } & Média (dp) & Média (dp) & \\
\hline Até 2 horas & $3,4(1,6)$ & $3,1(1,3)$ & 0,227 \\
$20-24$ horas & $4,3(2,7)$ & $4,5(2,6)$ & 0,601 \\
$40-48$ horas & $4,5(2,9)$ & $4,5(2,3)$ & 0,458 \\
$15-20$ dias & $0,7(0,9)^{(1)}$ & $0,7(1,9)^{(2)}$ & 0,503
\end{tabular}

${ }^{\S}$ Teste $t$ de Student

(1) $n=16 \quad(2) n=13$

Não foi encontrada diferença significativa na cicatrização perineal entre o grupo experimental e o controle em todos os momentos de avaliação, confirmando os achados de uma revisão sistemática que não apontou evidência de qualquer benefício associado à terapia LBI sobre a cicatrização de úlceras venosas em membros inferiores (Flemming, Cullum, 1999).

Convém comentar que foram encontradas dificuldades para avaliar a reparação tecidual, pelo curto período de observação e pelo reduzido número de puérperas que retornaram à maternidade após o parto.

A avaliação da cicatrização perineal aconteceu durante a internação das puérperas, com até cerca de 48 horas, após a episiotomia. É justamente nesta fase que 
ocorre a resposta inflamatória aguda pós-traumática, caracterizada pela dor, hiperemia, edema e calor local que começa a ceder a partir do terceiro dia após o trauma (Kumar, Abbas, Fausto, 2005). Os elevados valores da escala REEDA, constatados entre 20 e 48 horas após o parto, correspondem à reação inflamatória esperada para esse período.

Assim, considerou-se que o intervalo da internação foi insuficiente para uma avaliação adequada do processo de cicatrização. O acompanhamento das puérperas por uma semana a 15 dias após o parto permitiria avaliar melhor a cicatrização. Nesse sentido, foi agendada uma consulta puerperal com 15 a 20 dias, após a alta da mulher. É importante mencionar que a pesquisadora, considerando as dificuldades que as mulheres poderiam encontrar para retornar ao serviço, associou a entrega do resultado do Teste de Guthrie (teste do pezinho) à consulta para avaliação das condições perineais.

No entanto, somente 16 puérperas do grupo controle e 13 do experimental retornaram à maternidade $(55,8 \%)$, nas quais não foram observadas diferenças no processo cicatricial do períneo e nem no relato de dor perineal momentânea. Constatou-se que o retorno das puérperas à maternidade foi dificultado por diversos motivos. Um fator que contribuiu para essa situação foi a ausência de agendamento do retorno para realização de consulta puerperal. Merece destaque também o perfil da população atendida na instituição, que é constituída por mulheres que residem em localidades afastadas do serviço e que possuem situação socioeconômica desfavorável.

O protocolo inicial, constituído por três sessões de irradiação com LBI durante a internação das puérperas, foi proposto com a finalidade de avaliar o efeito sobre a cicatrização perineal, independente dela referir dor no local. As dificuldades constatadas no estudo piloto para analisar o reparo tecidual, foram o curto período após o trauma e o reduzido número de puérperas que retornaram à maternidade, que inviabilizaram a análise da cicatrização da episiotomia.

Em relação à redução na dor perineal, foi constatado no estudo piloto que o LBI pode proporcionar alívio da dor perineal, visto que houve uma redução significante no escore médio da dor perineal no grupo experimental, após a segunda e a terceira sessões de irradiação ( $p=0,003$ e $p<0,001$, respectivamente), comparado ao escore da dor verificado antes das sessões. No entanto, na comparação entre os 
grupos controle e experimental, não foram constatadas diferenças estatísticas nas médias da dor, antes e imediatamente após cada sessão de irradiação.

Embora o LBI tenha indicado resultados positivos no alívio da dor perineal, acredita-se que a dosimetria aplicada e o comprimento de onda de $660 \mathrm{~nm}$, com feixe de luz vermelho, foram insuficientes para atingir as camadas mais profundas da episiotomia, que, em geral, secciona pele, tecido subcutâneo, mucosa vaginal, músculos bulbocavernoso e transverso superficial do períneo.

De acordo com a literatura, o laser com luz vermelha penetra menos no tecido, enquanto o feixe de luz infravermelho tem maior poder de penetração, atingindo tecidos mais profundos (Enwemeka 2001; Genovese, 2007).

Considerando a profundidade atingida pelos feixes de luz do LBI, o tipo de lesão e os tecidos a serem irradiados, um novo protocolo de estudo foi proposto para o desenvolvimento de outro ensaio clínico, considerado como a segunda etapa desta pesquisa, descrita a seguir.

\subsection{Segunda Etapa}

\subsubsection{Tipo de estudo}

Como no estudo piloto, trata-se de um ensaio clínico controlado, randomizado, paralelo, com mascaramento duplo sobre os efeitos do LBI para a redução da dor perineal pós-episiotomia no parto normal. O cegamento ocorreu na avaliação do desfecho e para as participantes do estudo.

O protocolo deste estudo foi registrado na base de dados Australian New Zeland Clinical Trials Registry (ANZCTR), cadastradas junto a International Clinical Trials Registry Plataform da Organização Mundial de Saúde, sob o número de protocolo 00320866, em 08 de dezembro de 2009. 


\subsubsection{Local do Estudo}

O estudo foi realizado na mesma maternidade do piloto e os dados foram coletados apenas na Unidade de Alojamento Conjunto do Amparo Maternal.

\subsubsection{População}

Na segunda etapa do estudo a população também foi constituída de puérperas de pós-parto normal submetidas à episiotomia médio-lateral direita com o acréscimo de alguns critérios de inclusão diferentes do estudo piloto, descritos a seguir.

A população foi dividida randomicamente em três grupos paralelos - Grupo Experimental Infravermelho, composto por puérperas que receberam a irradiação com laser em baixa intensidade na região perineal utilizando o comprimento de onda infravermelho, Grupo Experimental Vermelho, constituído por puérperas que receberam a irradiação com laser em baixa intensidade na região perineal com comprimento de onda na faixa do vermelho e Grupo Controle, formado por mulheres que foram submetidas à simulação do tratamento, mas sem a irradiação do feixe de luz (grupo sham).

\subsubsection{Critérios de inclusão e exclusão}

Foram mantidos os mesmos critérios de inclusão da primeira etapa e acrescidos outros, conforme descrito abaixo:

\section{Critérios de inclusão da primeira etapa}

- idade igual ou maior que 18 anos;

- gravidez a termo (entre 37 e 41 semanas e 6 dias de idade gestacional);

- ter tido parto normal com episiotomia médio-lateral direita;

- feto único, vivo e em apresentação cefálica;

- recém-nascido em boas condições clínicas; 
- não apresentar laceração perineal associada a episiotomia;

- não ter dificuldades de comunicação ou compreensão;

- sem processo infeccioso, hemorróidas, hematoma, edema ou varizes na região da vulva;

- não utilizar drogas foto-sensibilizantes endógenas (tetraciclina, griseofulvina, sulfamida e furocumarina) ou exógenas (ácido retinoico e glicólico),

- não apresentar intercorrências clínicas ou obstétricas.

\section{Critérios de inclusão acrescentados}

- estar entre 6 e 56 horas de pós-parto;

- referir dor perineal, maior ou igual a três na escala numérica, no momento da abordagem.

Critérios de exclusão

Os critérios de exclusão do estudo piloto foram mantidos, ou seja, o uso de qualquer produto na região vulvoperineal, exceto água e sabão.

\subsubsection{Amostra e randomização}

$\mathrm{Na}$ segunda etapa do estudo optou-se por aumentar o tamanho amostral de 26 para 38 mulheres em cada grupo, tomando como base o ensaio clínico sobre crioterapia no alívio da dor perineal desenvolvido por Leventhal (2008). Assim, a amostra deste estudo foi constituída por 114 puérperas, com 38 mulheres em cada grupo.

A aleatorização da puérpera foi realizada da mesma forma que no piloto, utilizando-se também uma tabela randomizada gerada por computador e identificada individualmente por código numérico. Foi elaborada uma lista com 114 números, 
com 38 em cada um dos 3 grupos analisados (experimentais infravermelho e vermelho, e controle) (Apêndice 5).

O procedimento adotado para randomização foi o mesmo da etapa anterior, realizado por um indivíduo alheio ao estudo, com cada número da listagem colocado individualmente em um envelope opaco, numerado e fechado. O envelope foi aberto pela pesquisadora principal, para identificação do grupo da mulher, no momento da irradiação.

Seguindo os mesmos critérios do estudo piloto, as mulheres excluídas do estudo foram automaticamente substituídas por outras, utilizando-se a mesma tabela de randomização.

\subsubsection{Intervenção e desfechos}

Os grupos experimentais, vermelho e infravermelho, foram submetidos a uma única sessão de irradiação com laser em baixa intensidade, com o comprimento de onda específico, diretamente sobre a episiotomia, durante 10 segundos. A aplicação foi realizada de modo pontual, como na etapa anterior, tocando a ponteira ativa do laser na região da incisão cirúrgica. Foram realizados também três pontos de irradiação, independente da extensão da episiotomia, como no estudo piloto.

As participantes do grupo controle também foram submetidas a uma única sessão de tratamento, como no experimental, porém sem a emissão da irradiação, para possibilitar avaliar os possíveis efeitos placebo da terapia. O tempo de duração da simulação da irradiação e o número de pontos de aplicação foram iguais aos dos grupos experimentais.

A irradiação foi feita no próprio leito da puérpera, no Alojamento Conjunto, com a mulher em posição ginecológica. Como na primeira etapa, a pesquisadora principal e as puérperas fizeram uso de equipamentos de proteção individual (óculos) durante as irradiações.

O desfecho primário considerado foi redução na magnitude da dor perineal, avaliada por uma pesquisadora assistente treinada, com mascaramento do tratamento para essa profissional e para as puérperas. Nessa etapa, a intensidade da dor perineal 
foi avaliada antes, imediatamente após e 30 minutos depois da irradiação, por meio da aplicação da Escala Numérica (Anexo 1), utilizando-se os mesmos procedimentos descritos na primeira etapa.

Os mesmos desfechos secundários na primeira etapa foram utilizados neste estudo: idade materna, paridade, cor da pele, estado marital, escolaridade comprimento da episiotomia, idade gestacional, peso e o perímetro cefálico do RN. No entanto, outros desfechos considerados relevantes para a pesquisa foram acrescidos, tais como: trabalho renumerado, alergia medicamentosa, número de gestações e abortamentos anteriores, presença de acompanhante, índice de Apgar, número de analgésicos e outros medicamentos ingeridos, intervalo entre a medicação analgésica e a irradiação com o laser em baixa intensidade.

\subsubsection{Material}

Os equipamentos, instrumentos e procedimentos utilizados na segunda etapa foram os mesmos do estudo piloto, ou seja, aparelho Twin Laser ${ }^{\circledR}$, óculos de proteção individual e a régua Peri-Rule.

Considerando os resultados obtidos no estudo piloto, houve modificação do protocolo de aplicação do LBI para o desenvolvimento da segunda etapa dessa pesquisa. Nessa fase, foram utilizados o feixe de luz vermelho, no comprimento de onda $660 \mathrm{~nm}$, com meio ativo semicondutor de AlGaInP e o feixe de luz infravermelho, no comprimento de onda $780 \mathrm{~nm}$, com meio ativo semicondutor de GaAIAs.

O seguinte protocolo de irradiação foi empregado para ambos os feixes de luz:

- laser de diodo;

- tamanho do spot de $0,04 \mathrm{~cm}^{2}$;

- dose de $8,8 \mathrm{~J} / \mathrm{cm}^{2}$;

- potência de $35 \mathrm{~mW}$;

- duração da irradiação de 10 segundos por ponto; 
- $\quad$ energia de $0,35 \mathrm{~J}$ por ponto e;

- energia total de $1,05 \mathrm{~J}$.

No grupo controle o mesmo aparelho foi utilizado, mas sem a emissão da irradiação. Como no estudo piloto, durante o período de coleta de dados, o aparelho foi semanalmente submetido à avaliação da potência emitida, sem quaisquer alterações.

Foi utilizado o mesmo procedimento para evitar a contaminação da mulher, com a ponteira ativa do laser e a régua Peri-Rule ${ }^{\mathrm{TM}}$, que foram protegidas com uma camada de PVC, além da desinfecção com álcool 70\% entre as aplicações.

\subsubsection{Coleta de dados}

A coleta de dados dessa etapa ocorreu no período de 23 de novembro 2009 a 22 de março de 2010, e contou com o apoio de duas obstetrizes (assistentes da pesquisa), que foram previamente treinadas, além da pesquisadora principal.

Como na etapa anterior, os prontuários das puérperas foram consultados para obter as informações referentes à mulher e para checar os critérios de inclusão do estudo.

O procedimento de abordagem das puérperas elegíveis para a pesquisa foi similar ao estudo piloto, ocorrendo no próprio quarto das mulheres. Após a anuência da mulher e da assinatura no Termo de Consentimento Livre e Esclarecido (Apêndice 6), o formulário de coleta de dados contendo a identificação da puérpera, seus antecedentes obstétricos e dados do parto e do recém-nascido foi preenchido (Apêndice 7).

Antes da sessão de laserterapia, a assistente da pesquisa avaliou a magnitude da dor perineal e as limitações das atividades diárias referidas pela puérpera decorrentes da algia.

Em seguida, a pesquisadora principal abriu o envelope contendo o grupo randomizado para identificar o grupo da puérpera. Identificado o grupo da mulher, procedeu-se a avaliação da extensão da episiotomia e foi aplicada a laserterapia ou realizada a simulação do tratamento. 
Imediatamente após o término da sessão e da saída da pesquisadora principal do quarto, a assistente da pesquisa avaliou novamente a intensidade da dor perineal. Uma nova investigação das limitações das atividades cotidianas e da magnitude da dor no períneo ocorreu 30 minutos após a irradiação.

Com a finalidade de mascarar a avaliação do desfecho, a assistente da pesquisa permaneceu fora do quarto da puérpera durante a intervenção e não teve conhecimento do grupo ao qual a mulher pertencia. As puérperas também não receberam informação sobre o grupo em que foram alocadas.

Ao final da terapia, a assistente da pesquisa questionou a opinião das puérperas com relação à laserterapia.

\subsubsection{Variáveis do estudo}

\subsubsection{Variável independente}

A aplicação do laser em baixa intensidade na região perineal após a episiotomia médio-lateral direita, conforme a técnica descrita anteriormente.

\subsubsection{Variável dependente}

A magnitude da dor perineal antes, imediatamente após e 30 minutos depois da sessão de irradiação perineal.

\subsubsection{Outras variáveis}

\section{Características sociodemográficas}

- Idade materna - em anos completos no momento da admissão hospitalar; 
- Cor da pele - classificada como branca, negra e parda, conforme definição da própria mulher;

- Escolaridade - classificada como analfabeta, ensino fundamental, médio ou superior, completo ou incompleto;

- Trabalho remunerado - classificado em sim e não;

- Situação marital - classificada como com companheiro com e sem co-habitação e sem companheiro.

Características obstétricas e do parto atual

- Gestação - avaliada pelo número de gestações anteriores no momento da internação hospitalar, incluindo a gestão atual;

- Paridade - avaliada pelo número de partos anteriores, no momento da admissão;

- Abortamento - avaliada pelo número de abortamentos anteriores;

- Idade gestacional - avaliada em semanas completas no momento da admissão;

- Data e horário do parto - avaliada pela anotação no prontuário;

- Motivo da episiotomia - avaliada pela anotação no prontuário;

- Comprimento da episiotomia - avaliada antes da aplicação do laser, medida em centímetros no plano da pele na região do períneo, com início na fúrcula, utilizando-se a régua Peri-Rule ${ }^{\mathrm{TM}}$;

- Peso do recém-nascido - medido em gramas logo após o nascimento, obtido por registro no prontuário;

- Perímetro cefálico do recém-nascido - medido em centímetros logo após o nascimento, obtido por registro no prontuário;

- Boletim de Apgar - vitalidade do recém-nascido, no primeiro e quinto minutos de vida, obtido por registro no prontuário;

- Presença de acompanhante no parto atual - informada pela mulher e registrada como sim e não, e quem foi o acompanhante;

- Profissional que assistiu ao parto - avaliado pelo registro no prontuário. 
Limitações das atividades cotidianas e o uso de analgésicos

- Interferência da dor perineal - avaliada pela puérpera como sim, não ou não fez, segundo as dificuldades apresentadas para realizar as necessidades fisiológicas e atividades cotidianas, como andar, sentar, amamentar, urinar, evacuar e dormir;

- Medicação analgésica - avaliada pelo nome e quantidade de medicamentos analgésicos ingeridos durante o período de internação hospitalar;

- Histórico de alergia à medicamentos - classificado como sim e não.

\section{Avaliação da laserterapia}

- Nível de satisfação com a terapêutica empregada - as puérperas foram questionadas a respeito da intervenção realizada, classificando-a como muito bom, bom, regular, ruim, muito ruim e sem opinião;

- Conforto da intervenção - as puérperas foram questionadas a respeito da intervenção realizada, classificando-a confortável ou desconfortável;

- Opinião sobre o tratamento - as puérperas foram indagadas se realizariam novamente o procedimento em outro parto, classificado como sim e não.

\subsubsection{Tratamento e análise dos dados}

Para a análise estatística, utilizou-se o mesmo programa da etapa anterior, Statistical Package for Social Sciences (SPSS) for Windows, versão 13.0.

A aderência das variáveis quantitativas à distribuição normal foi avaliada por meio do teste Kolmogorov-Smirnov. Verificou-se que grande número das variáveis não tinha distribuição normal e, por isso, decidiu-se fazer as análises com testes não paramétricos.

A análise descritiva das variáveis quantitativas compreendeu o cálculo das médias, desvios-padrão, valores mínimos e máximos, utilizando o teste $t$ de Student e Kruskal-Wallis para a comparação dos grupos. Para as variáveis qualitativas foram 
calculadas as frequências absolutas e relativas e a comparação dos grupos foi realizada por meio do teste Qui-quadrado.

A comparação das médias entre os grupos foi utilizada a análise de variância com dois fatores, um fator independente (grupo) e outro fator foi o momento em que a irradiação foi realizada. As comparações múltiplas foram feitas pelo teste de Tukey - HSD (Honestly Significant Difference).

Foram considerados estatisticamente significantes os resultados cujos níveis descritivos (valores de p) foram iguais ou inferiores a 0,05 .

\subsubsection{Aspectos éticos}

O estudo, incluindo as duas etapas, foi aprovado pelo Comitê de Ética em Pesquisa da Escola de Enfermagem da Universidade de São Paulo, sob o número do processo 778/2008, conforme descrito anteriormente (Anexo 2).

A participação das puérperas também foi voluntária, mediante assinatura do Termo de Consentimento Livre e Esclarecido (Apêndice 6). 
No período de coleta de dados, entre 23 de novembro de 2009 e 22 de março de 2010, ocorreram 2.235 partos na maternidade, dos quais $1.720(76,9 \%)$ foram espontâneos, 511 (22,9\%), cesarianas e 04 (0,2\%) fórcipes. Dos partos normais, 600 $(34,9 \%)$ mulheres tiveram a integridade perineal preservada, $541(31,4 \%)$ tiveram laceração espontânea, 416 (24,2\%) sofreram incisão perineal, sendo 401 (23,3\%) episiotomia médio-lateral direita e $15(0,9 \%)$ mediana. A condição perineal não foi registrada em $163(9,5 \%)$ dos prontuários.

No período do estudo 401 mulheres foram elegíveis, destas 274 não preencheram os critérios de inclusão e 13 recusaram-se a participar, restando 114 puérperas, que foram divididas aleatoriamente em três grupos, com 38 em cada (experimental infravermelho, experimental vermelho e controle) (Figura 10).

Nesta pesquisa, não houve perda de seguimento ou migração entre os grupos. 


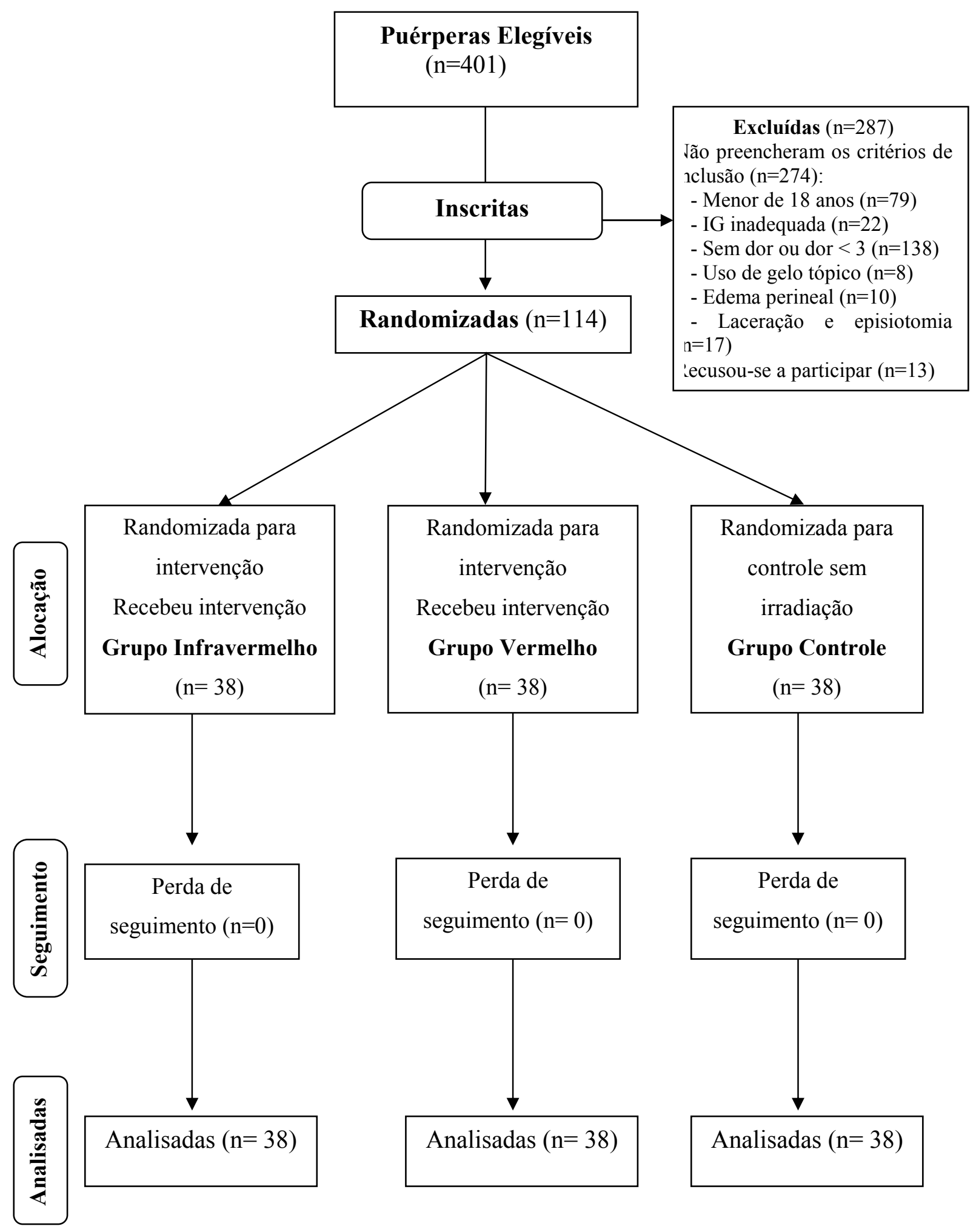

Figura 10 - Diagrama de recrutamento e seguimento das puérperas do estudo. Amparo Maternal, São Paulo, 2010. 
Com a finalidade de caracterizar as puérperas do estudo realizou-se a comparação das variáveis sociodemográficas dos três grupos pesquisados que estão apresentadas nos dados das Tabelas 3 a 5 .

A idade média das 114 puérperas participantes da amostra foi de 22,8 $\pm 4,4$ anos, com valor mínimo de 18 e máximo de 37 anos. Constatou-se que do total das mulheres, $49,1 \%$ eram de cor parda; $33,3 \%$, brancas e $17,5 \%$, negras. A maioria (64,9\%) tinha ensino médio completo ou incompleto, não exercia trabalho remunerado $(60,5 \%)$, não era fumante $(89,5 \%)$ e tinha companheiro $(77,2 \%)$, sendo a maior parte destas com co-habitação $(69,3 \%)$, conforme apresentado nos dados da Tabela 3. 
Tabela 3 - Distribuição das puérperas, segundo a idade, cor da pele, escolaridade, estado marital, trabalho remunerado, tabagismo e histórico de alergia medicamentosa. Amparo Maternal, São Paulo, 2010.

\begin{tabular}{|c|c|c|c|c|c|c|c|}
\hline \multirow{3}{*}{ Variável } & \multicolumn{6}{|c|}{ Grupos } & \multirow{3}{*}{ p-valor } \\
\hline & \multicolumn{2}{|c|}{ Controle } & \multicolumn{2}{|c|}{ Vermelho } & \multicolumn{2}{|c|}{ Infravermelho } & \\
\hline & $\mathrm{n}$ & $\%$ & $\mathrm{n}$ & $\%$ & $\mathrm{n}$ & $\%$ & \\
\hline Idade (anos) $\bar{x}(\mathrm{dp})$ & 22, & $(4,1)$ & 23,3 & $(4,5)$ & 22 & 4,7) & $0,616^{\S}$ \\
\hline Cor da pele & & & & & & & $0,424^{\beta}$ \\
\hline Parda & 17 & 44,7 & 17 & 44,7 & 22 & 57,9 & \\
\hline Branca & 15 & 39,5 & 15 & 39,5 & 8 & 21,1 & \\
\hline Negra & 6 & 15,8 & 6 & 15,8 & 8 & 21,1 & \\
\hline Escolaridade & & & & & & & $0,899^{\beta}$ \\
\hline Ensino fundamental & 10 & 26,3 & 8 & 21,1 & 12 & 31,6 & \\
\hline Ensino médio incompleto & 11 & 28,9 & 9 & 23,7 & 9 & 23,7 & \\
\hline Ensino médio completo & 14 & 36,8 & 18 & 47,4 & 13 & 34,2 & \\
\hline Superior & 3 & 7,9 & 3 & 7,9 & 4 & 10,5 & \\
\hline Trabalho remunerado & & & & & & & $0,371^{\beta}$ \\
\hline Não & 20 & 52,6 & 26 & 68,4 & 23 & 60,5 & \\
\hline Sim & 18 & 47,4 & 12 & 31,6 & 15 & 39,5 & \\
\hline Estado marital & & & & & & & $0,198^{\beta}$ \\
\hline Com companheiro & 25 & 65,8 & 31 & 81,6 & 32 & 84,3 & \\
\hline Sem companheiro & 13 & 34,2 & 7 & 18,4 & 6 & 15,8 & \\
\hline Tabagismo & & & & & & & $0,141^{\beta}$ \\
\hline Não & 32 & 84,2 & 33 & 86,8 & 37 & 97,4 & \\
\hline Sim & 6 & 15,8 & 5 & 13,2 & 1 & 2,6 & \\
\hline Alergia medicamentosa & & & & & & & $0,584^{\beta}$ \\
\hline Não & 36 & 94,7 & 36 & 94,7 & 34 & 89,5 & \\
\hline Sim & 2 & 5,3 & 2 & 5,3 & 4 & 10,5 & \\
\hline Total & 38 & 100 & 38 & 100 & 38 & 100 & \\
\hline
\end{tabular}

Constatou-se semelhança dos grupos quanto à idade $(p=0,616)$, cor da pele $(\mathrm{p}=0,424)$, escolaridade $(\mathrm{p}=0,899)$, estado marital $(\mathrm{p}=0,198)$, exercer trabalho 
remunerado $(\mathrm{p}=0,371)$, hábito de fumar cigarros $(\mathrm{p}=0,141)$ e presença de alergia medicamentosa $(\mathrm{p}=0,584)$ (Tabela 3$)$.

Do total das puérperas, somente $8(10,5 \%)$ referiram ter alergia a medicamentos, dos quais $3(37,5 \%)$ citaram alergia a dipirona, $4(50 \%)$ aos antibióticos (penicilina benzatina e amoxilina) e 1 (12,5\%) ao complexo B.

Com relação às características obstétricas e do parto atual, observou-se que a maioria era primigesta $(80,7 \%)$, nulípara $(88,6 \%)$, sem histórico de abortamento anterior $(89,5 \%)$, receberam apoio emocional durante o trabalho de parto e parto (94,7\%), predominando o marido $(42,6 \%)$ e a mãe $(21,3 \%)$ (Tabela 4$)$.

Tabela 4 - Distribuição das puérperas, segundo a história obstétrica e presença de acompanhante no parto. Amparo Maternal, São Paulo, 2010.

\begin{tabular}{|c|c|c|c|c|c|c|c|}
\hline \multirow{3}{*}{ Variável } & \multicolumn{6}{|c|}{ Grupos } & \multirow{3}{*}{$p$-valor ${ }^{\beta}$} \\
\hline & \multicolumn{2}{|c|}{ Controle } & \multicolumn{2}{|c|}{ Vermelho } & \multicolumn{2}{|c|}{ Infravermelho } & \\
\hline & $\mathrm{n}$ & $\%$ & $\mathrm{n}$ & $\%$ & $\mathrm{n}$ & $\%$ & \\
\hline Gestação & & & & & & & 0,343 \\
\hline Primigesta & 33 & 86,8 & 28 & 73,7 & 31 & 81,6 & \\
\hline Multigesta & 5 & 13,2 & 10 & 26,3 & 7 & 18,4 & \\
\hline Paridade & & & & & & & 0,068 \\
\hline Nulípara & 36 & 94,7 & 30 & 78,9 & 35 & 92,1 & \\
\hline Multípara & 2 & 5,3 & 8 & 21,1 & 3 & 7,9 & \\
\hline Abortamento & & & & & & & 0,327 \\
\hline Nenhum & 36 & 94,7 & 34 & 89,5 & 32 & 84,2 & \\
\hline Um ou mais & 2 & 5,3 & 4 & 10,5 & 6 & 15,8 & \\
\hline Acompanhante & & & & & & & 0,121 \\
\hline Não & 2 & 5,3 & 4 & 10,5 & - & - & \\
\hline Sim & 36 & 94,7 & 34 & 89,5 & 38 & 100,0 & \\
\hline Total & 38 & 100 & 38 & 100 & 38 & 100 & \\
\hline
\end{tabular}

${ }^{\beta}$ Teste de associação pelo Qui-quadrado

Observou-se que os três grupos foram similares em relação ao número de gestações $(p=0,343)$, partos $(p=0,068)$ e abortamentos $(p=0,327)$ e presença de um acompanhante durante o trabalho de parto e parto $(\mathrm{p}=0,121)$. 
Verificou-se que das 13 mulheres que tinham parto anterior, $6(46,2 \%)$ foram parto normal, 6 cesariana e $1(7,7 \%)$ foi submetida ao parto fórcipe.

Em 102 (89,5\%) prontuários, as justificativas para realizar a episiotomia não foram descritas. Dentre aqueles com registro, o períneo rígido foi o principal motivo apontado para indicar o procedimento, com $6(5,3 \%)$ casos. As demais justificativas foram relacionadas às condições do concepto, tais como: posição do feto (2), para auxiliar na descida fetal (2), presença de bossa serossanguinolenta (1) e sofrimento fetal (1).

Os dados relacionados à idade gestacional, ao recém-nascido, ao número de analgésicos ingeridos e o tempo entre sua ingestão e a irradiação estão apresentados nos dados da Tabela 5 . 
Tabela 5 - Comparação das médias e desvios-padrão (dp) das variáveis quantitativas entre os grupos controle, experimental infravermelho e vermelho. Amparo Maternal, São Paulo, 2010.

\begin{tabular}{|c|c|c|c|c|}
\hline \multirow{3}{*}{ Variável } & \multicolumn{3}{|c|}{ Grupos } & \multirow{3}{*}{$\underset{\text { value }^{\beta}}{p-}$} \\
\hline & $\begin{array}{l}\text { Controle } \\
(\mathrm{n}=38)\end{array}$ & $\begin{array}{l}\text { Vermelho } \\
(\mathrm{n}=38)\end{array}$ & $\begin{array}{c}\text { Infravermelho } \\
(\mathrm{n}=38)\end{array}$ & \\
\hline & Média (dp) & Média (dp) & Média (dp) & \\
\hline Idade gestacional (s) & $39,4(1,2)$ & $39,2(1,2)$ & $39,4(1,2)$ & 0,825 \\
\hline Peso (g) & $3216,3(406,1)$ & $3252,0(309,7)$ & $3226,3(291,7)$ & 0,924 \\
\hline Perímetro cefálico $(\mathrm{cm})$ & $33,8(1,2)$ & $33,9(1,5)$ & $34,0(1,0)$ & 0,646 \\
\hline Apgar $1^{\circ}$ minuto & $8,8(0,4)$ & $8,5(0,9)$ & $8,5(0,8)$ & 0,296 \\
\hline Apgar $5^{\circ}$ minuto & $9,6(0,5)$ & $9,4(0,6)$ & $9,5(0,5)$ & 0,134 \\
\hline Extensão da episiotomia & $3,0(0,8)$ & $3,1(0,8)$ & $3,1(0,2)$ & 0,889 \\
\hline Número de analgésicos & $4,5(2,2)$ & $3,6(1,6)$ & $4,0(2,1)$ & 0,211 \\
\hline Outros medicamentos & $1,9(1,1)$ & $1,8(0,8)$ & $1,8(1,0)$ & 0,981 \\
\hline $\begin{array}{l}\text { Tempo entre medicação } \\
\text { e irradiação do laser (h) }\end{array}$ & $5,4(2,1)$ & $5,2(1,9)$ & $5,5(2,1)$ & 0,953 \\
\hline $\begin{array}{l}\text { Tempo entre parto e } \\
\text { irradiação do laser }(\mathrm{h})\end{array}$ & $29,7(11,7)$ & $27,2(12,5)$ & $24,0(10,8)$ & 0,110 \\
\hline
\end{tabular}

Não foi verificada diferença estatística nas seguintes variáveis quantitativas dos grupos: idade gestacional $(p=0,825)$, peso do concepto $(p=0,924)$, perímetro cefálico do bebê $(p=0,646)$, índice de Apgar do primeiro e quinto minutos ( $p=0,296$ e $\mathrm{p}=0,134$, respectivamente), extensão da episiotomia $(\mathrm{p}=0,889)$, quantidade de analgésicos $(p=0,211)$ e outros medicamentos ingeridos $(p=0,981)$, tempo entre a 
ingestão da medicação e a intervenção com LBI $(p=0,953)$ e o tempo entre o parto e a irradiação $(\mathrm{p}=0,110)$.

Considerando o total das puérperas, a idade gestacional média foi de 39,4 \pm 1,2 semanas, o comprimento médio da episiotomia foi $3,1 \pm 0,8$ centímetros, sendo ingeridos em média 4,0 $\pm 2,0$ comprimidos de analgésico até o momento da irradiação, com tempo médio de 5,4 $\pm 2,0$ horas antes do início da sessão de LBI. Todas as participantes receberam medicação analgésica, sendo 111 (97,4\%) medicadas com dipirona sódica e $3(2,6 \%)$ com acetaminofeno (paracetamol). A maioria $(80,7 \%)$ das puérperas também foi medicada com diclofenaco de sódio para alívio da dor.

A seguir, os dados da Tabela 6 apresentam a comparação intra-gupo das médias da dor perineal antes e imediatamente após a aplicação da laserterapia.

Tabela 6 - Comparação das médias e desvios-padrão (dp) da dor perineal nos grupos controle, experimental vermelho e infravermelho, antes e imediatamente após a laserterapia. Amparo Maternal, São Paulo, 2010.

\begin{tabular}{lccc}
\hline \multirow{2}{*}{ Grupos } & \multicolumn{2}{c}{ Dor perineal } & \\
\cline { 2 - 3 } & Antes do LBI & $\begin{array}{c}\text { Imediatamente após } \\
\text { o LBI }\end{array}$ & \\
\cline { 2 - 3 } & Média $(\mathrm{dp})$ & Média $\boldsymbol{e}^{\beta}$ \\
\cline { 2 - 3 } & $4,7(1,9)$ & $3,4(1,7)$ & $<$ \\
\hline Controle & $4,4(1,6)$ & $3,4(2,1)$ & $<\mathbf{0 , 0 0 1}$ \\
Experimental vermelho & $4,3(1,4)$ & $2,9(1,8)$ & $<\mathbf{0 , 0 0 1}$ \\
Experimental infravermelho & & &
\end{tabular}

${ }^{\beta}$ Teste de Tukey

$\mathrm{Na}$ análise de variância a dois fatores pelo teste de Tukey, constatou-se que houve diferença significativa nas médias de dor intragrupo comparando a dor referida antes e imediatamente após a irradiação nos três grupos analisados $(\mathrm{p}<0,001)$, conforme indicado na Tabela 6 .

Ao comparar-se as médias da dor perineal e os desvios-padrão imediatamente após a intervenção e 30 minutos depois da irradiação, observou-se diferença significativa na redução da dor nos grupos controle $(\mathrm{p}=0,011)$ e também nos experimentais vermelho $(p=0,008)$ e infravermelho $(p=0,034)$, de acordo com os dados da Tabela 7. 
Tabela 7 - Comparação das médias e desvios-padrão (dp) da dor perineal nos grupos controle, experimental vermelho e infravermelho, imediatamente após e com 30 minutos depois da laserterapia. Amparo Maternal, São Paulo, 2010.

\begin{tabular}{lccc}
\hline \multirow{2}{*}{ Grupos } & \multicolumn{2}{c}{ Dor perineal } & \\
\cline { 2 - 3 } & $\begin{array}{c}\text { Imediatamente } \\
\text { após o LBI }\end{array}$ & 30 min após o LBI & \\
\cline { 2 - 3 } & Média $(\mathrm{dp})$ & Média $(\mathrm{dp})$ & \\
\hline Controle & $3,4(1,7)$ & $2,6(1,8)$ & $\mathbf{0 , 0 1 1}$ \\
Experimental vermelho & $3,4(2,1)$ & $2,4(2,1)$ & $\mathbf{0 , 0 0 8}$ \\
Experimental infravermelho & $2,9(1,8)$ & $2,1(1,4)$ & $\mathbf{0 , 0 3 4}$ \\
\hline
\end{tabular}

${ }^{\beta}$ Teste de Tukey

$\mathrm{Na}$ avaliação intragrupo pode-se observar que houve diferença estatisticamente significativa antes e 30 minutos após a laserterapia nos três grupos $(\mathrm{p}<0,001)$ (Tabela 8).

Tabela 8 - Comparação das médias e desvios-padrão (dp) da dor perineal nos grupos controle, experimental vermelho e infravermelho, antes e 30 minutos após a laserterapia. Amparo Maternal, São Paulo, 2010.

\begin{tabular}{lccc}
\hline \multirow{2}{*}{ Grupos } & \multicolumn{2}{c}{ Dor perineal } & \\
\cline { 2 - 3 } & Antes do LBI & $\mathbf{3 0}$ min após o LBI & \multirow{2}{*}{-value $^{\beta}$} \\
\cline { 2 - 3 } & Média (dp) & Média (dp) & \\
\hline Controle & $4,7(1,9)$ & $2,6(1,8)$ & $<\mathbf{0 , 0 0 1}$ \\
Experimental vermelho & $4,4(1,6)$ & $2,4(2,1)$ & $<\mathbf{0 , 0 0 1}$ \\
Experimental infravermelho & $4,3(1,4)$ & $2,1(1,4)$ & $<\mathbf{0 , 0 0 1}$ \\
\hline
\end{tabular}

${ }^{\beta}$ Teste de Tukey

A comparação entre os três grupos não demonstrou diferença significativa nos três momentos de avaliação da dor perineal $(\mathrm{p}=0,445)$. As médias não apresentaram diferenças estatisticamente significantes antes da irradiação entre os grupos controle e vermelho (4,7 versus 4,4; $\mathrm{p}=0,999)$, entre o controle e o infravermelho $(4,7$ versus 4,$3 ; p=0,999)$ e entre o vermelho e o infravermelho $(4,4$ versus 4,$3 ; p=0,999)$.

O mesmo resultado foi obtido na análise dos escores médios da dor no momento imediatamente após a intervenção, entre os grupos controle e vermelho 
(3,4 versus 3,$4 ; p=1,000)$, entre o controle e o infravermelho (3,4 versus 2,9; $\mathrm{p}=0,998)$ e entre o vermelho e o infravermelho $(3,4$ versus 2,$9 ; \mathrm{p}=0,998)$.

Não houve diferença estatística significante também na comparação das médias da dor perineal, 30 minutos após a laserterapia entre os grupos vermelho e infravermelho $(2,4$ versus 2,$1 ; p=0,999)$, entre o controle e o vermelho (2,6 versus $2,4 ; p=0,994)$ e entre o controle e o infravermelho (2,6 versus 2,$1 ; p=0,999)$.

A comparação das médias da dor perineal inicial, imediatamente e 30 minutos após a irradiação com LBI está apresentada no Gráfico 1.

Gráfico 1 - Comparação da dor em três momentos (antes da irradiação, imediatamente depois e 30 minutos após) nos grupos controle e experimental vermelho e infravermelho. Amparo Maternal, São Paulo, 2010.

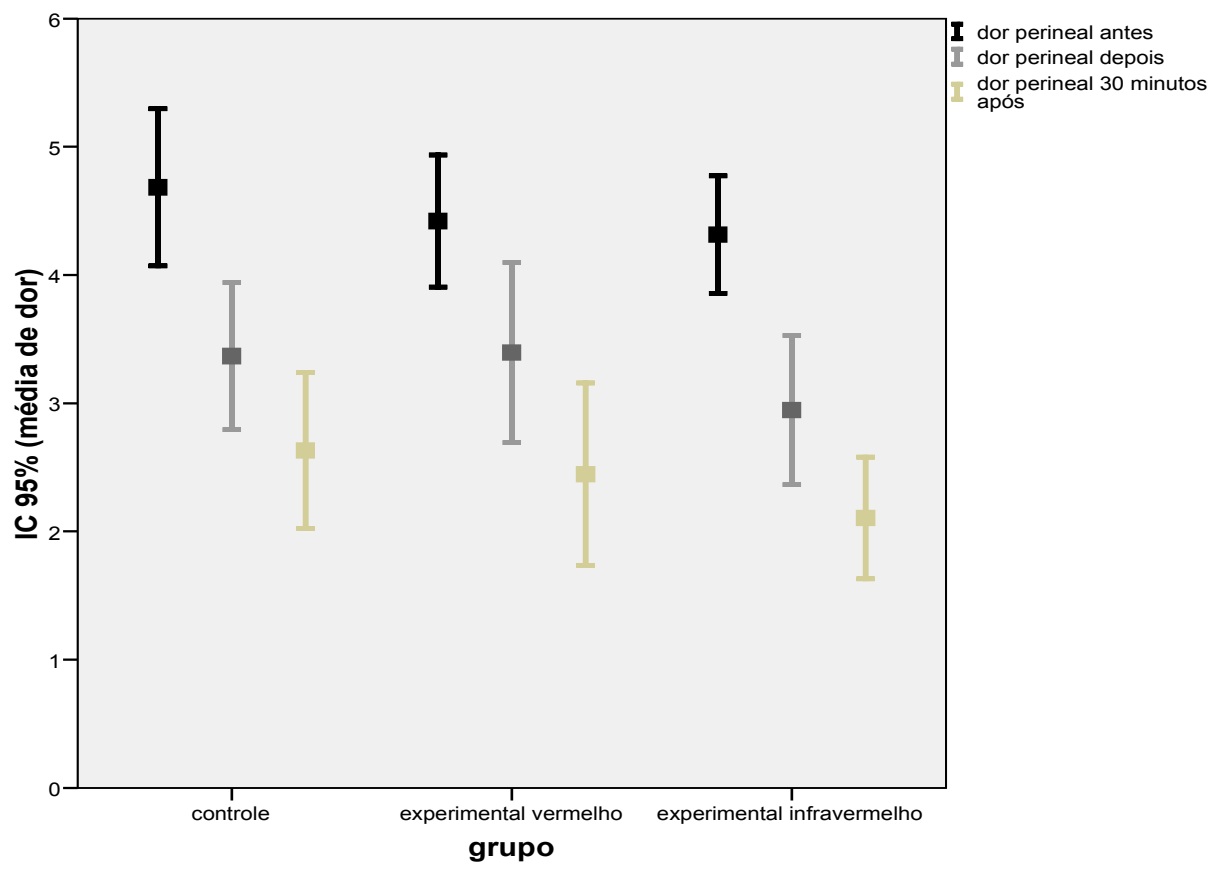

Ao avaliar os dados do Gráfico 1, constata-se a não existência de sobreposição dos intervalos de confiança nos momentos que antecederam a irradiação e 30 minutos após o procedimento nos três grupos estudados, indicando que houve alívio da dor na região perineal nos grupos controle e experimentais, vermelho e infravermelho. Observa-se ainda que houve similaridade na média da dor entre os três grupos nos três momentos de avaliação, indicando que não existe diferença na dor perineal entre os grupos. 
Considerando o critério clínico adotado no estudo como melhora de dor a redução de $30 \%$ no escore da dor perineal, observou-se que menos da metade das mulheres referiu alívio da dor $(44,8 \%)$ e destas, somente $24,6 \%$ (28) indicaram redução acima de 50\%, de acordo com a escala numérica (Tabela 9).

Tabela 9 - Porcentual de redução da dor perineal imediatamente após a intervenção com LBI nos grupos controle, experimental vermelho e infravermelho. Amparo Maternal, São Paulo, 2010.

\begin{tabular}{|c|c|c|c|c|c|c|c|c|}
\hline \multirow{3}{*}{$\begin{array}{l}\text { Redução da } \\
\text { intensidade da } \\
\text { dor }\end{array}$} & \multicolumn{6}{|c|}{ Grupos } & & \\
\hline & \multicolumn{2}{|c|}{ Controle } & \multicolumn{2}{|c|}{ Vermelho } & \multicolumn{2}{|c|}{ Infravermelho } & \multicolumn{2}{|c|}{ Total } \\
\hline & $\mathrm{n}$ & $\%$ & $\mathrm{n}$ & $\%$ & $\mathrm{n}$ & $\%$ & $\mathrm{n}$ & $\%$ \\
\hline Acima de $50 \%$ & 9 & 23,7 & 10 & 26,3 & 9 & 23,7 & 28 & 24,6 \\
\hline Entre 30 e $50 \%$ & 7 & 18,4 & 4 & 10,5 & 12 & 31,6 & 23 & 20,2 \\
\hline Menor que $30 \%$ & 22 & 57,9 & 24 & 63,2 & 17 & 44,7 & 63 & 55,3 \\
\hline
\end{tabular}

Quando analisadas as proporções de melhora da dor perineal 30 minutos após o uso do laser, constatou-se que aumentou o número de mulheres referindo alívio da dor $(68,4 \%)$ (Tabela 10$)$.

Tabela 10 - Porcentual de redução da dor perineal 30 minutos após a intervenção com LBI nos grupos controle, experimental vermelho e infravermelho. Amparo Maternal, São Paulo, 2010.

\begin{tabular}{|c|c|c|c|c|c|c|c|c|}
\hline \multirow{3}{*}{$\begin{array}{l}\text { Redução da } \\
\text { intensidade da } \\
\text { dor }\end{array}$} & \multicolumn{6}{|c|}{ Grupos } & & \\
\hline & \multicolumn{2}{|c|}{ Controle } & \multicolumn{2}{|c|}{ Vermelho } & \multicolumn{2}{|c|}{ Infravermelho } & \multicolumn{2}{|c|}{ Total } \\
\hline & $\mathrm{n}$ & $\%$ & $\mathrm{n}$ & $\%$ & $\mathrm{n}$ & $\%$ & $\mathrm{n}$ & $\%$ \\
\hline Acima de $50 \%$ & 13 & 34,2 & 17 & 44,7 & 19 & 50,0 & 49 & 43,0 \\
\hline Entre 30 e $50 \%$ & 14 & 36,8 & 5 & 13,2 & 10 & 26,3 & 29 & 25,4 \\
\hline Menor que $30 \%$ & 11 & 28,9 & 16 & 42,1 & 9 & 2,7 & 36 & 31,6 \\
\hline
\end{tabular}

De acordo com o teste Qui-quadrado, não houve diferença significativa entre os três grupos imediatamente $(p=0,234)$ e 30 minutos após a intervenção $(p=0,111)$, indicando que a redução na dor perineal foi similar entre os grupos.

Com relação à interferência da dor perineal no desenvolvimento das atividades cotidianas, antes da irradiação com LBI, observou-se que a maioria da 
puérperas referiu desconforto para sentar (109 - 95,6\%), andar (81 - 72,3\%), evacuar $(9-56,2 \%)$, dormir $(63-56,2 \%)$ e amamentar $(71-64,0 \%)$. O desconforto para urinar foi citado por $40(37,0 \%)$ mulheres, conforme apresentado nos dados da Tabela 11.

Convém mencionar que as puérperas que não realizaram as necessidades fisiológicas ou as atividades cotidianas até o momento da entrevista não foram consideradas nesta análise.

Tabela 11 - Frequência da interferência da dor perineal nas atividades cotidianas realizadas pelas puérperas antes da intervenção nos grupos controle, experimental vermelho e infravermelho. Amparo Maternal, São Paulo, 2010.

\section{Grupos}

\begin{tabular}{|c|c|c|c|c|c|}
\hline \multirow[t]{2}{*}{ Atividade } & Controle & Vermelho & Infravermelho & Total & \multirow[t]{2}{*}{ p-value ${ }^{\beta}$} \\
\hline & $\mathrm{n}(\%)$ & $\mathrm{n}(\%)$ & $\mathrm{n}(\%)$ & $\mathrm{n}(\%)$ & \\
\hline Sentar $(n=114)$ & & & & & 0,433 \\
\hline Não & $1(2,6)$ & $1(2,6)$ & $3(7,9)$ & $5(4,4)$ & \\
\hline Sim & $37(97,4)$ & $37(97,4)$ & $35(92,1)$ & $109(95,6)$ & \\
\hline $\operatorname{Andar}(n=112)$ & & & & & 0,296 \\
\hline Não & $9(23,7)$ & $14(36,8)$ & $8(22,2)$ & $31(27,7)$ & \\
\hline Sim & $29(76,3)$ & $24(63,2)$ & $28(77,8)$ & $81(72,3)$ & \\
\hline Urinar $(n=108)$ & & & & & 0,360 \\
\hline Não & $21(55,3)$ & $22(62,9)$ & $25(71,4)$ & $68(63,0)$ & \\
\hline Sim & $17(44,7)$ & $13(37,1)$ & $10(28,6)$ & $40(37,0)$ & \\
\hline Evacuar $(n=16)$ & & & & & 0,954 \\
\hline Não & $3(42,9)$ & $2(40,0)$ & $2(50,0)$ & $7(43,8)$ & \\
\hline Sim & $4(57,1)$ & $3(60,0)$ & $2(50,0)$ & $9(56,2)$ & \\
\hline Dormir $(n=112)$ & & & & & 0,105 \\
\hline Não & $16(42,1)$ & $12(32,4)$ & $21(56,8)$ & $49(43,8)$ & \\
\hline Sim & $22(57,9)$ & $25(67,6)$ & $16(43,2)$ & $63(56,2)$ & \\
\hline Amamentar $(n=$ & 111) & & & & 0,684 \\
\hline Não & $13(34,2)$ & $12(32,4)$ & $15(41,7)$ & $40(36,0)$ & \\
\hline Sim & $25(65,8)$ & $25(67,6)$ & $21(58,3)$ & $71(64,0)$ & \\
\hline
\end{tabular}

${ }^{\beta}$ Teste Qui-quadrado 
De acordo com o teste Qui-quadrado, não houve diferença significativa na interferência da dor perineal nas atividades diárias entre os três grupos, indicando similaridade entre eles, conforme mostram os dados da Tabela 11.

A Tabela 12 apresenta a interferência do desconforto perineal nas atividades cotidianas 30 minutos após a laserterapia.

Tabela 12 - Frequência da interferência da dor perineal nas atividades cotidianas realizadas pelas puérperas 30 minutos após intervenção nos grupos controle, experimental vermelho e infravermelho. Amparo Maternal, São Paulo, 2010.

\begin{tabular}{|c|c|c|c|c|c|}
\hline \multirow{3}{*}{ Atividade } & \multicolumn{3}{|c|}{ Grupos } & \multirow[b]{2}{*}{ Total } & \multirow{3}{*}{ p-value } \\
\hline & Controle & Vermelho & Infravermelho & & \\
\hline & n $(\%)$ & $\mathrm{n}(\%)$ & $\mathrm{n}(\%)$ & $\mathrm{n}(\%)$ & \\
\hline Sentar $(n=106)$ & & & & & 0,410 \\
\hline Não & $8(23,5)$ & $14(37,8)$ & $12(34,3)$ & $34(32,1)$ & \\
\hline Sim & $26(76,5)$ & $23(62,2)$ & $23(65,7)$ & $72(67,9)$ & \\
\hline Andar $(n=93)$ & & & & & 0,605 \\
\hline Não & $16(51,6)$ & $19(63,3)$ & $17(53,1)$ & $52(55,9)$ & \\
\hline Sim & $15(48,4)$ & $11(36,7)$ & $15(46,9)$ & $41(44,1)$ & \\
\hline Urinar $(n=27)$ & & & & & 0,161 \\
\hline Não & $9(81,8)$ & $3(50,0)$ & $9(90,0)$ & $21(77,8)$ & \\
\hline Sim & $2(18,2)$ & $3(50,0)$ & $1(10,0)$ & $6(22,2)$ & \\
\hline Dormir $(n=16)$ & & & & & 0,948 \\
\hline Não & $4(80,0)$ & $5(100)$ & $6(100)$ & $15(93,8)$ & \\
\hline Sim & $1(20,0)$ & - & - & $1(6,3)$ & \\
\hline Amamentar $(n=$ & & & & & 0,464 \\
\hline Não & $10(62,5)$ & $13(61,9)$ & $12(66,7)$ & $35(63,6)$ & \\
\hline Sim & $6(37,5)$ & $8(38,1)$ & $6(33,3)$ & $20(36,4)$ & \\
\hline
\end{tabular}

${ }^{\beta}$ Teste Qui-quadrado

Ao comparar as informações das Tabelas 11 e 12, constata-se que houve redução no número de mulheres que realizaram as atividades rotineiras no período de 30 minutos após o emprego do laser: sentar (de 114 para 106), deambular (de 112 para 93), urinar (de 108 para 27), evacuar (de 16 para nenhuma), dormir (de 112 para 
16) e amamentar (de 111 para 55). É importante destacar que nenhuma mulher referiu que evacuou no intervalo entre a irradiação e 30 minutos após a terapêutica.

Cerca de 30 minutos após a intervenção do LBI, menos da metade das mulheres apontou que a dor na região perineal interferiu na deambulação $(44,1 \%)$, na micção $(22,2 \%)$, no sono $(6,3 \%)$ e na amamentação $(36,4 \%)$, indicando que houve certo alívio da dor perineal para realizar tais atividades nos três grupos investigados. $\mathrm{Na}$ comparação entre estes grupos, não foram constatadas diferenças significativas na interferência da dor perineal em todas as atividades desenvolvidas com 30 minutos após a irradiação (Tabela 12).

Os dados da Tabela 13 apresentam a comparação apenas das atividades que, segundo as puérperas, tiveram interferência da dor perineal antes e 30 minutos após a aplicação do laser.

Tabela 13 - Comparação das atividades diárias que sofrem interferência da dor perineal referidas pelas puérperas, antes e 30 minutos após a intervenção nos grupos controle, experimental vermelho e infravermelho. Amparo Maternal, São Paulo, 2010 .

\begin{tabular}{|c|c|c|c|c|c|c|c|c|}
\hline \multirow{3}{*}{ Atividade } & \multicolumn{6}{|c|}{ Grupos } & & \\
\hline & \multicolumn{2}{|c|}{ Controle } & \multicolumn{2}{|c|}{ Vermelho } & \multicolumn{2}{|c|}{ Infravermelho } & \multicolumn{2}{|c|}{ Total } \\
\hline & $\mathrm{n}$ & $\%$ & $\mathrm{n}$ & $\%$ & $\mathrm{n}$ & $\%$ & $\mathrm{n}$ & $\%$ \\
\hline \multicolumn{9}{|l|}{ Sentar } \\
\hline Antes $(n=114)$ & 37 & 97,4 & 37 & 97,4 & 35 & 92,1 & 109 & 95,6 \\
\hline Depois $(n=106)$ & 26 & 76,5 & 23 & 62,2 & 23 & 65,7 & 72 & 67,9 \\
\hline \multicolumn{9}{|l|}{ Andar } \\
\hline Antes $(n=112)$ & 29 & 76,3 & 24 & 63,2 & 28 & 77,8 & 81 & 72,3 \\
\hline Depois $(n=93)$ & 15 & 48,4 & 11 & 36,7 & 15 & 46,9 & 41 & 44,1 \\
\hline \multicolumn{9}{|l|}{ Urinar } \\
\hline Antes $(n=108)$ & 17 & 44,7 & 13 & 37,1 & 10 & 28,6 & 40 & 37,0 \\
\hline Depois $(n=27)$ & 2 & 18,2 & 3 & 50,0 & 1 & 10,0 & 6 & 22,2 \\
\hline \multicolumn{9}{|l|}{ Dormir } \\
\hline Antes $(n=112)$ & 22 & 57,9 & 25 & 67,6 & 16 & 43,2 & 63 & 56,2 \\
\hline Depois $(n=16)$ & 1 & 20,0 & - & & - & & 1 & 6,3 \\
\hline \multicolumn{9}{|l|}{ Amamentar } \\
\hline Antes (n=111) & 25 & 65,8 & 25 & 67,6 & 21 & 58,3 & 71 & 64,0 \\
\hline Depois $(\mathrm{n}=55)$ & 6 & 37,5 & 8 & 38,1 & 6 & 33,3 & 20 & 36,4 \\
\hline
\end{tabular}


Por meio da análise da Tabela 13, percebe-se com maior clareza que houve redução na frequência de citação de interferência da dor perineal no desenvolvimento das atividades diárias após a aplicação da irradiação nos três grupos analisados. Merece destacar que, em ambos os momentos de avaliação, o desconforto causado pela dor perineal ao sentar foi citado com maior frequência pelas puérperas, constituindo a principal atividade prejudicada pela dor no local.

As participantes da pesquisa foram questionadas quanto à sua opinião sobre a aplicação do laser (Tabela 14).

Tabela 14 - Opinião das puérperas dos grupos controle, experimental vermelho e infravermelho sobre a laserterapia. Amparo Maternal, São Paulo, 2010.

\begin{tabular}{|c|c|c|c|c|c|c|c|c|}
\hline \multirow{3}{*}{ Opinião } & \multicolumn{6}{|c|}{ Grupos } & \multirow{2}{*}{\multicolumn{2}{|c|}{ Total }} \\
\hline & \multicolumn{2}{|c|}{ Controle } & \multicolumn{2}{|c|}{ Vermelho } & \multicolumn{2}{|c|}{ Infravermelho } & & \\
\hline & $\mathrm{n}$ & $\%$ & $\mathrm{n}$ & $\%$ & $\mathrm{n}$ & $\%$ & $\mathrm{n}$ & $\%$ \\
\hline Muito bom & 7 & 18,9 & 10 & 27,0 & 8 & 21,1 & 25 & 22,3 \\
\hline Bom & 22 & 59,5 & 25 & 67,6 & 29 & 76,3 & 76 & 67,9 \\
\hline Regular & 8 & 21,6 & 2 & 5,4 & 1 & 2,6 & 11 & 9,8 \\
\hline Total & $37^{\mathrm{a}}$ & 100 & $37^{\mathrm{a}}$ & 100 & 38 & 100 & 112 & 100 \\
\hline
\end{tabular}

Os achados apontaram que grande número das puérperas $(96,0 \%)$ submetidas à laserterapia teve opinião favorável ao procedimento realizado. Apenas três mulheres $(4,0 \%)$ disseram que a intervenção foi regular. Não houve diferença estatística na comparação das opiniões das mulheres nos grupos experimental, vermelho e infravermelho $(p=0,053)$.

As puérperas também foram questionadas com relação ao conforto durante a irradiação com o LBI (Tabela 15). 
Tabela 15 - Conforto referido pelas puérperas dos grupos controle, experimental vermelho e infravermelho durante a laserterapia. Amparo Maternal, São Paulo, 2010.

\begin{tabular}{|c|c|c|c|c|c|c|c|c|}
\hline \multirow{3}{*}{ Confortável } & \multicolumn{6}{|c|}{ Grupos } & \multirow{2}{*}{\multicolumn{2}{|c|}{ Total }} \\
\hline & \multicolumn{2}{|c|}{ Controle } & \multicolumn{2}{|c|}{ Vermelho } & \multicolumn{2}{|c|}{ Infravermelho } & & \\
\hline & $\mathrm{n}$ & $\%$ & $\mathrm{n}$ & $\%$ & $\mathrm{n}$ & $\%$ & $\mathrm{n}$ & $\%$ \\
\hline Sim & 33 & 86,8 & 35 & 92,1 & 36 & 94,7 & 104 & 91,2 \\
\hline Não & 5 & 13,2 & 3 & 7,9 & 2 & 5,3 & 10 & 8,8 \\
\hline Total & 38 & 100 & 38 & 100 & 38 & 100 & 114 & 100 \\
\hline
\end{tabular}

$\mathrm{p}=0,464$ (teste Qui-quadrado)

Para a maioria das mulheres submetidas à laserterapia, o procedimento foi considerado confortável $(93,4 \%)$, mas $5(6,6 \%)$ puérperas mencionaram desconforto durante a realização do procedimento, destas uma referiu que sentiu incômodo e quatro que a intervenção foi dolorosa.

Quando comparadas as informações entre os grupos vermelho e infravermelho, constatou-se que não houve diferença estatística significativa $(p=0,464)$ em relação ao conforto do tratamento, demonstrando que a opinião das mulheres sobre a terapêutica foi similar.

Para avaliar a possibilidade da utilização do laser em baixa intensidade para alívio da dor perineal em outro pós-parto, foi questionado se as puérperas fariam novamente a irradiação na região do períneo. A grande maioria (110 - 96,5\%) referiu que repetiria o tratamento, e somente $4(3,5 \%)$ disseram que não o faria, porque não perceberam alívio da dor perineal após a intervenção (Tabela 16).

Tabela 16 - Distribuição das puérperas nos grupos controle, experimental vermelho e infravermelho, de acordo com a possibilidade de repetição do tratamento. Amparo Maternal, São Paulo, 2010.

\section{Grupos}

\begin{tabular}{lllllllll}
\multirow{2}{*}{ Repetiria } & \multicolumn{2}{c}{ Controle } & \multicolumn{2}{c}{ Vermelho } & \multicolumn{2}{c}{ Infravermelho } & \multicolumn{2}{c}{ Total } \\
\cline { 2 - 7 } & $\mathrm{n}$ & $\%$ & $\mathrm{n}$ & $\%$ & $\mathrm{n}$ & $\%$ & $\mathrm{n}$ & $\%$ \\
\hline Sim & 37 & 97,4 & 36 & 94,7 & 37 & 97,4 & 110 & 96,5 \\
Não & 1 & 2,6 & 2 & 5,3 & 1 & 2,6 & 4 & 3,5 \\
\hline \multirow{2}{*}{ Total } & 38 & 100 & 38 & 100 & 38 & 100 & 114 & 100 \\
\hline $\mathrm{p}=0,772$ (teste Qui-quadrado) & & & & & &
\end{tabular}


Não foi encontrada diferença estatística significativa $(p=0,772)$ entre as puérperas dos três grupos quanto à repetição do tratamento com laserterapia, indicando similaridade na opinião das mulheres com relação ao tratamento proposto. 
6 DISCUSSÃO 
O período pós-natal e as morbidades decorrentes do parto têm sido relativamente negligenciados pelos profissionais de saúde e familiares, por considerarem essa fase como um momento para descanso e recuperação da saúde da mulher, e por isso, focam a atenção nos cuidados ao RN (Glazener, 2005; Alexandre et al., 2006; Pitangui, 2009; Oliveira, 2009).

No entanto, as morbidades maternas decorrentes do parto vêm sendo mais estudadas pela comunidade científica nos últimos anos, como afirmam Levitt et al. (2004) ao apontarem que, entre 1999 e 2003, foram desenvolvidos 671 estudos científicos com foco nos cuidados realizados no período pós-parto, indicando a recente preocupação dos profissionais de saúde com a qualidade de vida da puérpera.

O trauma perineal é um exemplo de problema de saúde diretamente relacionado ao parto vaginal, cuja gravidade associa-se à assistência prestada durante o nascimento, à natureza e à extensão da lesão perineal (Glazener, 2005), que vem sendo foco de diversos estudos científicos com o objetivo de prevenir a lesão e promover cuidados com o trauma, tais como: o alívio da dor e do desconforto, o estímulo à cicatrização e a prevenção de infecções.

Conforme referido anteriormente, a episiotomia é uma intervenção realizada com frequência nos partos normais que pode interferir diretamente na qualidade de vida da puérpera, e está associada a diversas morbidades maternas (Carroli, Miquilini, 2009). Na maternidade campo deste estudo, durante o período de coleta de dados, ocorreram 1.720 partos espontâneos, dos quais a maioria das mulheres $(65,1 \%$ - 957) apresentou traumatismo perineal, destas 31,4\% (541) tiveram laceração espontânea e 24,2\% (416) episiotomia, considerando tanto as nulíparas como as multíparas.

É importante mencionar que a equipe obstétrica do CPN do Amparo Maternal atua conforme as prerrogativas da Humanização da Assistência ao Parto, preconizadas pela OMS e pelo Ministério da Saúde do Brasil que recomenda o mínimo de intervenções durante o parto e o uso restrito de infusão endovenosa de ocitocina e de episiotomia (OMS, 1996; Brasil, 2001), justificando as baixas taxas do procedimento na instituição estudada.

Maternidades que não seguem essas recomendações podem apresentar índices excessivamente elevados desse procedimento. Estudo descritivo desenvolvido em um 
hospital-maternidade do Estado de São Paulo constatou uma taxa de 90,24\% de episiotomia nos partos normais, independente da história obstétrica (Santos et al., 2008). Em estudo realizado em um hospital universitário de São Paulo, Oliveira e Miquilini (2005) apontaram que dos 122 partos normais ocorridos na maternidade no mês de outubro de 2000 , em 76,2\% foram realizadas episiotomia médio-lateral direita, dos quais 95,2\% eram primigestas, corroborando com a afirmativa de Althabe et al. (2002) que reportaram que 94,2\% das primíparas assistidas no Brasil sofrem a intervenção.

A dor na região do períneo é o principal sintoma associado ao trauma local, sendo uma condição vivenciada com frequência pelas puérperas (Bick, 2005; Oliveira, 2009). A dor perineal pode surgir a partir das primeiras horas após o parto e persistir por muitos meses (Carroli, Mignini, 2009). Alguns estudos constataram 9,8\% de mulheres referindo dor perineal no período de Greenberg (Almeida, Riesco, 2008), 92\% nas primeiras 24 horas do puerpério e 7\% com 6 semanas de pós-parto (Macarthur, Macarthur, 2004) e 48\% 2 meses após o parto (Declerq et al., 2008).

Conforme referido anteriormente, a dor perineal está associada à prática rotineira da episiotomia (Declerq et al., 2008; Carroli, Mignini, 2009). Evitar a incisão perineal e reparar apropriadamente quando houver o traumatismo são as condutas primárias para evitar ou reduzir a dor e o desconforto perineais pós-natal (Enkin et al., 2005). Entretanto, ainda não existem evidências disponíveis suficientes que apontem a melhor maneira de se prevenir e tratar os traumas perineais (Albers, 2005).

Uma grande variedade de medidas terapêuticas medicamentosas e não medicamentosas são empregadas na prática clínica para o alívio da dor perineal. No entanto, recentes revisões sistemáticas investigando a eficácia dos métodos farmacológicos, como os analgésicos orais (Chou et al., 2010), tópicos (Hedayati et al., 2005) e retais (Hedayati et al., 2003), e das medidas não medicamentosas, como a ultrassonografia (Hay-Smith, 1998) e o resfriamento tópico (East et al., 2007), apontaram limitadas evidências para indicar a efetividade dessas terapias na redução da dor perineal pós-parto.

Considerando que o laser é uma terapêutica analgésica utilizada com frequência pela fisioterapia e pela odontologia para tratamento de dores agudas e crônicas, este estudo teve como finalidade verificar a efetividade do laser em baixa 
intensidade para o alívio da dor perineal em puérperas com parto normal submetidas a episiotomia médio-lateral direita, durante o período de internação hospitalar.

Participaram da pesquisa 114 mulheres, distribuídas em três grupos de tratamento: grupo experimental infravermelho $(\mathrm{n}=38)$ e grupo experimental vermelho $(\mathrm{n}=38)$, que foram comparados com o tratamento placebo, realizado no grupo controle $(\mathrm{n}=38)$.

Os resultados apontaram que os três grupos analisados foram homogêneos em relação às características sociodemográficas, como a idade $(\mathrm{p}=0,616)$, a cor da pele $(\mathrm{p}=0,424)$, a escolaridade $(\mathrm{p}=0,899)$, o estado marital $(\mathrm{p}=0,198)$, ter trabalho remunerado $(p=0,371)$, ter o hábito de fumar $(p=0,141)$ e a presença de alergia medicamentosa $(\mathrm{p}=0,584)$.

A similaridade entre os grupos de comparação também foi constatada nas informações referentes à história obstétrica, como o número de gestações $(p=0,343)$, de partos $(p=0,068)$ e de abortamentos anteriores $(p=0,327)$ e presença de um acompanhante durante o trabalho de parto e parto $(\mathrm{p}=0,121)$. Convém mencionar que neste estudo um grande número de mulheres que tiveram episiotomia $(92,1 \%)$ era constituído de nulípara, corroborando a ideia disseminada por Rezende (2008) de que a episiotomia é quase sempre indispensável nas primiparturientes.

Merece comentar que as justificativas para a realização da episiotomia não foram descritas em 89,5\% (102) dos prontuários. Estudos realizados anteriormente na mesma maternidade apontaram o registro das justificativas em $89 \%$ (Leventhal, 2008) e $82,9 \%$ dos casos (Oliveira, 2009), ao contrário dos resultados obtidos na presente pesquisa. Dentre os 12 prontuários que apresentaram os motivos para a prática da episiotomia, a principal indicação descrita foi rigidez perineal (seis casos), corroborando as indicações apresentadas nos estudos citados (Leventhal, 2008; Oliveira, 2009) e com o trabalho realizado por Oliveira e Miquilini (2005).

Também foram encontradas semelhanças entre os grupos de comparação nas seguintes variáveis quantitativas: idade gestacional $(\mathrm{p}=0,825)$, peso do concepto $(\mathrm{p}=0,924)$, perímetro cefálico do bebê $(\mathrm{p}=0,646)$, boletim de Apgar no primeiro e quinto minutos de vida do $\mathrm{RN}$ ( $\mathrm{p}=0,296$ e $\mathrm{p}=0,134$, respectivamente), extensão da episiotomia $(p=0,889)$, quantidade de analgésicos ingeridos $(p=0,211)$, tempo entre a ingestão desta medicação e o emprego do laser $(p=0,953)$, número de outros medicamentos ingeridos $(p=0,981)$ e o tempo entre o parto e a irradiação $(p=0,110)$. 
Os achados indicam que os grupos apresentaram características semelhantes no início da comparação, podendo-se avaliar o impacto do laser em baixa intensidade na redução da dor perineal, com o mínimo de efeitos de outros fatores que poderiam interferir nos resultados (Jadad, 1998).

Na maternidade estudada a prescrição médica de rotina no pós-parto normal inclui a administração de medicação via oral e, por isso, 97,4\% das participantes deste estudo foram medicadas com dipirona sódica, 2,6\% receberam o acetaminofeno/paracetamol e $80,7 \%$ utilizaram o diclofenaco de sódio para controle da dor pós-parto. Nos grupos experimentais, vermelho e infravermelho, até o momento da irradiação, foram ingeridos em média $3,6 \pm 1,6$ e 4,0 $\pm 2,1$ comprimidos, respectivamente; enquanto no grupo controle, a média foi de 4,5 $\pm 2,2$. Não houve diferença estatística significante na quantidade de comprimidos ingeridos nos três grupos de comparação $(\mathrm{p}=0,211)$.

O tempo médio entre a administração de analgésicos e a irradiação com laser em baixa intensidade foi superior a 5 horas nos três grupos de comparação, sem apresentar diferença estatística $(\mathrm{p}=0,953)$, sendo $5,4 \pm 2,1$ horas no grupo controle, $5,2 \pm 1,9$ horas no vermelho e 5,5 $\pm 2,1$ horas no infravermelho. No entanto, observou-se que mesmo após a administração dos analgésicos orais, um número expressivo de mulheres referiu dor na região perineal igual ou maior que 3 na Escala Numérica, corroborando com os achados do ensaio clínico desenvolvido por Steen et al. (2000), e indicando que o tratamento medicamentoso foi insuficiente para o alívio dessa dor.

Revisões sistemáticas que analisaram a eficácia analgésica do acetaminofeno e da dipirona para alívio da dor pós-operatória indicaram que as medicações possuem efetiva ação analgésica e poucos efeitos colaterais (Toms et al., 2008; Edwards et al., 2010). Chou et al. (2010) em revisão sistemática sobre o uso de uma dose única de paracetamol no controle da dor perineal aguda constataram que maior quantidade de mulheres que recebeu a medicação reportou alívio da dor comparadas ao grupo placebo $(\mathrm{RR}=2,14$; IC95\% 1,59 - 2,89), indicando que o fármaco é mais efetivo que o placebo, embora a qualidade dos estudos não esteja clara.

Outra revisão sistemática demonstrou que uma única dose do antiinflamatório não esteroide - diclofenaco, é eficaz para o controle da dor de intensidade moderada a grave em adultos no pós-operatório, indicando que $50 \%$ a 
60\% dos 1.512 participantes dos estudos vivenciaram alívio da dor (Derry et al., 2009).

O uso do analgésico poderia ser considerado uma limitação deste estudo, mas também pode ser analisado como uma condição pragmática, visto que geralmente não há como evitar que as mulheres recebam a medicação prescrita de rotina. Merece comentar que os estudos pragmáticos consideram os elementos da realidade e fortalecem a validade externa dos resultados encontrados, aumentando a possibilidade de aplicabilidade na prática clínica.

Considerando as necessidades individuais, é provável que, para obter o alívio da dor perineal, haja necessidade do uso concomitante de tratamentos sistêmicos e localizados (Steen, 2005, East et al., 2007). Neste sentido, buscou-se avaliar a efetividade do LBI na redução da dor perineal sem a restrição da ingesta de analgésicos orais.

Embora os reais mecanismos de ação da laserterapia sejam desconhecidos, o efeito analgésico do laser pode ser explicado pela redução da inflamação local, pela interferência na mensagem prejudicando a transmissão do estímulo doloroso local, pela redução do limiar de excitabilidade dos receptores dolorosos, pela normalização e equilíbrio da energia no local da lesão e pelo estímulo a liberação de betaendorfinas, conforme já referido anteriormente (Tunér, Hode, 1999; Brugnera, Ladalardo, Cruz, 2007; Genovese, 2007).

Pesquisas sobre a utilização do LBI para a redução da dor tiveram início há mais de 30 anos (Chow et al., 2009). Atualmente, diversos estudos científicos in vitro $e$ in vivo, incluindo seres humanos, estão sendo desenvolvidos, utilizando diferentes protocolos de tratamento para avaliar os efeitos analgésicos do LBI. Entretanto, os resultados destes estudos apresentam conclusões divergentes a respeito da eficácia dessa terapia no alívio da dor aguda ou crônica. Enwemeka (2009) acrescenta que mais de $30 \%$ dos estudos sobre laserterapia publicados não apresentam detalhes relevantes da irradiação e utilizam medições imprecisas e dosagens incorretas nos protocolos de irradiação, comprometendo a avaliação da eficácia do tratamento no alívio da dor.

Revisões sistemáticas desenvolvidas pela Biblioteca Cochrane sobre a eficácia do LBI na redução da dor da artrite reumatoide (Brosseau et al., 2005), da osteoartrite (Brosseau et al., 2007) e da dor lombar inespecífica (Yousefi-Nooraie et 
al., 2008), não apresentaram conclusões definitivas sobre o assunto em razão da heterogeneidade das populações estudadas e das terapêuticas aplicadas, corroborando a afirmação de Enwemeka (2009).

Ao realizar a leitura de artigos científicos sobre o tratamento com o laser em baixa intensidade no alívio da dor desencadeada por afecções osteomusculares, observou-se que muitas pesquisas não apresentaram informações metodológicas importantes, referentes ao protocolo de irradiação e ao desenho de pesquisa. Os ensaios clínicos desenvolvidos com mais rigor metodológico resultaram em conclusões divergentes sobre a eficácia do LBI, conforme descrito a seguir.

Meireles et al. (2010) desenvolveram um ensaio clínico randomizado e controlado com duplo cegamento, para avaliar a efetividade do LBI na redução da dor e na melhora na função das mãos de pacientes com artrite reumatoide. Os pesquisadores analisaram 82 pacientes, divididos em grupo placebo laser $(n=41)$ e grupo laser $(\mathrm{n}=41)$. Os indivíduos do grupo laser foram tratados com laser AlGaAs, com comprimento de onda de $785 \mathrm{~nm}$, luz infravermelha, poder $70 \mathrm{~mW}$ e dose de 3 $\mathrm{J} / \mathrm{cm}^{2}$, irradiado de modo pontual, por contato direto, duas vezes por semana durante dois meses, perfazendo 16 sessões de laserterapia. $\mathrm{Na}$ análise intragrupo, comparando os escores obtidos antes e ao final do tratamento, os autores encontraram diferenças significativas na dor, na capacidade funcional e na inflamação $(p<0,05)$. Entretanto, na análise entre os grupos de comparação, não foram constatadas diferenças estatísticas na dor geral na mão direita $(p=0,163)$ e na mão esquerda $(p=0,154)$, e também não houve diferença na funcionalidade das mãos. Nesse estudo, os autores concluíram que o laser não foi efetivo com o comprimento de onda, a dose e o poder empregado.

Resultados semelhantes foram encontrados no ensaio clínico controlado e randomizado com duplo mascaramento que avaliou a efetividade do LBI no tratamento da dor na articulação temporomandibular (ATM). A terapêutica foi realizada empregando-se o comprimento de onda de $632,8 \mathrm{~nm}$, no feixe de luz vermelha, com poder de $30 \mathrm{~mW}$ e dose de 1,5 J, aplicada diretamente sobre a articulação duas a três vezes por semana, durante 8 semanas. Os pesquisadores também não constataram diferença significativa na redução da dor entre os grupos laser $(n=26)$ e sham $(n=26)$ nos períodos de 2 semanas $(p=0,618), 4(p=0,384)$ e 8 
semanas $(\mathrm{p}=0,961)$, demonstrando que o laser não foi melhor que o placebo na redução da dor da ATM (Emshoff et al., 2008).

Em contraponto, ensaio clínico com duplo cegamento conduzido por Chow et al. (2006) para determinar a eficácia do LBI no alívio da cervicalgia crônica constatou que o laser promoveu benefícios clínicos relevantes no alívio desse desconforto. A amostra foi composta por 90 indivíduos com queixa de dor cervical durante um tempo igual ou superior a 3 meses, divididos randomicamente em grupo laser $(n=45)$ e grupo sham $(n=45)$. O protocolo terapêutico empregado foi o laser com feixe infravermelho $(830 \mathrm{~nm})$, densidade de poder de $0,67 \mathrm{~W} / \mathrm{cm}^{2}$ e poder de $300 \mathrm{~mW}$, aplicado em até 50 pontos na região cervical, durante 7 semanas consecutivas, perfazendo no total de 14 sessões. A dor cervical foi avaliada antes, depois e um mês após o término do tratamento, por meio da Escala Analógica Visual. A média de alívio da dor foi significativamente maior no grupo laser comparado ao grupo sham $(\mathrm{p}<0,001)$ no início do tratamento e um mês após completar a terapia. Nesse período, houve uma redução na média dor de 2,7 pontos (IC 95\% -3,3 a -2,1) no grupo laser e um aumento de 0,3 pontos (IC 95\% - - 4 , a 0,9) no grupo sham, indicando que o protocolo utilizado promoveu alívio na dor cervical crônica.

Estudo desenvolvido por Hakgüder et al. (2003) para avaliar o efeito do LBI na síndrome de dor miofascial, utilizando a Escala Analógica Visual, a avaliação termográfica e algométrica - técnica que mensura a fisiologia do sistema nociceptivo em indivíduos normais ou portadores de diferentes síndromes álgicas, observou efeito benéfico da irradiação no alívio dessa dor. Foram analisados 62 pacientes com a síndrome, divididos aleatoriamente em grupo laser $(n=31)$ e grupo controle $(n=31)$. Os indivíduos do grupo laser realizaram exercícios de alongamento e foram irradiados diariamente por 10 dias com um aparelho laser com semicondutor de GaAsAl, emitindo luz infravermelha, com comprimento de onda de $780 \mathrm{~nm}$, poder de $10 \mathrm{~mW}$ e dosagem de $5 \mathrm{~J} / \mathrm{cm}^{2}$, enquanto o grupo controle recebeu apenas os exercícios de alongamento. Os autores encontraram diferença significativa nos escores da dor na comparação entre os grupos, com redução significativa da dor no grupo laser imediatamente após a irradiação e 3 semanas depois, considerando a dor referida pelos pacientes $(p<0,001)$, os valores algométricos $(p<0,001)$ e os 
termográficos $(\mathrm{p}<0,01)$. Uma das limitações dessa pesquisa foi não apresentar um grupo placebo para comparação.

Resultados similares nos escores de dor foram constatados no estudo randomizado, controlado e duplo-cego para avaliar a eficácia do LBI na redução da dor na musculatura mastigatória. Foram avaliados 16 indivíduos com disfunção miofascial, desta vez comparando grupo laser e sham. A irradiação foi realizada associando dois diferentes comprimentos de onda (660 nm e $890 \mathrm{~nm}$ ) na mesma sessão de tratamento. Pela análise intragrupo, observou-se redução significativa nos escores médios da dor imediatamente após a terapia em ambos os grupos - laser $(p=0,001)$ e sham $(p=0,049)$ e uma semana após o tratamento - laser $(p=0,003)$ e sham $(p=0,028)$. Na comparação entre os grupos, foi constatada diferença nos escores de dor, com redução estatística da dor no grupo laser comparado ao sham ( $\mathrm{p}=0,031)$ ao final do tratamento (Shirani et al., 2009).

Rampini et al. (2009) em revisão de literatura afirmam que o emprego do LBI na prevenção e tratamento da mucosite oral induzida pelo tratamento de quimioterapia e/ou radioterapia como protocolo de tratamento oncológico também está sendo estudado com o propósito de avaliar a eficácia da laserterapia na redução da incidência da mucosite oral e da dor local.

Schubert et al. (2007) desenvolveram um estudo randomizado e controlado com 70 pacientes submetidos à transplante de células hematopoiéticas, com tratamento quimioterápico. O estudo consistiu na comparação de dois lasers de GaAlAs com diferentes níveis de intensidade, vermelho (650 nm e $40 \mathrm{~mW}$ ) e infravermelho (780 nm e $60 \mathrm{~mW}$ ) com um grupo sham. O Twin Laser® foi utilizado nessa pesquisa, com contato direto na mucosa oral em seis diferentes áreas, a partir do primeiro dia pós-transplante, uma vez ao dia, no período de 7 a 13 dias. Os autores constataram redução significativa na gravidade da mucosite oral $(p=0,003)$ e no escore da dor $(\mathrm{p}=0,01)$ somente nos indivíduos tratados com laser vermelho comparado ao grupo sham. Não houve diferença estatística entre o grupo infravermelho e o sham. Os autores concluíram que a profilaxia com LBI com 650 $\mathrm{nm}$ é mais efetiva na redução da gravidade da mucosite e no alívio da dor que o laser $780 \mathrm{~nm}$.

Ensaio clínico semelhante publicado mais recentemente com 22 pacientes submetidos ao transplante de células hematopoiéticas, em tratamento radioterápico e 
quimioterápico, observou que o grupo tratado com LBI $(n=12)$ apresentou menor frequência de mucosite oral com diferença estatística $(\mathrm{p}=0,02)$ comparado ao grupo controle, que foi submetido ao tratamento convencional. A gravidade das lesões orais também foi significativamente menor no grupo laser $(p=0,026)$. Nesse estudo, a mucosa oral também foi irradiada com o equipamento Twin Laser ${ }^{\circledR}$, nos comprimentos de onda vermelho $(660 \mathrm{~nm})$ e infravermelho $(780 \mathrm{~nm})$, por contato direto, com dose de $6,3 \mathrm{~J} / \mathrm{cm}^{2}$ e $25 \mathrm{~mW}$, durante 10 segundos, uma vez por dia no período de 15 dias. Constatou-se que os pacientes tratados com LBI tiveram menor frequência de mucosite oral e lesões de menor gravidade que os pacientes com o tratamento convencional, indicando que a terapia foi efetiva no tratamento da doença (Khouri et al., 2009).

Os resultados desses estudos apontam que a terapia com laser em baixa intensidade para prevenção e tratamento de mucosite oral nos pacientes oncológicos apresenta-se como uma opção viável, corroborando os resultados da revisão de literatura desenvolvida por Rampini et al. (2009).

Ainda no contexto da saúde bucal, Turhani et al. (2006) em ensaio clínico com mascaramento dos participantes analisaram o efeito de uma única dose de LBI na percepção da dor em 76 indivíduos que colocaram aparelho fixo. Os participantes foram divididos aleatoriamente em grupo placebo laser $(n=38)$ e grupo laser $(n=38)$, que recebeu irradiação pontual com $670 \mathrm{~nm}, 140 \mathrm{~mW} / \mathrm{cm}^{2}$ por 30 segundos em cada lado do dente, em sessão única. O estudo constatou que houve redução significativa na prevalência de dor no grupo laser entre 6 e 30 horas após a terapia, comparado ao placebo $(\mathrm{p}<0,05)$ mas, sem diferença estatística na intensidade da dor referida em ambos os grupos.

Ensaio clínico randomizado, controlado e com cegamento dos participantes avaliou o alívio da dor em úlceras orais provocadas pela estomatite. Foi utilizado o laser de $\mathrm{CO}_{2}$ em baixa intensidade, com comprimento de onda de $10,6 \mathrm{~nm}$ e $1 \mathrm{~W}$ de potência, de modo desfocado, também em uma única sessão. Houve redução considerável nos escores de dor idiopática e de contato imediatamente após a aplicação do laser, passando de $6,0 \pm 1,3$ e $8,4 \pm 1,3$ para $0,07 \pm 0,3$ e 0,7 $\pm 0,8$; respectivamente. No grupo placebo, tratado com gel aquoso sem anestésico, não foram observadas mudanças nos escores de dor idiopática e de contato. As diferenças 
entre os grupos foram estatisticamente significativas $(p<0,001)$, demonstrando que o LBI pode reduzir a dor da afta (Zand et al., 2009).

Estudo desenvolvido na Faculdade de Odontologia da Universidade de São Paulo - Brasil avaliou a efetividade do LBI na prevenção e na redução da gravidade das lesões provocadas pelo vírus de herpes labial. Foi utilizado o mesmo equipamento empregado no atual estudo (Twin Laser ${ }^{\circledR}$ ), com uma sessão por semana, durante 10 semanas. Os indivíduos foram divididos aleatoriamente nos grupos controle $(n=30)$, com aplicação tópica de aciclovir e experimental $(n=41)$, com irradiação de laser com comprimento de onda de $780 \mathrm{~nm}, 60 \mathrm{~mW}$ e $3,0 \mathrm{~J} / \mathrm{cm}^{2}$, de modo pontual. Constatou-se diminuição significativa no tamanho das lesões ( $p=0,013)$ e no edema local $(\mathrm{p}=0,031)$ no grupo experimental comparado ao controle, contudo, sem redução significante nos escores de dor $(\mathrm{p}=0,051)$ (Carvalho et al., 2010).

Em um contexto geral, observa-se que o LBI apresenta efeitos benéficos na prevenção de lesões na cavidade oral e no alívio da dor proveniente dessas lesões.

No campo da saúde da mulher, alguns pesquisadores estudaram a utilização do laser em baixa intensidade no tratamento de linfedema pós-mastectomia (Piller, Thelander, 1998; Carati et al., 2003; Kaviani et al., 2006; Lau Cheing, Cheing, 2009).

Estudo australiano com amostra composta por 10 mulheres com linfedema unilateral após o esvaziamento axilar (mastectomia radical) e radioterapia para tratamento do câncer da mama, que receberam 16 sessões de laserterapia por mais de 10 semanas, constatou que houve redução do edema no braço afetado após a irradiação, com relatos de melhora da dor e da mobilidade do membro. No entanto, no estudo não houve grupo de comparação (Piller, Thelander, 1998).

Resultados similares foram constatados no ensaio clínico randomizado controlado e com duplo cegamento, também desenvolvido na Austrália. Participaram do estudo 61 mulheres pós-mastectomia, divididas em grupo placebo $(n=28)$ e laser $(n=33)$, que receberam uma ou duas sessões do LBI na região axilar do braço afetado. O protocolo utilizado foi a luz com $904 \mathrm{~nm}$ de comprimento de onda, energia pulsátil média de $5 \mathrm{~mW}$, energia total por ponto de $300 \mathrm{~mJ}$, dose de $1,5 \mathrm{~J} / \mathrm{cm}^{2}$ e dose total de $5,1 \mathrm{~J}$, por contato direto na região afetada, durante 3 semanas. Observou-se que houve redução no volume do membro afetado 3 meses após o 
tratamento sobretudo nos indivíduos que foram tratados com dois ciclos de LBI, mas sem diferença significativa comparado ao tratamento placebo (Carati et al., 2003).

Estudo desenvolvido no Irã com 11 mulheres divididas em grupo laser $(n=6)$ e grupo sham $(n=5)$ obteve diferentes resultados com relação à terapêutica no tratamento de linfedema pós-mastectomia. O tratamento foi realizado com o laser GaAs com comprimento de onda de $890 \mathrm{~nm}$ e $1,5 \mathrm{~J} / \mathrm{cm}^{2}$ aplicados em cinco pontos do braço e na região axilar, 3 vezes por semana, durante 3 semanas, com repetição do protocolo após o intervalo de 8 semanas, perfazendo 18 sessões de irradiação. Constatou-se redução na circunferência do braço afetado e na dor local em ambos os grupos, sem diferença significativa ( $\mathrm{p}=0,31 ; \mathrm{p}=0,6$, respectivamente) (Kaviani et al., 2006).

O estudo de Lau Cheing e Cheing (2009), realizado na China, comparou 21 mulheres com linfedema pós-mastectomia unilateral alocadas aleatoriamente no grupo laser, que receberam 12 sessões de laserterapia, e no grupo controle, sem a irradiação do laser. Houve redução no volume do braço no grupo laser, com diferença significativa entre os grupos $(p<0,05)$, com efeitos que duraram 4 semanas após o início do tratamento.

Embora as pesquisas citadas anteriormente apresentem efeitos benéficos do LBI no tratamento de linfedema pós-mastectomia, elas ainda mencionam a necessidade de desenvolver outros estudos sobre a avaliação dos efeitos analgésicos da laserterapia, para que o tratamento seja indicado na prática clínica.

$\mathrm{Na}$ área da obstetrícia, foram encontrados dois estudos que utilizaram o laser em baixa intensidade no tratamento da episiotomia, mas com pouca qualidade metodológica.

O estudo desenvolvido na República Checa comparou os efeitos da fototerapia utilizando três fontes de luz - o laser em baixa intensidade, a luz halógena e o Diodo Emissor de Luz (LED) - com um grupo controle. As participantes foram 2.436 puérperas com episiotomia, divididas em quatro grupos para análise dos diferentes métodos de alívio da dor perineal. O estudo concluiu que a melhor das opções estudadas foi o LBI que poderia ser complementado com a aplicação de luz halógena. No entanto, alguns aspectos metodológicos dessa pesquisa são questionáveis, tais como: a falta de randomização, a ausência dos critérios de 
avaliação, a falta de descrição mais detalhada da aplicação das terapias e a explicitação dos possíveis conflitos de interesse (Kymplová et al., 2003).

Rzakylieva et al. (2006) analisaram os efeitos do laser na estimulação da cicatrização perineal em 86 puérperas com perineotomia ou episiotomia. A amostra foi dividida em grupo controle $(n=40)$, submetido ao tratamento tópico com aplicação de antissépticos e grupo laser $(n=46)$, que além do método tradicional, recebeu de 6 a 7 sessões de laserterapia. A dosimetria do laser foi definida individualmente, conforme a manifestação e a gravidade da lesão perineal, com frequência média de impulsos de 80 a $100 \mathrm{~Hz}, 80 \mathrm{~mW}$ de potência, indução magnética de 20 miliesla e tempo médio de irradiação de 6 a 8 minutos. Concluiu-se que o laser promove a redução da intensidade da dor perineal e da dispareunia depois de duas a três sessões da terapia, melhora consideravelmente o processo cicatricial e permite o rápido desaparecimento de sinais localizados de inflamação. No entanto, assim como na pesquisa de Kymplová et al. (2003), questiona-se alguns aspectos metodológicos, tais como: a falta de randomização, a ausência dos critérios de avaliação, a falta de descrição mais detalhada da aplicação das terapias e de cegamento, e a ausência de resultados relativos aos desfechos avaliados.

No atual estudo, foram constatadas reduções significativas intragrupo nos escores médios da dor perineal imediatamente após a irradiação $(p<0,001)$ e com 30 minutos depois do tratamento $(\mathrm{p}<0,001)$ nos três grupos avaliados. No entanto, os escores médios da dor perineal foram similares entre os grupos nos três momentos de avaliação, indicando que o alívio da dor perineal com a laserterapia foi equivalente ao tratamento placebo.

Neste estudo, considerou-se como mudança clinicamente significativa na dor perineal uma redução de dois pontos na escala numérica, o que corresponde a uma diminuição de 30\% na dor perineal, conforme referido por Farrar et al. (2001). Assim, considerando as proporções de melhora da dor perineal igual ou superior a $30 \%$, constatou-se que menos da metade $(44,8 \%)$ das mulheres referiu alívio da dor perineal imediatamente após o tratamento, sendo 55,3\% no grupo experimental infravermelho, $36,8 \%$ no vermelho e $42,1 \%$ no controle. No período de 30 minutos após a laserterapia, a maioria $(68,4 \%)$ das participantes referiu redução nos escores de dor maior ou igual a $30 \%$, das quais $76,3 \%$ puérperas eram do grupo infravermelho, $57,9 \%$ do vermelho e $71 \%$ do controle. Entretanto, observou-se 
similaridade na redução da dor perineal entre os três grupos $(p=0,234)$, indicando que os resultados obtidos com a terapia com laser foram equivalentes aos do tratamento placebo.

De acordo com Turner (2001), uma série de fatores pode influenciar nos resultados de qualquer tratamento de dor. Estes fatores incluem a história natural e a regressão da dor, ou seja, a dor pode melhorar ou até mesmo resolver completamente independente da terapia utilizada; os efeitos específicos do tratamento, atribuídos unicamente às características da terapêutica; e os efeitos inespecíficos do tratamento que incluem a atenção profissional e a expectativa do paciente e do profissional de saúde sobre a terapêutica analgésica, entre outros. Em relação ao cuidador, a demonstração de amizade, o calor humano, a simpatia, a empatia, a atitude positiva e a expectativa da eficácia da terapêutica proposta são condições inespecíficas que podem influenciar diretamente o resultado do tratamento da dor.

Segundo Fletcher e Fletcher (2006), os indivíduos apresentam uma tendência a alterar seu comportamento quando são alvos de interesse e recebem atenção especial, independente da natureza específica da intervenção. $O$ fenômeno é conhecido como efeito Hawthorne, frequentemente observado em participantes de pesquisas clínicas.

É importante salientar que, durante a coleta de dados, a pesquisadora auxiliar forneceu às puérperas informações relacionadas à amamentação, cuidado com as mamas, com o RN e com o traumatismo perineal. Por isso, acredita-se que os efeitos terapêuticos obtidos neste estudo poderiam ser atribuídos ao fenômeno Hawthorne.

Outra questão relevante a ser apresentada é que, ao promover um tratamento analgésico empregando o LBI, o clínico deve considerar um conjunto de fatores - o comprimento de onda, o poder, a densidade de poder, a energia e a densidade de energia emitida pelo aparelho, assim como o tamanho do spot e as características clínicas do paciente e do trauma, que incluem o local, o tamanho e a profundidade da lesão a ser tratada. Além disso, também devem ser considerados o modo, a frequência, o tempo, a dose por sessão e a dose cumulativa da irradiação (Enwemeka 2001; Chow et al., 2009; Enwemeka, 2009). Os referidos autores defendem que o sucesso do tratamento analgésico do LBI está intrinsecamente relacionado à dosimetria correta e à seleção adequada dos parâmetros citados. 
Sabe-se que o comprimento e a profundidade da episiotomia podem variar consideravelmente em cada mulher, e que a incisão secciona pele, tecido subcutâneo, mucosa vaginal e musculatura superficial, podendo atingir também os tecidos musculares mais profundos, que possuem aproximadamente, 3 a 5 centímetros de profundidade (Kettle, 2005; Rezende, 2008).

Conforme citado na introdução, quanto maior o comprimento de onda do dispositivo de laserterapia maior a penetração do feixe no tecido-alvo. Assim, o feixe de luz vermelha, na faixa de 620 a $690 \mathrm{~nm}$, penetra menos no tecido irradiado atingindo entre 0,5 e $2,5 \mathrm{~mm}$ de profundidade, e o feixe infravermelho, na faixa de 720 a $1.500 \mathrm{~nm}$, pode atingir de 8 a $10 \mathrm{~mm}$ de profundidade (Enwemeka, 2001).

Considerando a profundidade atingida pelos feixes de luz emitidos pelo dispositivo laser em baixa intensidade e as características da episiotomia, acredita-se que o protocolo de irradiação utilizado nesta pesquisa foi insuficiente para atingir as camadas mais profundas da lesão e consequentemente, para promover o alívio da dor perineal.

Nesse sentido, sugere-se que pesquisas adicionais envolvendo puérperas com traumatismo perineal sejam realizadas para a busca e a definição de um protocolo de irradiação efetivo para o alívio da dor perineal.

Com relação à interferência da dor perineal no desenvolvimento das atividades cotidianas e nas necessidades básicas antes da irradiação, constatou-se neste trabalho que a maioria das puérperas referiu desconforto perineal ao sentar, andar, evacuar, dormir e amamentar durante a internação hospitalar, sem diferença estatística significativa entre os três grupos $(p>0,05)$. Destaca-se que 95,6\% das puérperas mencionaram maior desconforto ao sentar, seguido pela deambulação (72,3\%). Dados semelhantes foram identificados por Macarthur e Macarthur (2004), Alexandre et al. (2006) e Beleza (2008).

Pesquisa desenvolvida na Alemanha com mulheres submetidas à episiotomia verificou que elas apresentaram dor perineal para sentar, andar, evacuar e deitar no período de 1 a 5 dias depois do parto (Dannecker et al., 2004). Estudo de coorte desenvolvido no Reino Unido com 241 mulheres que tiveram parto vaginal com e sem traumatismo perineal constatou que as puérperas com episiotomia e laceração espontânea de segundo grau apresentaram escores maiores de dor na região do períneo ao movimentar $(4,28 \pm 2,3)$, sentar $(4,23 \pm 2,3)$ e repousar $(2,75 \pm 2,3)$ no 
primeiro dia e 7 semanas pós-parto, com diferença significativa comparado com períneo íntegro e laceração de primeiro grau ( $(\mathrm{p} \square 0,05)$. No quinto dia pós-parto, constatou-se que as mulheres com episiotomia tiveram significativamente mais dor em repouso $(p=0,007)$ e ao sentar $(p<0,001)$ do que aquelas com laceração de segundo grau (Andrews et al., 2008).

Neste estudo, houve redução na frequência de citação de interferência da dor perineal no desenvolvimento das atividades cotidianas 30 minutos após a intervenção com laser. Num contexto geral, 95,6\% das mulheres referiam dor para sentar antes da irradiação passando para $67,9 \%$ após o procedimento, para deambular a mudança foi de $72,3 \%$ para $44,1 \%$, para urinar foi de $37,0 \%$ para $22,2 \%$, para dormir passou de $56,2 \%$ para $6,3 \%$ e para amamentar a redução foi de $64,0 \%$ para $36,4 \%$.

Merece comentar que, nos dois momentos de avaliação, o desconforto causado pela dor perineal ao sentar foi citado com maior frequência pelas puérperas, constituindo a principal atividade dificultada pela dor no períneo. Este resultado corrobora os achados dos estudos desenvolvidos por Steen (2005) que afirma que é frequente a queixa das puérperas de que não conseguem se sentar, indicando a incapacidade de sentar-se confortavelmente; e por Steen e Marchant (2007), que verificaram que o mais alto nível de dor perineal foi relatado pelas mulheres quando estavam sentadas, com variação entre $94 \%$ e 98\%, no primeiro dia pós-parto, permanecendo ainda elevada mesmo após 10 dias (42\% a 54\%).

Pesquisa citada anteriormente também observou que a dor na região perineal foi a que mais interferiu nas necessidades básicas de sono, locomoção e eliminações, interferindo também nas atividades de amamentação e cuidados com o RN, nos períodos de 20 a 24 horas, 56 a 60 horas e com 10 dias depois do parto (Alexandre et al., 2006).

Em relação às sensações informadas pelas participantes durante a irradiação, os achados apontaram que expressivo número de puérperas $(96,0 \%)$ submetidas à laserterapia referiu opinião favorável ao procedimento realizado, sem diferença significativa na comparação entre os grupos experimentais: vermelho e infravermelho $(\mathrm{p}=0,053)$.

Para a maioria das mulheres que recebeu a laserterapia, o procedimento foi considerado confortável (93,4\%). Quando comparadas as opiniões das mulheres dos grupos vermelho e infravermelho, constatou-se que não houve diferença estatística 
$(\mathrm{p}=0,464)$ em relação ao conforto do tratamento, indicando similaridade na opinião das mulheres sobre a terapêutica.

A maioria das participantes desta pesquisa $(96,5 \%$ - 110) referiu que repetiria o tratamento com LBI em outro período pós-parto, sem diferença significativa entre os grupos $(\mathrm{p}=0,772)$ mostrando aceitação do tratamento no campo da obstetrícia.

Apesar dos resultados desta pesquisa não apresentarem benefícios do LBI no alívio da dor perineal, comparando os grupos experimentais com o controle, acreditase que com a ampliação do conhecimento acerca da laserterapia e com a adequação do protocolo terapêutico na obstetrícia, essa tecnologia poderá ser útil no tratamento de traumatismos perineais.

Merece destacar também que o Conselho Regional de Enfermagem de São Paulo, em 2009, emitiu parecer favorável à utilização do laser de baixa intensidade pelo enfermeiro, no tratamento clínico de feridas (CAT N ${ }^{0}$ 011/2009), avaliando como lícito a prática do uso do LBI pelo enfermeiro (COREN-SP, 2009). Este parecer acrescenta que os procedimentos executados ou prescritos por este profissional devam estar respaldados em evidências científicas, fortalecendo a necessidade de desenvolver mais estudos sobre a temática, com rigor metodológico, para que inferências sobre a efetividade do LBI no alívio da dor perineal sejam mais conclusivas. 
7 CONCLUSÃO 
Neste estudo avaliou-se o efeito do tratamento com laser em baixa intensidade no alívio da dor perineal durante o período de internação hospitalar após o parto normal com episiotomia médio-lateral direita. Participaram desta pesquisa 114 mulheres distribuídas aleatoriamente em três grupos de investigação: grupo controle, em que houve a simulação do tratamento com laserterapia; grupo experimental vermelho, irradiado com LBI com comprimento de onda vermelho; grupo experimental infravermelho, tratado com LBI com comprimento de onda na faixa do infravermelho. Cada grupo foi constituído por 38 puérperas.

Os resultados obtidos rejeitam a hipótese de que a irradiação com laser em baixa intensidade diminui a intensidade da dor perineal referida pelas puérperas com episiotomia médio-lateral direita durante o período de internação hospitalar.

A comparação das médias da dor perineal entre os grupos controle, vermelho e infravermelho, não demonstrou diferença estatisticamente significativa nos três momentos de avaliação - antes, imediatamente após e depois de 30 minutos da irradiação.

$\mathrm{Na}$ avaliação intragrupo houve diferença significativa nos três momentos de avaliação da dor perineal nos três grupos de comparação, considerando a dor referida pela puérpera antes e imediatamente após a irradiação, imediatamente após e 30 minutos depois da intervenção, e antes e 30 minutos depois da laserterapia.

Não houve diferença significativa na proporção de redução da dor perineal entre os três grupos de comparação imediatamente após a aplicação do laser em baixa intensidade e 30 minutos depois da intervenção, indicando que o alívio na dor foi similar entre os grupos.

Não foi observado nenhum efeito adverso atribuído à irradiação com laser em baixa intensidade.

Com relação à interferência da dor perineal no desenvolvimento das atividades cotidianas antes da irradiação com LBI, observou-se que a maioria das puérperas referiu desconforto para sentar, andar, evacuar, dormir e amamentar. Não houve diferença significativa na interferência da dor perineal nas atividades diárias entre os três grupos analisados.

Cerca de 30 minutos após a intervenção com LBI, menos da metade das mulheres apontou que a dor na região perineal interferiu na deambulação, na micção, no sono e na amamentação. Na comparação entre os três grupos, não foram 
constatadas diferenças significativas na interferência da dor perineal em todas as atividades desenvolvidas com 30 minutos após a irradiação.

Houve redução na frequência de citação de interferência da dor perineal no desenvolvimento das atividades diárias após a aplicação da irradiação. O desconforto causado ao sentar constituiu a principal atividade prejudicada pela dor perineal.

Os achados apontaram que quase todas as puérperas submetidas à laserterapia tiveram opinião favorável ao procedimento realizado, sendo considerado confortável pela maioria, que também referiu que repetiria o tratamento em outra oportunidade. Não houve diferença estatística na comparação das opiniões das mulheres sobre o LBI nos grupos experimental vermelho e infravermelho. 
8 CONSIDERAÇÕES FINAIS 
A definição dos parâmetros adequados de irradiação é fundamental para a obtenção de um efeito biomodulatório satisfatório com o laser em baixa intensidade. A condução deste estudo científico foi importante porque constituiu o primeiro passo na construção do conhecimento a respeito da aplicabilidade da laserterapia na prática clínica obstétrica no Brasil. No entanto, é necessário que novas propostas de pesquisa, contemplando diferentes protocolos terapêuticos com o laser em baixa intensidade, sejam desenvolvidas para determinar um protocolo efetivo para o alívio da dor e do desconforto perineal entre as puérperas. 
Albers L, Garcia J, Renfrew M, McCandlish R, Elbourne D. Distribution of genital tract trauma in childbirth and related postnatal pain. Birth. 1999;26(1):11-7.

Albers L, Sedler KD, Bedrick EJ, Teaf D, Peralta P. Midwifery care measures in the second stage of labor and reduction of genital tract trauma at birth: a randomized trial. J Midwifery Womens Health. 2005;50(5):365-72.

Albers LL, Greulich B, Peralta P. Body mass index, midwifery intrapartum care, and childbirth lacerations. J Midwifey Womens Health. 2006;51:249-53.

Albers LL, Borders N. Minimizing genital tract trauma and related pain following spontaneous vaginal birth. J Midwifery Womens Health. 2007;52(3):246-53.

Alexandre CW. Prevalência, características e impacto da dor no cotidiano da puérpera. [dissertação]. São Paulo: Escola de Enfermagem, Universidade de São Paulo; 2002.

Alexandre CW, Kimura AF, Tsunechiro MA, Oliveira SMJV. A interferência da dor nas atividades e necessidades da puérpera. Rev Nurs. 2006;93(9):664-8.

Almeida SFS, Riesco MLG. Ensaio clínico controlado aleatório sobre duas técnicas de sutura do trauma perineal no parto normal. Rev Lat Am Enferm. 2008;16(2):2729.

Althabe F, Belizán JM, Bergel E. Episiotomy rates in primiparous women in Latin America: hospital based descriptive study. BMJ. 2002;324:945-6.

Andrews V, Thakar R, Sultan AH, Jones PW. Evaluation of postpartum perineal pain and dyspareunia: a prospective study. Eur J Obstet Gynecol Reprod Biol. 2008;137(2):152-6.

Aytan H, Tapisiz OL, Tuncay G, Avsar FA. Severe perineal lacerations in nulliparous women and episiotomy type. Eur J Obstet Gynecol Reprod Biol. 2005;121:46-50.

Beleza ACS. A dor perineal no pós-parto normal com episiotomia: mensuração, caracterização e efeitos da crioterapia [tese]. Ribeirão Preto: Escola de Enfermagem de Ribeirão Preto, Universidade de São Paulo;2008.

Berquó E, Garcia S, Lago T, coordenadoras. PNDS 2006: Pesquisa Nacional de Demografia e Saúde da Criança e da Mulher [texto na Internet]. Brasília: Secretaria de Ciência, Tecnologia e Insumos Estratégicos, Ministério da Saúde; 2009. [citado 2010 abr. 2]. Disponível em:

http://bvsms.saude.gov.br/bvs/pnds/img/relatorio_final_pnds2006.pdf

Bick D. Postpartum management of the perineum. In: Henderson C, Bick D. Perineal Care: an international issue. Quay Books MA Healthcare Limited; 2005. p.113-26.

Bjordal JM, Johnson MI, Iversen V. Aimbire F, Lopes-Martins RAB. Low-level laser therapy in acute pain: a systematic review of possible mechanisms of action and 
clinical effects in randomized placebo-controlled trials. Photomed Laser Surg. 2006; 24(2):158-68.

Bologna ED, Santos AECG, Brugnera AJ. Normas de segurança. In: Brugnera AJ, Santos AECG, Bologna ED, Ladalardo TCCGP. Atlas de laserterapia aplicada à clínica odontológica. $1^{\mathrm{a}}$ ed. São Paulo: Livraria Santos Editora; 2007. p.9-12.

Brasil. Ministério da Saúde. Secretaria de Políticas de Saúde. Área Técnica de Saúde da Mulher. Parto, aborto e puerpério: assistência humanizada à saúde. Brasília: Ministério da Saúde; 2001.

Brosseau L, Welch V, Wells GA, de Bie R, Gam A, Harman K, Morin M, Shea B, Tugwell P. Low level laser therapy (classes I, II and III) for treating rheumatoid arthritis (Cochrane Review). In: The Cochrane Library, Issue 4, 2005. Oxford, Update Software.

Brosseau L, Welch V, Wells GA, de Bie R, Gam A, Harman K, Morin M, Shea B, Tugwell P. Low level laser therapy (classe III) for treating osteoarthritis (Cochrane Review). In: The Cochrane Library, Issue 1, 2007. Oxford, Update Software.

Brugnera AJ, Ladalardo TCCGP, Cruz FM. Introdução. In: Brugnera AJ, Santos AECG, Bologna ED, Ladalardo TCCGP. Atlas de laserterapia aplicada à clínica odontológica. $1^{\text {a }}$ ed. São Paulo: Livraria Santos Editora; 2007. p.1-8.

Brugnera AJ, Villa RG, Genovese WJ. Laser na odontologia. São Paulo: Pancaste Editora; 1991.

Burroughs A. Uma introdução à enfermagem maternal. $6^{\mathrm{a}}$ ed. Porto Alegre: Artes Médicas; 1995. Assistência de enfermagem durante o período puerperal; p.221-34.

Cambier D, Blom K, Ollevier G, De Muynck M, Vanderstraeten G. The influence of low intensity infrared laser irradiation on conduction characteristics of peripheral nerve: a randomised, controlled, Double blind study on the sural nerve. Lasers Med Sci. 2000; 15:195-200.

Carati CJ, Anderson SN, Gannon BJ, Piller NB. Treatment of postmastectomy lymphedema with low-level laser therapy: a double blind, placebo-controlled trial. Cancer. 2003;98(6):1114-22.

Carroli G, Mignini L. Episiotomy for vaginal birth (Cochrane Reviews). In: The Cochrane Library, Issue 1, 2009. Oxford, Update Software.

Carvalho RR, Eduardo FP, Ramalho KM, Antunes JLF, Bezinelli LM, Magalhães MJCG, Pegoretti T, Freitas PM, Eduardo CP. Effect of laser phototherapy on recurring herpes labialis prevention: an in vivo study. Lasers Med Sci. 2010;25:39702.

Chaves LD. Dor pós-operatória: aspectos clínicos e assistência de enfermagem. In: Chaves LD, Leão ER, editoras. Dor $5^{\circ}$ sinal vital: reflexões e intervenções de enfermagem. $2^{a}$ ed. São Paulo: Livraria Martinari; 2007. p.184-211. 
Chou D, Abalos E, Gyte GML, Gülmezoglu AM. Paracetamol/acetaminophen (single administration) for perineal pain in the early postpartum period (Cochrane Review). In: The Cochrane Library, Issue 10, 2010. Oxford, Update Software.

Chow TR, Heller GZ, Barnsley L. The effect of $300 \mathrm{~mW}, 830 \mathrm{~nm}$ laser on chronic neck pain: a double-blind, randomized, placebo-controlled study. Pain. 2006;124:201-10.

Chow RT, Johnson MI, Lopes-Martins RAB, Bjordal JM. Efficacy of low-level laser therapy in the management of neck pain: a systematic review and meta-analysis of randomized placebo or active-treatment controlled trials. Lancet. 2009;374:1897908.

Cools J. La terapia laser hoy. Barcelona: Centro Documentación Láser de Meditec; 1984.

Cordon R. Princípios do laser em odontologia. [monografia]. São Paulo (SP):

Faculdade de Odontologia da Universidade de São Paulo; 2000.

Conselho Regional de Enfermagem de São Paulo. Parecer COREN-SP CAT N011/2009. Uso do laser de baixa intensidade pelo profissional enfermeiro, no tratamento clínico de feridas; 2009.

Dahlen HG, Homer CSE, Cooke M, Upton AM, Nunn R, Brodrick B. Perineal outcomes and maternal comfort related to the application of perineal warm packs in the second stage of labor: a randomized controlled trial. Birth. 2007;34(4):282-90.

Dannecker C, Hillemanns P, Strauss A, Hasbargen U, Hepp H, Anthuber C.

Episiotomy and perineal tears presumed to be imminent: randomized controlled trial. Acta Obstet Gynecol Scand. 2004;83:364-8.

Declercq E, Cunningham DK, Johnson C, Sakala C. Mother's reports of postpartum pain associated with vaginal and cesarean deliveries: results of a national survey. Birth. 2008;35(1):16-24.

Derry P, Derry S, Moore RA, McQuay HJ. Single dose oral diclofenac for acute postoperative pain in adults (Cochrane Review). In: The Cochrane Library, Issue 2, 2009. Oxford, Update Software.

Derry C, Derry S, Moore RA, McQuay HJ. Single dose oral ibuprofen for acute postoperative pain in adults (Cochrane Review). In: The Cochrane Library, Issue 3, 2009. Oxford, Update Software.

East CE, Begg L, Henshall NE, Marchant P, Wallace K. Local cooling for relieving pain from perineal trauma sustained during childbirth (Cochrane Review). In: The Cochrane Library, Issue 4, 2007. Oxford: Update Software.

Edwards J, Meseguer F, Faura C, Moore RA, McQuay HJ, Derry S. Single dose dipyrone for acute postoperative pain (Cochrane Review). In: The Cochrane Library, Issue 9, 2010. Oxford, Update Software. 
Emshoff R, Bosh R, Pumpel E, Schoning H, Strobl H. Low-level laser therapy for treatment of temporomandibular joint pain: a double-blind and placebo-controlled trial. Oral Med Oral Pathol Oral Radiol Endod. 2008;105:452-6.

Enkin M, Keirse MJNC, Neilson J, Crowther C, Duley L, Hodnett E, et al. Guia para atenção efetiva na gravidez e no parto. $3^{\mathrm{a}}$ ed. Rio de Janeiro: Guanabara Koogan; 2005. Dor e desconforto perineal; p.243-7.

Enwemeka C. Attenuation and penetration of visible $632.8 \mathrm{~nm}$ and invisible infrared 904nm light in soft tissues. Laser Therapy. 2001;13:95-101.

Enwemeka CS, Parker JC, Dowdy DS, Harkness EE, Sanford LE, Woodruff LD. The efficacy of low-level lasers in the tissue repair and pain control: a meta-analysis sudy. Photomed Laser Surg. 2004; 22(4):323-9.

Enwemeka, CS. Intricacies of dose in laser phototherapy for tissue repair and pain relief. Photomed Laser Surg. 2009;27(3):387-93.

Farrar JT, Young JP Jr, LaMoreaux L, Werth JL, Poole RM. Clinical importance of changes in chronic pain intensity measured on an 11-point numerical pain rating scale. Pain. 2001;94(2):149-58.

Ferreira DM, Zângaro RA, Villaverde AB, Cury Y, Frigo L, Piccolo G, Longo I, Barbosa DG. Analgesic effect of He-Ne $(632,8 \mathrm{~nm})$ low-level lser therapy on acute inflammatory pain. Photomed Laser Surg. 2005;23(2):177-81.

Flemming K, Cullum NA. Laser therapy for venous leg ulcers (Cochrane Review). In: The Cochrane Library, Issue 1, 1999. Oxford, Update Software.

Fletcher RH, Fletcher SW. Epidemilogia clínica: elementos essenciais. $4^{\mathrm{a}}$ ed. Porto Alegre: Artmed; 2006. Tratamento; p.154-78.

Francisco AA, Oliveira SMJV, Santos JO. Avaliação e tratamento da dor perineal no pós-parto normal. Acta Paul Enferm. No prelo.

Genovese WJ. Laser de baixa intensidade: aplicações terapêuticas em odontologia. São Paulo: Livraria Santos Editora; 2007. Introdução; p.1-4.

Genovese WJ, Prokopowitsch I. Caracterísitcas físicas da radiação laser. In: Genovese WJ. Laser de baixa intensidade: aplicações terapêuticas em odontologia. São Paulo: Livraria Santos Editora; 2007. p.4-12.

Genovese WJ, Rodrigues JML. Classificação dos principais tipos de laser. In: Genovese WJ. Laser de baixa intensidade: aplicações terapêuticas em odontologia. São Paulo: Livraria Santos Editora; 2007. p.13-30.

Genovese WJ, Frigo L. Dor, reparação e inflamação. In: Laser de baixa intensidade: aplicações terapêuticas em odontologia. São Paulo: Livraria Santos Editora; 2007. p.31-38 
Genovese WJ, Barreira Filho JL. Efeitos terapêuticos dos lasers de baixa intensidade. In: Genovese WJ. Laser de baixa intensidade: aplicações terapêuticas em odontologia. São Paulo: Livraria Santos Editora; 2007. p.39-46.

Glazener C. Women's health after delivery. In: Henderson C, Bick D. Perineal care: an international issue. London: Quay Books; 2005. p.11-7.

Goldberg J, Holtz D, Hyslop T, Tolosa JE. Has the use of routine episiotomy decreased? Examination of episiotomy rates from 1983 to 2000. Obst Ginecol. 2002; (3):395-400.

Goldman L. História do laser em medicina. In: Pimenta, LHM. Laser em medicina e biologia. São Paulo: Roca; 1990. p.1-3.

Graham ID, Carroli G, Davies C, Medves JM. Episiotomy rates around the world: an update. Birth. 2005;32(3):219-23.

Hagiwara S, Iwasaka H, Okuda K, Noguchi T. GaAlAs (830nm) Low-level laser enhances peripheral endogenous opioid analgesia in rats. Lasers Surg Med. 2007; 39:797-802.

Hakguder A, Birtane M, Gurean S, Kokino S, Turan FN. Efficacy of low level laser therapy in myofascial pain syndrome: an algometric and thermographic evaluation. Lasers Surg Med. 2003;33:339-43.

Hay-Smith J. Therapeutic ultrasound for postpartum perineal pain and dyspareunia (Cochrane Review). In: The Cochrane Library, Issue 3, 1998. Oxford: Update Software.

Hedayati H, Parsons J, Crowther CA. Rectal analgesia for pain from perineal trauma following childbirth (Cochrane Review). In: The Cochrane Library, Issue 3, 2003. Oxford: Update Software.

Hedayati H, Parsons J, Crowther CA. Topically applied anaesthetics for treating perineal pain after childbirth (Cochrane Review). In: The Cochrane Library, Issue 2, 2005. Oxford: Update Software.

Hill PD. Psychometric Properties of REEDA. J Nurse-Midwifery. 1990;35:162-5.

Hopkins JT, McLoda TA, Seegmiller JG, Baxter GD. Low-level laser therapy facilitates superficial wound healing in humans: a triple-blind, sham-controlled study. J Athl Train. 2004; 39(3):223-9.

Internacional Association for Study of Pain (IASP). Terminology. [on line].

Disponível em: http://www.iasp-pain.org

Jadad AR. Randomised controlled trials. London: BMJ Books; 1998.

Junqueira LC, Carneiro J. Histologia básica. Rio de Janeiro: Guanabara Koogan; 2008. 
Karu T. Molecular mechanism of the therapeutic effect of low-intensity laser radiation. Laser Life Sci. 1988; 2(1):53-74.

Karu T. Photobiology of low-power laser effects. Health Physics. 1989; 56(5):691704.

Karu TI. Low-power laser therapy. In: Biomedical photonics handbook; 2003. p. 125.

Kaviani A, Fateh M, Yousefi-Nooraie R, Alinagi-zadeh MR, Ataie-Fashtami L. Low-level laser therapy in management of postmastectomy lymphedema. Lasers Med Sci. 2006;21:90-4.

Kettle C. Anatomy of the pelvic floor. In: Henderson C, Bick D. Perineal Care: an international issue. Quay Books MA Healthcare Limited; 2005. p.18-31.

Khouri VY, Stracieri ABPL, Rodrigues MC, Moraes DA, Pieroni F, Simões BP, Voltarelli JC. Use of therapeutic laser for prevention and treatment of oral mucositis. Braz Dent J. 2009;20(3):215-20.

Klein MC, Gauthier RJ, Robbins JM, Kaczorowski J, Jorgensen SH, Franco ED, et al. Relationship of episiotomy to perineal trauma and morbidaty, sexual, dysfunction, and pelvic floor relaxation. Am J Obstet Gynecol. 1994;171(3):591-8.

Knight KL. Crioterapia no tratamento das lesões esportivas. São Paulo: Manole; 2000 .

Kumar V, Abbas AK, Fausto N. Patologia: bases patológicas das doenças. 7. ed. Rio de Janeiro: Elsevier; 2005.

Kymplová J, Navrátil L, Kníz J. Contribution of phototherapy to the treatment of episiotomies. J Clin Laser Med Surg. 2003;21(1):35-9.

Labrecque M, Eason E, Daniels F, Ymayo MR, Bourget MM. Episiotomia de rotina: as evidências contra. Diag Trat. 2000;5(2):43-50.

Lau Cheing RW, Cheing GL. Managing postmastectomy lymphedema with lowlevel laser therapy. Photomed Laser Surg. 2009;27(5):763-9.

Leventhal LC. Analgesia pela bolsa de gelo sobre no períneo após o parto normal: ensaio clínico randomizado [tese] São Paulo: Escola de Enfermagem, Universidade de São Paulo; 2008.

Levitt C, Shaw E, Wong S, Kaczorowski J, Springate R, Sellors J, et al. Systematic review of the literature on postpartum care: methodology and literature search results. Birth. 2004;31(3):196-202.

Lim W, Lee S, Kim I, Chung M, Kim M, Lim H, Park J, Kim O, Choi H. The antiinflammatory of $635 \mathrm{~nm}$ light-emitting-diode irradiation compared with existing COX inhibitors. Lasers Surg Med. 2007;39:614-21. 
Lucas C, Criens-Poublon LJ, Cockrell CT, Haan RJ. Wound healing in cell studies and animal model experiments by low level laser therapy; were clinical studies justified? A Systematic review. Lasers Med Sci. 2002;17:110-134.

Macarthur AJ, Macarthur C. Incidence, severity, and determinants of perineal pain after vaginal delivery: a prospective cohort study. Am J Obstet Gynecol. 2004;191:1199-204.

Martins-Costa S, Ramos JGL, Brietzke E, Stuazinaki JV, Dias EC. Episiotomia: o que há de verdade nesse tradicional procedimento? Femina. 2001;29(4):201-4.

Meireles SM, Jones A, Jennings F, Suda AL, Parizotto NA, Natour J. Assessment of the effectiveness of low-level laser therapy on the hands of patients with rheumatoid arthritis: a randomized double-blind controlled trial. Clin Rheumatol. 2010;29:501-9.

Mendonça SHF, Leão ER. Implantação e monitoramento da dor como $5^{\circ}$ sinal vital: o desenvolvimento de um processo assistencial. In: Chaves LD, Leão ER, editoras. Dor $5^{\circ}$ sinal vital: reflexões e intervenções de enfermagem. $2^{a}$ ed. São Paulo: Livraria Martinari; 2007. p.624-30.

Metcalfe A, Tohill S. Perineal tear assessment and the development of the PeriRule $^{\mathrm{TM}}$. In: Henderson C, Bick D. Perineal Care: an international issue. Quay Books MA Healthcare Limited, 2005. p.87-97.

Mintertag J. Física aplicada do laser. In: Pimenta, LHM. Laser em medicina e biologia. São Paulo: Roca; 1990. Cap.2, p.5-11.

Mizutani K, Musya Y, Wakae K, Kobayashi T, Tobe M, Taira K, Harada T. A Clinical study on serum prostaglandin $\mathrm{E}_{2}$ with low-level laser therapy. Photomed Laser Surg. 2004;22(6):537-9.

Mohammed I. Low-level therapy accelerates collateral circulation and enhances microcirculation. Photomed Laser Surg. 2005;23(3):289-94.

Myers-Helfgott MG, Helfgott AW. Uso rotineiro da episiotomia na obstetrícia moderana: ela deve ser feita? Obstetr Ginecol Clin North Am. 1999;26(2): 305-25.

Neme B. Obstetrícia básica. $3^{\text {a }}$ ed. São Paulo: Sarvier; 2005. Parto: assistência; p.1035-65.

Oliveira SMJV, Miquilini EC. Frequência e critérios para indicar a episiotomia. Rev Esc Enferm USP. 2005;39(3):288-95.

Oliveira SMJV. Comparação do tempo de aplicação da bolsa de gelo para o alívio da dor perineal após o parto normal: ensaio clínico randomizado. [tese livre-docência]. São Paulo (SP): Escola de Enfermagem da Universidade de São Paulo; 2009.

Organização Mundial de Saúde. Assistência ao parto normal: um guia prático. Saúde Materna e Neonatal/Unidade de Maternidade Segura Saúde Reprodutiva e da Família. Genebra; 1996. 
Paula CV. Atuação de enfermagem em doentes com dor. In: Teixeira MJ. Dor: manual para o clínico. São Paulo: Ed. Atheneu; 2006. p.221-6.

Piller NB, Thelander A. Treatment of chronic postmastectomy lymphedema with low level laser therapy: a 2,5 year follow-up. Lymphology. 1998;31(2):74-86.

Pimenta CAM. Dor: manual clínico de enfermagem. São Paulo: [s.n]; 2000. p.1-60.

Pitangui ACR. Avaliação do efeito da estimulação elétrica nervosa transcutânea (TENS) no alívio da dor pós-episiotomia em primíparas submetidas ao parto normal. [dissertação]. Ribeirão Preto (SP): Escola de Enfermagem de Ribeirão Preto da Universidade de São Paulo; 2007.

Pitangui ACR, Sousa L, Ferreira CHJ, Gomes FA, Nakano AMS. Mensuração e características da dor perineal em primíparas submetidas à episiotomia. Acta Paul Enf. 2009;22(1):77-82.

Rampini MP, Ferreira EMS, Ferreira CG, Antunes HS. Utilização da terapia com laser de baixa potência para prevenção de mucosite oral: revisão de literatura. Rev Bras Cancerol 2009;55(1):59-68.

Rzakylieva L., Israfilbeili S., Gasimova G. Application of magnet laser radiation to stimulate healing of perineum injuries in the maternity patients. Georgial Medical News. 2006;9(138):71-3.

Rezende J. Obstetrícia fundamental. $11^{\mathrm{a}}$ ed. Rio de Janeiro: Guanabara Koogan; 2008. Bases morfológicas e funcionais do sistema genital. p.3-20.

Ricci SS. Enfermagem materno-neonatal e saúde da mulher. Rio de Janeiro: Guanabara Koogan; 2008. p.332-41.

Riesco MLG, Oliveira SMV. Avaliação do edema perineal no pós-parto: concordância entre observadores. Rev Gaúcha Enferm. 2007;28(4):465-72.

Rocha Júnior, Oliveira RG, Farias RE, Andrade LCF, Aarestrup FM. Modulação da proliferação fibroblástica e da resposta inflamatória pela terapia a laser de baixa intensidade no processo de reparo tecidual. Rev Bras Dermato. 2006;81(2):150-6.

Rosner B. Fundamentals of biostatistics. $6^{\text {th }}$ ed. Belmont: Thomson-Brooks Cole; c2006. p.416.

Royal College of Obstetricians and Gynaecologists. Methods and materials used in perineal repair. Guideline n ${ }^{\mathrm{o}}$ 23. Londres: RCOG Press; 2004.

Santos JO, Bolanho IC, Mota JQC, Coleoni L, Oliveira MA. Frequência de lesões perineais ocorridas nos partos vaginais em uma instituição hospitalar. Esc Anna Nery Rev Enferm. 2008;12(4):658-63.

Scarabotto LB, Riesco MLG. Fatores relacionados ao trauma perineal no parto normal em nulíparas. Rev Esc Enf USP. 2006;40(3):389-95. 
Shirani AM, Gutknecht N, Taghizadeh M, Mir M. Low-level laser therapy and myofacial pain dysfunction syndrome: a randomized controlled clinical trial. Lasers Med Sci. 2009;24:715-20.

Shorten A, Donsante J, Shorten BA. Birth positon, accoucheur, and perineal outcomes: informing women about choices for vaginal birth. Birth. 2002;29(1):1827.

Shubert MM, Eduardo FP, Guthrie KA, Franquin JC, Bensadoun RJJ, Migliorati CA, Lloid CME, Eduardo CP, Walter NF, Marques MM, Hamdi M. A phase III randomized Double-blind placebo-controlled clinical trial to determine the efficacy of low level laser therapy for the prevention of oral mucositis in patients undergoing hematopoietic cell transplantation. Support Care Cancer. 2007;15:1145-54.

Silva SF. Sutura do trauma perineal no parto normal: estudo comparativo entre duas técnicas. [dissertação]. São Paulo: Escola de Enfermagem da Universidade de São Paulo; 2002.

Smeltzer SC, Bare BG. Brunner \& Suddarth: tratado de enfermagem médicocirúrgico. $9^{a}$ ed. Rio de Janeiro: Guanabara Koogan; 2002. Tratamento da dor. vol.1, p.167-191.

Souza FAEF, Hortense P. Mensuração da dor. In: Chaves LD, Leão ER, editoras. Dor $5^{\circ}$ sinal vital: reflexões e intervenções de enfermagem. $2^{a}$ ed. São Paulo: Livraria Martinari; 2007. p.100-117.

Steen M, Cooper K, Marchant P, Griffiths-Jones M, Walker J. A randomised controlled trial to compare the effectiveness of icepacks and Epifoam with cooling maternity gel pads at alleviating postnatal perineal trauma. Midwifery. 2000;16(1):48-55.

Steen M. "I can’t sit down": easing genital tract trauma. Br J Midwifery. 2005;13(5):311-4.

Steen M, Briggs M, King D. Alleviating postnatal perineal trauma: to cool or not to cool? Br J Midwifery. 2006;14(5):304-8.

Steen M, Marchant P. Ice packs and cooling gel pads versus no localised treatment for relief of perineal pain: a randomised controlled trial. Evid Based Midwifery. 2007;5(1):16-22.

Tavares MR. Efeito do laser terapêutico na cicatrização tendinosa: estudo experimental em ratos. [dissertação]. Ribeirão Preto (SP): Escola de Engenharia de São Carlos/Faculdade de Medicina de Ribeirão Preto da Universidade de São Paulo; 2002.

Teixeira MJ. Dor: manual para o clínico. São Paulo: Ed. Atheneu; 2006.

Fisiopatologia da dor aguda e crônica; p.9-24.

Teixeira MJ, Filho JV. Tratamento da dor aguda e pós-operatória. In: Teixeira MJ. Dor: manual para o clínico. São Paulo: Ed. Atheneu; 2006. p.207-219. 
Teixeira MJ, Yeng LT. Avaliação da dor. In: Teixeira MJ. Dor: manual para o clínico. São Paulo: Ed. Atheneu; 2006. p.25-38.

Tomasso G. Debemos seguir haciendo La episiotomía em forma rutinaria? Rev Obstet Gynaecol de Venezuela. 2002;62(2):115-21.

Toms L, McQuay HJ, Derry S, Moore RA. Single dose oral paracetamol (acetaminophen) for postoperative pain in adults (Cochrane Review). In: The Cochrane Library, Issue 4, 2008. Oxford, Update Software.

Tunér J, Hode L. Low level laser therapy: clinical practice and scientific background. Swden: Prima Books; 1999.

Turhani D, Scheriau M, Kapral D, Benesch T, Jonke E, Bantleon HP. Pain relief by single low-level laser irradiation in orthodontic patients undergoing fixed appliance therapy. Am J of Orthod Dentofacial Orthop. 2006;130:371-7.

Turner JA. Nonspecific treatment effects. In: Loeser JD, Butler SH, Chapman CR, Turk DC. Bonica's management of pain. Philadelphia: Lippincott Williams\&Wilkins; 2001. p.1649-56.

Yousefi-Nooraie R, Schonstein E, Heidari K, Rashidian A, Pennick V, AkbariKamrani M, Irani S, Shakiba B, Mortaz HS, Jonaidi AR, Mortaz-Hedjri S. Low level laser therapy for nonspecific low-back pain (Cochrane Review). In: The Cochrane Library, Issue 2, 2008. Oxford, Update Software.

Zand N, Ataie-Fashtami L, Djavid GE, Fateh M, Alinaghizadeh MR, Fatemi SM, Arbabi-Kalati F. Relieving pain in minor aphthous stomatitis by a single sesión of non-thermal carbón dioxide laser irradiation. Lasers Med Sci. 2009;24:515-20.

Ziegel EE, Cranley MS. Enfermagem Obstétrica. $8^{\mathrm{a}}$ ed. Rio de Janeiro: Guanabara Koogan; 1985. 
APÊNDICES 


\section{APÊNDICE 1}

\section{Tabela de Randomização}

Primeira Etapa

1. Grupo 1

2. Grupo 2

3. Grupo 2

4. Grupo 1

5. Grupo 2

6. Grupo 1

7. Grupo 1

8. Grupo 1

9. Grupo 2

10. Grupo 1

11. Grupo 2

12. Grupo 2

13. Grupo 1

14. Grupo 1

15. Grupo 2

16. Grupo 2

17. Grupo 2

18. Grupo 1

19. Grupo 1

20. Grupo 2

21. Grupo 2

22. Grupo 1

23. Grupo 1

24. Grupo 2

25. Grupo 1

26. Grupo 1

27. Grupo 2

28. Grupo 2

29. Grupo 1

30. Grupo 1
31. Grupo 2

32. Grupo 1

33. Grupo 1

34. Grupo 2

35. Grupo 1

36. Grupo 2

37. Grupo 2

38. Grupo 1

39. Grupo 2

40. Grupo 1

41. Grupo 1

42. Grupo 2

43. Grupo 2

44. Grupo 1

45. Grupo 2

46. Grupo 1

47. Grupo 2

48. Grupo 2

49. Grupo 1

50. Grupo 2

51. Grupo 2

52. Grupo 1 


\section{APÊNDICE 2 \\ Termo de Consentimento Livre e Esclarecido \\ Primeira Etapa}

Prezada Senhora

Eu, Jaqueline de Oliveira Santos, enfermeira e estudante do curso de Pós-Graduação, nível Doutorado, da Escola de Enfermagem da Universidade de São Paulo, estou pesquisando sobre o efeito do laser em baixa intensidade no alívio da dor perineal pós-parto normal. Esta pesquisa é para saber se o laser quando irradiado no local da episiotomia (corte vaginal realizado durante o parto) altera a sensação de dor no local e acelera a cicatrização após o parto normal.

A pesquisa será formada por dois grupos de mulheres: um grupo será feita aplicação do laser de baixa intensidade no períneo e no outro grupo não será aplicada a irradiação, embora todos os procedimentos necessários para a utilização da terapia serão realizados. O grupo que cada mulher participará será definido por sorteio. Você não terá conhecimento de qual grupo pertencerá.

A primeira aplicação do laser em baixa intensidade será realizada com até duas horas após o parto, a segunda com 20 a 24 horas e a terceira com 40 a 48 horas após o nascimento do seu bebê. Você será encaminhada a uma sala isolada e terá que utilizar óculos de proteção para evitar qualquer problema nos olhos. Você terá que ficar na posição ginecológica durante a aplicação do laser que será feita encostando a ponteira do laser sobre seu corte durante 10 segundos. Além disso, após as aplicações você responderá a algumas perguntas a respeito do tratamento. Gostaria de lhe informar que as pesquisas não apresentam efeitos colaterais do tratamento.

Participando desta pesquisa você estará contribuindo para o avanço dos estudos nesta área e para a melhoria da qualidade do atendimento prestado, beneficiando assim todas as mulheres que passarem por isso. Em caso de necessidade de algum esclarecimento, o meu telefone para contato é (11) 81000111 ou pelo telefone do Comitê de Ética em Pesquisa (11) 30617548. 
$\mathrm{Eu}$,

$\mathrm{RG} \mathrm{n}^{\circ}$ abaixo assinada, recebi e entendi as informações acima e concordo em participar voluntariamente como colaboradora da pesquisa. Declaro que conheço os meus direitos que estão explicados a seguir:

- Tenho a garantia de receber orientações sobre as dúvidas que eu tiver sobre a pesquisa.

- Tenho a liberdade de não aceitar participar e deixar de participar da pesquisa em qualquer momento e isso não vai me causar nenhum prejuízo e não interferirá na minha assistência neste hospital;

- Sei que os resultados desta pesquisa serão transformados em trabalho científico e apresentados em congressos e revistas da área da saúde, e em nenhum momento, o meu nome aparecerá como colaboradora ou participante da pesquisa.

Este documento contém duas vias, sendo que uma ficará em seu poder e a outra comigo, garantindo as condições citadas acima.

São Paulo, 


\section{APÊNDICE 3}

\section{Formulário de Coleta de Dados}

Primeira Etapa

( ) Grupo Experimental ( ) Grupo Controle

$\mathrm{N}^{\circ}$

\section{A) DADOS DO PRONTUÁRIO}

\section{Dados pessoais}

Iniciais

Idade: anos

$\mathrm{RH}$

Peso: quilos

Altura: metros

\section{Dados obstétricos}

a) N. ${ }^{\circ}$ de gestações: Paridade: Abortamento:

b) Idade gestacional: semanas

c) Anestesia: ( ) Sim ( ) Não Qual?

d) Técnica de sutura: ( ) Contínua ( ) Interrompida ( ) Ambas

e) Fio de sutura empregado: ( ) Categute simples ( ) Categute cromado ( ) Vicryl

g) Peso do recém-nascido: gramas PC: centímetros

\section{Medicação}

a) Usou algum analgésico: ( ) Sim （ ) Não

Qual? (freqüencia, dose, horário, solicitado ou prescrito de rotina)

\section{B) DADOS DA ENTREVISTA}

Data:

Horário: horas

a) Cor: ( ) branca ( ) negra ( ) parda ( ) amarela/oriental ( ) vermelha

b) Escolaridade:

( ) Analfabeto

( ) Ensino fundamental incompleto

( ) Ensino fundamental completo

( ) Ensino médio incompleto

c) Ocupação atual:

d) Estado marital: ( ) com companheiro com co-habitação ( ) com companheiro sem co-habitação ( ) sem companheiro
( ) Ensino médio completo

( ) Ensino superior incompleto

( ) Ensino superior completo 
e) Você teve um acompanhante no parto atual? ( ) Sim ( ) Não

Quem?

( ) No trabalho de parto ( ) No parto

\section{C) EXAME PERINEAL}

Comprimento da episiotomia: centímetros

\section{D) CONTROLE DA IRRADIAÇÃO E AVALIAÇÃO DA DOR}

Data do parto:

Horário: horas

Como você classifica sua dor numa escala de zero a dez?

\begin{tabular}{|l|c|c|c|c|c|c|}
\hline \multirow{2}{*}{$\begin{array}{c}\text { Período da aplicação do } \\
\text { laser }\end{array}$} & \multicolumn{2}{|c|}{$\begin{array}{c}\text { Previsão da } \\
\text { irradiação }\end{array}$} & \multicolumn{2}{c|}{$\begin{array}{c}\text { Realização da } \\
\text { irradiação }\end{array}$} & \multicolumn{2}{c|}{$\begin{array}{c}\text { Escores de DOR } \\
\text { (0 a 10) }\end{array}$} \\
\cline { 2 - 7 } & Data & Horário & Data & Horário & Antes & \multicolumn{1}{|c|}{ Após } \\
\hline Até 2 h após o parto & & & & & & \\
\hline De 20 a 24 h após o parto & & & & & & \\
\hline De 40 a 48 h após o parto & & & & & & \\
\hline De 7 a 10 dias após o parto & $\mathrm{XXX}$ & $\mathrm{XXX}$ & $\mathrm{XXX}$ & $\mathrm{XXX}$ & $\mathrm{XXX}$ & \\
\hline
\end{tabular}

\section{E) AVALIAÇÃO DA CICATRIZAÇÃO}

Escore antes da primeira irradiação:

Escore antes da segunda irradiação:

Escore antes da terceira irradiação:

Escore após 7 a 10 dias do parto:

\section{F) AVALIAÇÃO DAS LIMITAÇÕES DAS ATIVIDADES DIÁRIAS DAS MULHERES EM FUNÇÃO DA DOR PERINEAL}

Quais funções estão limitadas ou prejudicadas por causa da dor perineal (com 20 a 24 horas após o parto)?

\begin{tabular}{|l|l|l|l|}
\hline \multicolumn{1}{|c|}{ Atividade } & \multicolumn{1}{c|}{ Sim } & Não & Não fiz \\
\hline Sentar & & & \\
\hline Andar & & & \\
\hline Urinar & & & \\
\hline Evacuar & & & \\
\hline Dormir & & & \\
\hline Amamentar & & & \\
\hline
\end{tabular}


Quais funções estão limitadas ou prejudicadas por causa da dor perineal (com 40 a 48 horas após o parto)?

\begin{tabular}{|l|l|l|l|}
\hline \multicolumn{1}{|c|}{ Atividade } & \multicolumn{1}{c|}{ Sim } & Não & Não fiz \\
\hline Sentar & & & \\
\hline Andar & & & \\
\hline Urinar & & & \\
\hline Evacuar & & & \\
\hline Dormir & & & \\
\hline Amamentar & & & \\
\hline
\end{tabular}

G) DADOS RELACIONADOS À OPINIÃO DAS PUÉRPERAS EM RELAÇÃO AO USO DO LASER

a) Qual a sua opinião sobre a aplicação do laser em baixa intensidade?

( ) Muito bom ( ) Bom ( ) Regular ( ) Ruim ( ) Muito ruim ( ) Sem opinião 


\section{APÊNDICE 4 \\ Termo de Autorização da Pesquisa \\ Primeira e Segunda Etapas}

\section{Ilma Senhora Maria Enir Loubert}

\section{DD. Presidente Executiva do Amparo Maternal - São Paulo}

Prezada Senhora,

$\mathrm{Eu}$, Jaqueline de Oliveira Santos, aluna do Programa de Pós-Graduação em Enfermagem, nível Doutorado, da Escola de Enfermagem da Universidade de São Paulo, venho por meio desta solicitar autorização para a coleta de dados da pesquisa, entitulada: "ENSAIO CLÍNICO RANDOMIZADO SOBRE A EFETIVIDADE DO LASER EM BAIXA INTENSIDADE NA CICATRIZAÇÃO E NA DOR PERINEAL APÓS O PARTO NORMAL".

Este estudo consiste no projeto da tese de doutorado, realizada sob orientação da Prof ${ }^{a}$ Dr $^{a}$ Sonia M. Junqueira V. de Oliveira, que tem como objetivos: avaliar os efeitos da aplicação do laser em baixa intensidade na região perineal após a episiorrafia, identificar a frequência e a magnitude da dor perineal referida pelas puérperas submetidas à irradiação com laser em baixa intensidade e avaliar o processo de cicatrização da episiorrafia com a aplicação do laser.

Os dados serão coletados mediante autorização das mulheres que atenderem aos critérios de inclusão na pesquisa, e concordarem em participar após lerem e assinarem o Termo de Consentimento Livre e Esclarecido.

Informo que os resultados obtidos serão apresentados em eventos científicos e enviados para publicação em periódicos da área.

Agradeço a sua colaboração e coloco-me à disposição para os esclarecimentos que se fizerem necessários. Meus telefones para contato são (11) 3294-9308 e (11) 8100-0111.

Jaqueline de Oliveira Santos

Sonia M J V de Oliveira

São Paulo, 13 de outubro de 2008. 


\section{APÊNDICE 5}

\section{Tabela de Randomização}

Segunda Etapa

1. Grupo 2

31. Grupo 3

2. Grupo 1

32. Grupo 1

3. Grupo 3

33. Grupo 3

4. Grupo 2

34. Grupo 1

5. Grupo 3

35. Grupo 1

6. Grupo 2

36. Grupo 3

7. Grupo 3

37. Grupo 2

8. Grupo 2

38. Grupo 3

9. Grupo 1

39. Grupo 1

10. Grupo 3

40. Grupo 3

11. Grupo 3

41. Grupo 1

12. Grupo 2

42. Grupo 2

13. Grupo 2

43. Grupo 1

14. Grupo 1

44. Grupo 3

15. Grupo 3

45. Grupo 1

16. Grupo 2

46. Grupo 1

17. Grupo 2

47. Grupo 3

18. Grupo 1

48. Grupo 3

19. Grupo 1

49. Grupo 2

20. Grupo 2

50. Grupo 1

21. Grupo 3

51. Grupo 2

22. Grupo 2

52. Grupo 2

23. Grupo 3

53. Grupo 1

24. Grupo 3

54. Grupo 3

25. Grupo 2

55. Grupo 2

26. Grupo 1

56. Grupo 1

27. Grupo 2

57. Grupo 2

28. Grupo 1

58. Grupo 3

29. Grupo 3

59. Grupo 1

30. Grupo 2

60. Grupo 3 
61. Grupo 1

62. Grupo 2

63. Grupo 3

64. Grupo 2

65. Grupo 3

66. Grupo 3

67. Grupo 2

68. Grupo 1

69. Grupo 2

70. Grupo 3

71. Grupo 2

72. Grupo 1

73. Grupo 1

74. Grupo 3

75. Grupo 3

76. Grupo 1

77. Grupo 3

78. Grupo 1

79. Grupo 1

80. Grupo 2

81. Grupo 3

82. Grupo 1

83. Grupo 1

84. Grupo 3

85. Grupo 2

86. Grupo 1

87. Grupo 2
88. Grupo 1

89. Grupo 3

90. Grupo 2

91. Grupo 2

92. Grupo 1

93. Grupo 3

94. Grupo 1

95. Grupo 1

96. Grupo 2

97. Grupo 2

98. Grupo 3

99. Grupo 2

100. Grupo 1

101. Grupo 3

102. Grupo 1

103. Grupo 2

104. Grupo 3

105. Grupo 2

106. Grupo 1

107. Grupo 2

108. Grupo 1

109. Grupo 3

110. Grupo 2

111. Grupo 3

112. Grupo 1

113. Grupo 3

114. Grupo 2 


\section{APÊNDICE 6 \\ Termo de Consentimento Livre e Esclarecido \\ Segunda Etapa}

Prezada Senhora,

Eu, Jaqueline de Oliveira Santos, enfermeira obstétrica e aluna do Curso de Pós-Graduação, nível Doutorado, da Escola de Enfermagem da Universidade de São Paulo estou pesquisando sobre o efeito do laser em baixa intensidade no alívio da dor perineal pós-parto normal. Esta pesquisa é para saber se o laser quando irradiado no local da episiotomia (corte vaginal realizado durante o parto) altera a sensação de dor no local após o parto normal.

A pesquisa será formada por três grupos de mulheres: em um grupo será feita a aplicação do laser de baixa intensidade no períneo com luz infravermelha, em outro grupo será realizada a irradiação com laser de luz vermelha, e no outro grupo não será aplicada a irradiação, embora todos os procedimentos necessários para a utilização da terapia serão realizados. O grupo que você participará será definido por sorteio e você não terá conhecimento de qual grupo pertencerá.

A aplicação do laser em baixa intensidade será realizada em uma única sessão, durante o período de internação no alojamento conjunto do Amparo Maternal. Você ficará na mesma enfermaria, sendo protegida com biombo e terá que usar óculos de proteção para evitar qualquer problema nos olhos. Você ficará na posição ginecológica durante a aplicação que será feita encostando a ponteira do laser sobre seu corte durante 10 segundos em três pontos, no começo, no meio e no final do corte perineal. Além disso, após a aplicação você responderá a algumas perguntas a respeito do tratamento. Informo que a terapia não tem efeitos colaterais.

Com sua participação nesta pesquisa você estará contribuindo para o avanço dos estudos e para a melhoria da qualidade do atendimento prestado, beneficiando assim todas as mulheres que passarem por isso. Em caso de necessidade de mais esclarecimentos, meu telefone para contato é (11) 81000111 ou pelo telefone do Comitê de Ética em Pesquisa (11) 30617548. 
$\mathrm{Eu}$,

$\mathrm{RG} \mathrm{n}^{\circ}$ , abaixo assinada, recebi e entendi as informações acima

e concordo em participar voluntariamente como colaboradora da pesquisa. Declaro que conheço os meus direitos que estão explicados a seguir:

- Tenho a garantia de receber orientações sobre as dúvidas que eu tiver sobre a pesquisa.

- Tenho a liberdade de não aceitar participar e deixar de participar da pesquisa em qualquer momento e isso não vai me causar nenhum prejuízo e não interferirá na minha assistência neste hospital;

- Sei que os resultados desta pesquisa serão transformados em trabalho científico e apresentados em congressos e revistas da área da saúde, e em nenhum momento, o meu nome aparecerá como colaboradora ou participante da pesquisa.

Este documento contém duas vias, sendo que uma ficará em seu poder e a outra comigo, garantindo as condições citadas acima.

São Paulo,

Colaboradora

Jaqueline de Oliveira Santos 


\section{APÊNDICE 7}

\section{Formulário de Coleta de Dados}

Segunda Etapa

$\mathrm{N}^{\circ}$

Grupos:

( ) Infravermelho ( ) Vermelho ( ) Controle

\section{DADOS DO PRONTUÁRIO}

\section{Dados pessoais}

Iniciais

Idade:

anos

$\mathrm{RH}$

\section{Dados obstétricos}

a) N. ${ }^{\circ}$ de gestações:

Paridade:

Abortamento:

IG: semanas

b) Profissional que assistiu ao parto:

( ) Enf a obstétrica ( ) Acad. de obstetrícia ( ) Médico

d) Data do parto:

Horário do parto: horas

e) Motivo da episiotomia:

\section{Dados do RN}

a) Peso do recém-nascido: gramas

b) Perímetro cefálico: $\mathrm{cm}$

c) Apgar $1^{\circ}$ minuto:

d) Apgar $5^{\circ}$ minuto:

\section{Medicação}

a) Usou algum analgésico: ( ) Sim ( ) Não

Qual? Horário? 


\section{DADOS DA ENTREVISTA}

a) Cor: ( ) branca ( ) negra ( )parda ( ) amarela/oriental ( ) vermelha

b) Escolaridade:

( ) Analfabeto

( ) Ensino médio completo

( ) Ensino fundamental incompleto

( ) Ensino superior incompleto

( ) Ensino fundamental completo

( ) Ensino superior completo

( ) Ensino médio incompleto

c) Ocupação atual:

d) Estado marital: ( ) com companheiro com co-habitação ( ) com companheiro sem co-habitação ( ) sem companheiro

e) Você fuma? ( ) Sim （ ) Não Quantos cigarros ao dia?

f) Você tem alergia a algum medicamento?

( ) Sim ( ) Não Qual?

g) Você teve um acompanhante no parto atual?

( ) Sim ( ) Não Quem?

Em quais momentos: ( ) No trabalho de parto ( ) No parto

EXAME PERINEAL

Comprimento da episiotomia: centímetros

\section{CONTROLE DA IRRADIAČ̃̃O E AVALIAČ̃̃O DA DOR}

Como você classifica sua dor numa escala de zero a dez?

\begin{tabular}{|c|c|c|c|}
\hline \multirow{2}{*}{$\begin{array}{c}\text { Data e Horário } \\
\text { da aplicação do laser }\end{array}$} & \multicolumn{3}{|c|}{ Escores de DOR (0 a 10) } \\
\cline { 2 - 4 } & $\begin{array}{c}\text { Antes da } \\
\text { irradiação }\end{array}$ & $\begin{array}{c}\text { Imediatamente } \\
\text { após a irradiação }\end{array}$ & $\begin{array}{c}30 \text { minutos após a } \\
\text { irradiação }\end{array}$ \\
\hline & & & \\
\hline
\end{tabular}




\section{AVALIAC̄̃̃O DAS LIMITAÇÕES DAS ATIVIDADES DIÁRIAS DAS MULHERES EM FUNCẼ̃O DA DOR PERINEAL}

a) Quais atividades estão limitadas ou prejudicadas por causa da dor perineal?

\begin{tabular}{|l|c|c|c|c|c|c|}
\hline \multirow{2}{*}{ Atividade } & \multicolumn{3}{|l|}{ ANTES DA IRRADIAÇÃO } & \multicolumn{3}{|c|}{$\begin{array}{c}\text { 30 MINUTOS APÓS A } \\
\text { IRRADIAÇÃO }\end{array}$} \\
\cline { 2 - 7 } & Sim & Não & Não fiz & Sim & Não & Não fiz \\
\hline Sentar & & & & & & \\
\hline Andar & & & & & & \\
\hline Urinar & & & & & & \\
\hline Evacuar & & & & & & \\
\hline Dormir & & & & & & \\
\hline Amamentar & & & & & & \\
\hline
\end{tabular}

\section{OPINIÃO DAS PUÉRPERAS EM RELAÇ̃̃O AO USO DO LASER}

a) Qual a sua opinião sobre a aplicação do laser em baixa intensidade?

( ) Muito bom ( ) Bom ( ) Regular ( ) Ruim ( ) Muito ruim ( ) Sem opinião

b) A terapia com laser em baixa intensidade foi:

( ) confortável ( ) desconfortável

Por quê?

c) Se você tivesse dor no períneo novamente depois de outro parto, utilizaria essa mesma técnica?

( ) $\operatorname{sim}$ ( ) não

Por quê? 


\section{ANEXO 1}

\section{Escala Numérica}

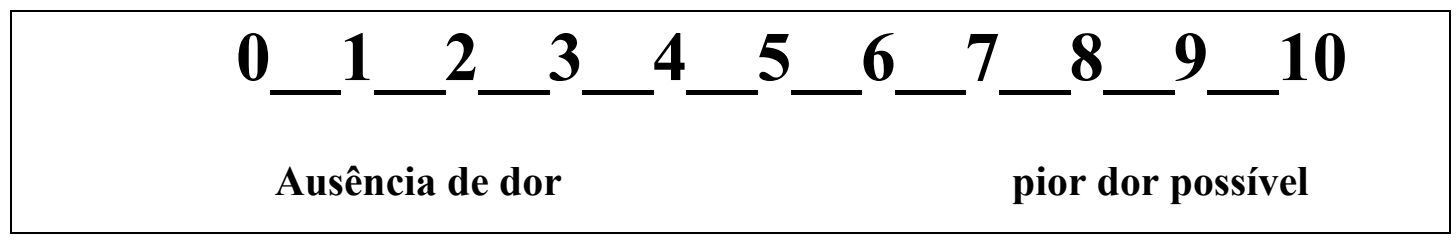




\title{
ANEXO 2
}

\section{Carta de Aprovação do Comitê de Ética em Pesquisa}

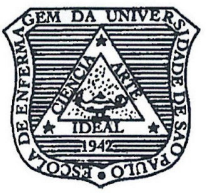

\author{
UNIVERSIDADE DE SÃO PAULO \\ ESCOLA DE ENFERMAGEM \\ Av. Dr. Enéas de Carvalho Aguiar, 419 - CEP 05403-000 \\ T2 Fone.: 3061-7548 - Fax.: 3061-7548 \\ C.P. 41633 - CEP 05422-970 - e-mail.: edipesq@usp.br
}

São Paulo, 29 de abril de 2009.

\section{DECLARAÇÃO}

\section{Ref.: Processo $n^{\circ} 778 / 2008 /$ CEP-EEUSP}

Declaro para os devidos fins que o Comitê de Ética em Pesquisa da Escola de Enfermagem da Universidade de São Paulo aprovou, em 18/11/2008, o projeto de pesquisa "Ensaio clínico randomizado sobre a efetividade do laser em baixa intensidade na cicatrização e na dor perineal após o parto normal", a ser desenvolvido pela pesquisadora Jaqueline de

Oliveira Santos, sob a orientação da Professora Doutora Sonia Maria Junqueira Vasconcellos de Oliveira.

Analisado sob o aspecto ético-legal, atende às exigências da Resolução $n^{\circ}$ 196/96 do Conselho Nacional de Saúde.

Atenciosamente,

Maria fat finandes

Prof. ${ }^{a}$ Dr. ${ }^{a}$ Maria de Fátima Prado Fernandes Coordenadora do Comitê de Ética em Pesquisa da Escola de Enfermagem da Universidade de São Paulo 